\title{
EQUITY, TEACHING PRACTICE AND THE CURRICULUM
}

EXPLORING DIFFERENCES IN ACCESS TO KNOWLEDGE

Edited by

Ninni Wahlström 


\section{Equity, Teaching Practice and the Curriculum}

This book explores how different classroom discourses and concepts of knowledge permeate teaching in high- and low-performance classrooms. Drawing on empirical research from classrooms in Sweden, it presents a theory-based framework for classroom research.

The book examines the central concepts of knowledge, curriculum, pedagogy and equity to discuss differences in access to knowledge and the implications of these differences for students' future opportunities and well-being. It analyses the relationships between different teaching factors and discusses teaching from democratic perspectives developed within curriculum theory. Combining insights from curriculum theory with insights from sociolinguistic and sociocultural classroom research, this project breaks new ground in how knowledge from curriculum content is recontextualised into concrete teaching practices in the context of a standards-based curriculum.

Providing valuable insights into the intersections between classroom practice, student performance and teacher expectations, this book will be of great interest to academics, researchers and post-graduate students in the fields of curriculum research, education policy, teacher education and classroom practice.

Ninni Wahlström is Professor at the Department of Didactics and Teachers' Practices at Linnaeus University, Sweden. 


\section{Routledge Research in Education}

This series aims to present the latest research from right across the field of education. It is not confined to any particular area or school of thought and seeks to provide coverage of a broad range of topics, theories and issues from around the world.

Recent titles in the series include:

International Perspectives on Drama and Citizenship Education Acting Globally

Edited by Nicholas McGuinn, Norio Ikeno, Ian Davies, and Edda Sant

Meeting the Challenges of Existential Threats through Educational Innovation

A Proposal for an Expanded Curriculum

Edited by Herner Saeverot

Lived Democracy in Education

Young Citizens' Democratic Lives in Kindergarten, School and Higher

Education

Edited by Rune Herheim, Tobias Werler, and Kjellrun Hiis Hauge

Multimodal Signs of Learning

Tracking semiosis in the classroom

Shirley Palframan

A Retrospective Study of a Dialogic Elementary Classroom Understanding Long-Term Impacts of Discursive Pedagogies Lynn Astarita Gatto

Equity, Teaching Practice and the Curriculum

Exploring Differences in Access to Knowledge

Edited by Ninni Wablström

For a complete list of titles in this series, please visit www.routledge.com/ Routledge-Research-in-Education/book-series/SE0393 


\section{Equity, Teaching Practice and the Curriculum}

Exploring Differences in Access to

Knowledge

Edited by Ninni Wahlström

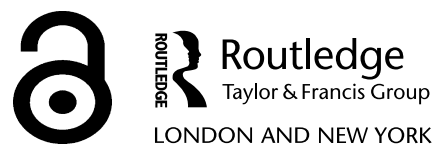


First published 2022

by Routledge

4 Park Square, Milton Park, Abingdon, Oxon OXI4 4RN

and by Routledge

605 Third Avenue, New York, NY 10158

Routledge is an imprint of the Taylor o Francis Group, an informa business

(C) 2022 selection and editorial matter, Ninni Wahlström; individual chapters, the contributors

The right of Ninni Wahlström to be identified as the author of the editorial material, and of the authors for their individual chapters, has been asserted in accordance with sections 77 and 78 of the Copyright, Designs and Patents Act 1988.

The Open Access version of this book, available at www. taylorfrancis.com, has been made available under a Creative Commons Attribution-Non Commercial-No Derivatives 4.0 license.

Trademark notice: Product or corporate names may be trademarks or registered trademarks, and are used only for identification and explanation without intent to infringe.

British Library Cataloguing-in-Publication Data

A catalogue record for this book is available from the British Library

Library of Congress Cataloging-in-Publication Data

A catalog record has been requested for this book

ISBN: 978-1-032-11020-2 (hbk)

ISBN: 978-1-032-11021-9 (pbk)

ISBN: 978-1-003-21806-7 (ebk)

DOI: $10.4324 / 9781003218067$

Typeset in Galliard

by SPi Technologies India Pvt Ltd (Straive) 


\section{Contents}

List of Illustrations

vii

List of Contributors

Preface and Acknowledgements

viii

1 Introduction: The Role of the School as the Promotion of Knowledge, Equity and Democratic Norms

NINNI WAHLSTRÖM

2 Policy, Knowledge and Promoting a Democratic Stance NINNI WAHLSTRÖM

3 Equity in Education: Equal Opportunities for What? NINNI WAHLSTRÖM

4 Exploring the Importance of Teacher Feedback: Connecting Truthfulness and Student Learning JEFF FRANK

5 The Students' Role in Standards-Based Education: Critical Reflections on Pedagogical Implications BETTINA VOGT

6 Curriculum Coherence: Exploring the Intended and Enacted Curriculum in Different Schools 
vi Contents

7 Principal Agency: Educational Leadership at the Intersection Between Past Experiences and Present Environments

KATARINA STÅHLKRANTZ

8 Teaching Repertoires and Student Perceptions of Knowledge in High- and Low-Performance Classrooms DANIEL ALVUNGER

9 Pedagogical Segregation from Students' Perspectives CATARINA SCHMIDT

10 Knowledge, Curriculum and Teaching on Matters that Concern: A concluding Discussion

JEFF FRANK, CATARINA SCHMIDT, DANIEL SUNDBERG, BETTINA VOGT AND NINNI WAHLSTRÖM

Index 


\section{Illustrations}

\section{Figures}

8.1 Birch tree class: Teaching repertoires (\%) 113

8.2 Larch tree class: Teaching repertoires (\%) 113

9.1 Classroom pedagogies 127

9.2 Organisation and teaching talk (\%) 133

\section{Tables}

3.1 A framework for analysis from the perspective of capability approach based on Unterhalter (2009) and Unterhalter and Brighouse (2007)

3.2 A framework for analysis of equity in education, based on Fraser's (2004) principle of parity of participation

3.3 A framework of curriculum theory and equity based on an institutional perspective in the principle of parity of participation (Fraser, 2004) and on an individual perspective in the capability approach (Sen, 2005; Nussbaum, 2011)

7.1 Schools and principals

8.1 Description of classes and contextual information about schools

8.2 Curriculum areas included in study

8.3 Coding scheme for elements of lesson elements and teaching repertoires in classroom discourse

9.1 Teaching factors

9.2 Focus Group interviews, 15 students

9.3 Curriculum tasks 


\section{Contributors}

Daniel Alvunger is an associate professor in Education at Linnæus University, Sweden. His research concerns curriculum studies, with a focus on the intertwined relationships between transnational policy, national educational reforms and their implications in local schools. Other research areas are teacher education, teacher leadership and school development. A recent publication is Curriculum Making in Europe: Policy and Practice Within and Across Diverse Contexts (Emerald, 2021, co-edited with M. Priestley, S. Philippou and T. Soini).

Jeff Frank is an associate professor at St. Lawrence University in Canton, NY (USA). He is a philosopher of education who has published two books and whose work has appeared in philosophy of education journals and generalist journals like the Teachers College Record and Educational Researcher. Currently, he is focusing on what teachers and schools can do to support students through the ongoing Covid pandemic.

Catarina Schmidt is an associate professor at Jönköping University, Sweden. Her research focuses on conditions and possibilities for children's and adolescent's literacy learning in relation to agency, multilingualism and multimodality, and social and ecological sustainability. In cooperation with Ninni Wahlström and Amy Vetter, she has recently published the chapter "The Situational in Critical Literacy" in The Handbook of Critical Literacies (Routledge, 2021).

Katarina Ståhlkrantz is a senior lecturer of education at Linnaeus University, Sweden. Her research area is education policy and its implications for the governing of schools at both a national and municipal level. She is particularly interested in research on educational leadership, and she teaches in various school leadership training programs.

Daniel Sundberg is a professor of education at Linnaeus University, Sweden, and chief editor of Educational Research in Sweden. His main field of research is comparative and historical perspectives on education reforms, curriculum and pedagogy in the complex interconnections of transnational, national and local curriculum and classroom arenas, 
see for example 'Transnational Competence Frameworks and National Curriculum-Making: The Case of Sweden' for Comparative Education (2021, together with A Nordin).

Bettina Vogt is a senior lecturer of education at Linnaeus University, Sweden. In her research, she focuses on the fields of comparative education and curriculum studies. Within these areas, she is mainly interested in questions that can be related to the critical study of the social, the didactical and normative dimensions of educational assessment and the implications for different actors and different levels of the education system.

Ninni Wahlström is a professor of education at Linnaeus University, Sweden. Her current research focuses on transnational and national policy discourses and their implications for national curriculum and classroom teaching from a perspective of educational philosophy and curriculum theory. She has been scientifically responsible for two research projects regarding the relations between education policy, curriculum and classroom teaching, of which the first project is reported in the book Transnational Curriculum Standards and Classroom Practices: The New Meaning of Teaching (Routledge, 2018), co-edited with D. Sundberg. 


\section{Preface and Acknowledgements}

This book is the product of a collective eight years of study in education policy, curriculum, and classroom research from a curriculum theory perspective in the research group Studies in Curriculum, Teaching and Evaluation (SITE) at Linnaeus University in Sweden. The research presented in this book expands on the findings of our previous book, Transnational Curriculum Standards and Classroom Practices: The New Meaning of Teaching, edited by N. Wahlström and D. Sundberg (Routledge, 2018), and dives deeper into perspectives of knowledge and equity underpinning national education policy and curricula. Our overarching interest is exploring the question, 'What does this policy or curriculum reform imply for the teaching situation in preschool or school for the individual child or student?' In order to answer that question, we need to understand the 'life in classrooms,' with its discourses of communication, teaching repertoires, and learning repertoires as being embedded in a broader context of societal values and norms, some of which are implicit while others are clear. The key issue in curriculum theory is what knowledge is of most worth, that is, what knowledge should be selected for the new generation to learn? This question needs to be followed by examining what students are actually given the opportunity to learn in school, as an effect of the processes of recontextualisation between the curriculum arena and the teaching arena. Our research shows that what students get the opportunity to learn in school differ for different groups of students and different schools, due to the organising of the national school system, the segregation of schools and residential areas and each school's and teacher's individual interpretation of the curriculum. This broad understanding of the pedagogical questions of what, why, who and how in relation to different teaching environments and teaching content for different social groups is an expression of a pedagogical interest that has closer affinity to the concept of 'Didaktik' in German-speaking countries and northern Europe than with the English term didactics.

In both the SITE research group and the specific project that forms the basis of this book, we are particularly interested in discovering how the meaning of different educational policies takes form and develops in transnational and national societal arenas, as well as in programmatic regulative arenas. Additionally, we want to examine how these policies are recontextualised 
and enacted in local municipal, school and classroom arenas. The research project presented in this book is titled 'Exploring the Elusive Teaching Gap: Equity and Knowledge Segregation in Teaching Processes.' It focuses on the educational question of how different classroom discourses and concepts of knowledge affect students' opportunities to develop knowledge that is considered valuable in relation to assessment and grading in low- and high-performance classrooms. A national standards-based curriculum with emphasis on subject knowledge and knowledge requirements for assessment and grading constitutes the external framework for the study. Most of the chapters in this study draw on data from Swedish schools, but the educational environment of the United States is also represented in chapter 4. While the first four chapters are overarching and conceptual, the five subsequent chapters focus on empirical data from schools participating in the study. Finally, in the concluding chapter, we present our conclusions and summarise our most important arguments.

A research project is dependent on the willingness of many participants to contribute. First, I am grateful to the schools, principals and teachers who have generously shared their time and allowed us access to their schools, classrooms and activities so that we could carry out our project according to plan. No classroom research project can move forward without close collaboration with the school's teachers, so thank you all for your productive cooperation! I would also like to thank the researchers participating in the project - Daniel Sundberg, Jeff Frank, Catarina Schmidt, Daniel Alvunger, Bettina Vogt and Katarina Ståhlkrantz - for contributing to many fruitful seminars and discussions throughout the course of this project. Thank you for your excellent work and for presenting your contributions at the 'European Conference on Educational Research' (ECER), the 'Teachers MatterBut How?' conference, and the 'Nordic Educational Research Association' conference (NERA). Finally, I am grateful to the Swedish Research Council, which has financed the project for four years (Registration number: 2017-03501).

Ninni Wablström Editor 
Taylor \& Francis

http://taylorandfrancis.com 


\section{Introduction}

\section{The Role of the School as the Promotion of Knowledge, Equity and Democratic Norms}

\section{Ninni Wablström}

Schools are important places for the maintenance of democratic norms. Meanwhile, schools are constantly exposed to policy reforms and changes that threaten to weaken their function of educating a new generation for democracy when one-sided priorities for education tend to dominate policy arenas. National constitutions and societal institutions cannot by themselves guarantee democracy. Instead, as Levitsky and Ziblatt (2018, p. 283) point out, democracy 'is a shared enterprise,' the fate of which depends on all of us. Democracies ultimately rest on shared, unwritten rules of accepted and unaccepted codes of conduct and standpoints. In short, democracy requires that values such as being knowledgeable, being able to negotiate, compromising, deliberating and showing mutual respect are appreciated and highly valued in society. It is hard to find any societal institution other than the school that has the capacity to take on the task of, for each new generation, offering well-founded knowledge and promoting democratic norms, with the potential to develop a democratic society struggling with the question of what can be considered the 'common good.'

Critics of democracy often claim that politics is too important and complicated to be left to 'ordinary' people (Burman, 2021). An opposite way of reasoning is to emphasise the importance of offering citizens knowledge, a sense of tolerance and a habit of reflective thinking through education that enables individuals to form their own well-founded opinions. The term wellfounded means examining a problem from different perspectives and considering which measures seem to be most favourable, considering the potential conflicts of the goals and social groups concerned. This is what characterises the adoption of a democratic stance. The school's task of offering in-depth knowledge on various school subjects is necessary but not sufficient for developing and maintaining democratic values and norms. Teaching content also needs to include reflections on the consequences of varying perspectives of action regarding the utilisation of knowledge in society and how these perspectives can be understood from different social, physical and environmental perspectives. Therefore, teaching subject knowledge and democratic norms is intertwined and must be understood as two aspects of the same goal for compulsory education - to educate democratic citizens. 


\section{Ninni Wablström}

In this volume, the question of knowledge is discussed from three perspectives: how knowledge appears in policy and curriculum, how it is taught in classrooms and how it is assessed. The perspective from which the question of knowledge is understood and discussed is based on the concepts of democracy and equity (see Carr \& Hartnett, 1996). The key question that permeates this book is how teachers can adopt a democratic stance in their teaching and how students can be offered the opportunity for reflective learning. The assumption is that teachers, in general, want their students to succeed. However, even if we believe that teachers are socially conscious, we do not expect teachers to build social movements (Anyon, 2014) or to conduct micropolitics at the classroom level for students 'becoming revolutionary' (Youdell, 2011, p. 139). Instead, our purpose herein is to focus on education perspectives and the fostering of a democratic stance. The aim revolves around the question of how the concepts of knowledge and teaching in everyday activities may include a way of looking at the world that instils a democratic attitude in the students and how the teaching conducted in various learning environments can be discussed from a perspective not only of knowledge achievements but also of equity and democracy. The policy rhetoric claiming that teachers primarily need to set high expectations for their students to succeed (e.g. OECD, 2012) is too simplistic because teaching situations are far more complex than that - as are all social situations that include individuals with different prerequisites, preferences and desires involved in a common activity. Instead, the authors of the following chapters have directed their focus on the aspects of knowledge, curriculum and teaching that the students encounter in diverse teaching contexts, both in schools considered high performing and low performing in terms of average grades. The aim is to highlight aspects of education hindering or promoting education of good quality, based on a broad understanding of compulsory school as a space for civic education.

\section{Educating Democratic Citizens}

At the beginning of the 21 st century, democracy faces various challenges. One challenge is the neoliberal reform agenda that has characterised most Western countries from the 1990s onwards. Many Western countries have also experienced how right-wing populism has grown stronger as a political force that has influenced political values in society outside the specific party. A third challenge of democracy is the voluntary and involuntary isolation that affects people's willingness and ability to get in touch with each other.

The solution for welfare services advocated in neoliberalism is usually marketed solutions, such as competition and privatisation. While the former "social" liberalism was characterised by political responsibility, regulation for equal treatment, state bureaucracy and trust in professional expertise, the 'new' liberalism, 'neoliberalism,' was closely linked to New Public Management (NPM). NPM is characterised by an ideology for the public sector based on efficiency, standards, competition and accountability (Gunter et al., 
2016). With NPM as the governing philosophy for schools, concepts such as competition, freedom of choice, knowledge achievement and accountability of results became leading concepts. The political philosopher Nancy Fraser describes the neoliberal movement as 'progressive neoliberalism,' in that the movement developed from a contradictory alliance between progressive social movements pushing issues of diversity and the needs of minority groups on the one hand and strong financial interests on the other hand, expecting opportunities for the opening of new markets (Fraser, 2017). Neoliberalism views the state as a necessary partner to provide conditions for implementing the market orientation of the public sector in practice. This means that the state is expected to provide the tools required to regulate a public sector that includes both private and public actors (Olssen, 2009).

Sweden, where the referenced classroom studies have been conducted, is a good example of the shift from social liberalism to neoliberalism within the education policy arena. In 1991, the Swedish school system changed from being a state-run and state-funded national school system to becoming a decentralised responsibility for the municipalities. Meanwhile, a new regulation for free school choice was introduced, along with a system of what is called independent schools that allowed private actors, including individuals, organisations, and limited companies, to become owners of publicly funded schools. Thus, all schools are still publicly funded, but the responsibility for how financial resources are used is left to the individual organiser of the school. Thereby, the neoliberal policy was expected to promote individual freedom of choice and competition between schools aimed at stimulating pedagogical development and quality schooling. The democratic implication of a displacement to neoliberalism as the dominating force of international and national education policy is the changing way the individual citizen can make his or her voice heard. In a system of 'social' liberalism, the individual citizen expresses his or her opinion by casting a vote in the general elections and, thus, holding politicians accountable. In a neoliberal system, the political responsibility for the performance of public services becomes more unclear. Instead, the citizen expresses herself by 'exiting,' that is, 'voting with one's feet' by simply changing providers in the public sector based on the freedom of choice. The democratic challenge is to maintain a common frame of reference that keeps society together and identifies who is ultimately accountable in a highly decentralised and diversified welfare system.

During the early 2000s, right-wing populism affected politics and government coalitions in several European countries. What the right-wing populist parties have in common is that they combine nationalism with value conservatism. They are critical of immigration and of the European Union (EU) and take conservative positions on issues of family policy, gender equality and sexual minorities (Jungar, 2017). Populism can be described as an ideology that views society as divided into two homogeneous and contradictory groups: the 'people' and the (corrupt) 'elite.' Populists argue that politics should express the genuine will of the people. While right-wing populist parties combine their views of the division of the people and the elite with 
nationalism, left-wing populist parties instead combine their populism with a socialist ideal (Mudde \& Kaltwasser, 2017). The democratic challenge lies in populism's view of one people with a common will, which implies that the power in a democracy belongs to the majority, 'the people.' Thus, a populist approach to democracy lacks the characteristic hallmarks of liberal democracy with its protection of minorities and independent institutions for areas such as judiciary, media, culture and education.

A third challenge to democracy, finally, lies in the voluntary and involuntary isolationism that affects people's interests and prospects of getting in touch with each other. Unlike the two -isms discussed earlier, isolationism is not a matter of ideology but of human conditions and behaviour. The pandemic in 2020 and 2021 can be taken as an example of involuntary isolation from other people. The threat of infection meant that democratic rights became downgraded when governments took action to stop the spread of infection. The democratic challenge lies in the fact that fundamental rights, such as the freedoms of assembly, demonstration, travel, and other freedoms in the private sphere, are restricted by temporary recommendations and laws.

Conversely, voluntary isolationism, for example, is evident in residential segregation as an effect of a tendency for different social groups to seek housing in different residential areas, mainly based on economic resources. In school systems that include the free choice of school, there is a tendency to choose schools where one's social group dominates. On social media, new opportunities open up further voluntary isolationism by looking for social groups that largely share one's own interests and ways of thinking and acting, which contribute to both confirmation and community. The democratic challenge is that voluntary isolation from other social groups contributes to a one-sidedness in perspectives and a reduced habit or willingness to listen to voices other than those that already feel familiar.

The examples of the challenges highlighted above point to the need for a reconnection of the tasks of compulsory school and civic education - that is, promoting a habit of acting according to democratic norms and values. However, challenges to democracy as a social governance system and a way of cohabiting in society go beyond what individual teachers can take responsibility for or actually influence. Nonetheless, what individual teachers can do is adopt a democratic stance in their subject-based teaching. I define teaching with a democratic stance as teaching that consciously opens up reflective thinking regarding various consequences for diverse social groups and society as a whole about the knowledge that is the subject of teaching. A democratic stance in education is characterised by an aspiration to reflect on different perspectives and conflicting standpoints about an issue, aiming at conversations with students on how to arrive at what can be considered 'the common good,' acknowledging the interests involved (Wahlström, 2020, 2021). An underlying interest of the studies presented in the chapters in this book is the students' lives in the classroom: What enacted concepts of knowledge do they encounter, and what communicative discourses and teaching repertoires are formed in their classrooms? What are the implications of these 
factors for the possibilities for students to develop a democratic stance? An assumption is that dominating concepts of knowledge underpinning curriculum have implications for the teacher's selection of the teaching content, the teacher's choice of teaching repertoires, and the approach to knowledge and participation that students are offered. Thus, the nature of the concept of knowledge related to a curriculum has real consequences in real classrooms, because the kind of knowledge underlying curricular content constitutes the framework for the teacher's pedagogical choices. Even if subjects' traditions partly rely on different concepts of knowledge, foundational policy ideas of what counts as important knowledge for the next generation permeate the goals, subject content, requirements and standards that characterise a curriculum. This, in turn, has implications for how teaching and assessment practices are understood and carried out by teachers.

The content of this book, which I relate to the research field of curriculum theory, could be viewed as an empirically based contribution to the debate on the need for knowledge-based curricula. Regarding the necessity of promoting democracy, both as a form of governance and as foundational norms of living together in society, I argue that the knowledge concept based on transactional realism, developed within the philosophy of pragmatism, has the potential to foster reflective thinking and pluralism through the consideration of various aspects of an object, which forms the basis of the concept. John Dewey's transactional realism places human beings as actors in an environment of physical things and social relationships. The term transactional means that there is always some form of mutual influence of meaning in the interaction between individuals and their environment (Dewey, 1949/1991). For example, a chair is given a diverse meaning and takes alternative forms depending on whether it is an item in a store, a reading chair in a home environment or a desk chair in the workplace. However, despite the many contexts and meanings, we still know that it is the chair we are looking at. Even if knowledge is constructed about a certain human context, it cannot be constructed randomly because knowledge about an object or phenomenon must always be considered about a physical and social reality. Based on the premise that the individual is always already within an environment, the distinction between human and environment, subject and object, and individual and society is exceeded (Dewey, 2008). Thus, the fundamental theoretical problem is not to overcome the gap between subject and object or between individual and society, but to explore the conditions, relationships and consequences within the environments.

At the same time, it is important to add the concept of justice and its interpretation for the consideration of what counts as equitable education for all students within a national school system for compulsory education. The empirical studies that form the basis of this book revolve around an interest in exploring the teaching and the view of knowledge that students encounter in diverse educational environments. At a time of comparative national and international knowledge measurements, we are here interested in the students' educational journey up to the day when large-scale knowledge 
measurement takes place. From which kind of learning environments and with what learning experiences do they arrive at a common national test in, for example, science subjects or in reading comprehension? If equity is understood only as the right to achieve an approved result in a certain highstakes test, we risk ignoring the entire educational situation to rely only on a codified result of a test or a grade. When comparisons of equity are merely based on figures, there is a lack of knowledge about the qualities of the teaching and learning environment that students encounter in their daily lives at school and what they have the opportunity to learn (Cherryholmes, 1988 ). For a theoretical conceptualisation of equity in education, two theories of justice have been central to this project: Nancy Fraser's (2004) principle of parity of participation, in terms of redistribution, recognition, and representation, at an institutional level, and Amartya Sen's (1999) and Martha Nussbaum's (2007) capability approach at an individual level.

\section{Elaborating on Curriculum Theory Analysis on Classroom Discourses}

The research project that mainly underlies the chapters in this book examines the factors that affect knowledge segregation in schools beyond socioeconomic and residential factors. In a Swedish context, we explore how actual teaching can promote or impede the schooling success of different groups in relation to standards-based curricula. The project takes its starting point in the educational question of how classroom discourses and concepts of knowledge affect students' access to knowledge 'that counts' in a standards- and performance-based school system. Because of previous insights and results from a comparative classroom study conducted in 2014-2016 focusing on the subject of social science in school year 6, we had some insights into how the enacted standardised curriculum is taught, including teaching repertoires, learning repertoires and what content counts as knowledge (Wahl-

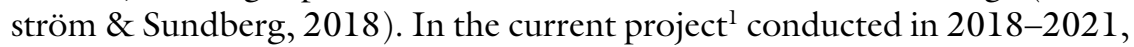
the focus is on differences in versions of knowledge, curriculum, and teaching and learning repertoires between and within high- and low-performing schools. The purpose of this research project is to generate a theory-based framework for classroom research based on curriculum theory, in which the relationships between teaching factors are analysed and explained. Moreover, the project aims to gain knowledge on the relationships between the patterns of classroom discourses, student performance and teacher expectations. The study also provides insights into the process of recontextualising knowledge from curriculum content into concrete teaching from the perspective of equity. Through the interest in different versions of curriculum and teaching, the focus is the teaching factor, not the teacher factor.

This project can be described as a comparative classroom study inspired by classic classroom studies related to curriculum research (Bellack et al., 1966; Hansen, 1995; Jackson, 1968/1990; Lundgren, 1981). Two interdependent relationships are important for this study, drawing on the work of 
Walter Doyle (1992). The first assumption is that it is not possible to draw any definite boundary between curriculum content and pedagogy. To fully understand the complexity of teaching, teaching content and teaching repertoires are viewed as intertwined and interdependent because it is not possible to distinguish between 'the what' and 'the how' of teaching in a precise way. A second assumption is that teachers and students are interdependent actors in the formation of curriculum content. The multifaceted transformation from the curriculum's text content to actual teaching content is understood as constituting 'curriculum events.' Lessons represent communicated 'texts' that are interpreted and acted on by the students for a certain purpose. The teacher 'authors' curriculum events to facilitate the students' learning; simultaneously, the students contribute to shaping the 'texts' through their participation and thus become co-authors of the events. Classroom interactions between teachers and their students represent a negotiation process in which the students can adopt a legitimising role as co-authors of curriculum events; however, classroom interactions entail a series of alignments and conflicts that can also result in students taking a position of resistance (Doyle, 1992). A major task for curriculum theory is to conceptualise the underlying presumptions that limit curriculum content and the consequential choices of teaching content as well as to explore the pedagogic implications that follow from the concepts of curriculum, that is, forming the curriculum (Biesta, 2014; Young, 2013).

Comparative classroom studies build on the assumption that lessons can be understood as distinguishable systems with characteristics that can be compared. The key feature of lessons as systems focuses on consistency in patterns concerning the selection of knowledge and interactions between teachers and students rather than on details (Cohen et al., 2003). Lessons as 'systems' are at the same time embedded in larger institutional and societal structures that must be considered in comparisons between national school systems (Alexander, 2001). In 'internal' comparative classroom studies within the same national school systems, the impact of geographic and social factors, the school's governing system and disparities between school organisers need to be taken into consideration. The methods used for this research project were developed on the frameworks advanced by Alexander (2001) and Klette et al. (2005), with coding categories for teaching and learning repertoires to capture types of classroom discourses and their effects on student activity, reciprocal listening and so forth. In addition to this kind of coding scheme, we also apply coding categories regarding concepts of knowledge that appear in the videotaped curriculum events, built on knowledge categorisations made by Deng and Luke (2008) and Roberts (2007). For a comprehensive overview of methodological matters, see Wahlström (2019). Classroom discourses are understood and analysed as constituting a communicative system that emerges about specific content and a specific combination of teachers and students contextualised by space and time (Alexander, 2001; Klette et al., 2005; Molinari et al., 2013; Wahlström \& Sundberg, 2018; Wells \& Arauz, 2006). 
The data were collected through video and audio recordings and observations of lessons. The selections of schools were based on performance data (grades) from the Swedish National Agency for Education (NAE, 202l) and their databases, SIRIS and SALSA. The sample criteria to be met are that the selection should include two high-performing and two low-performing schools (statistically significant for five years, retrospectively). The classroom study included four in-depth case studies of classes (school year 8), and the data collection period covered one full school year. Each classroom observation consists of 16 lessons, eight lessons per academic year in two subject areas - science and reading (Swedish) - to allow systematic comparisons. The study thus includes 64 videotaped lessons evenly distributed in the two subjects. After every other recorded lesson, interviews were conducted with teachers as well as with a group of students in each subject. In summary, this study comprises 32 interviews with teachers and students. In addition, the principals of each of the participating schools were interviewed.

All participating children and their parents, as well as the participating teachers, were informed of the conditions of the study and gave written consent for participation and research publications. The study was carried out under the general requirements for research ethics (Swedish Research Council, 2017) regarding information, consent, confidentiality and use of data. The survey was approved by the Ethical Review Board. The participating schools and the cited individuals were given fictitious names to protect their identities.

\section{An Overview of the Chapters}

Considering a general interest in the role of the school in a democratic society, the relationships between knowledge, curriculum and teaching have been explored from diverse perspectives in the different chapters. In the introductory chapters, the interest is directed towards a theoretically based understanding and conceptualisation of concepts that are significant to the theme of the book. In the subsequent chapters, the empirical results mainly form the basis for the findings and discussions.

In Chapter 2, 'Policy, Knowledge and Promoting a Democratic Stance,' by Ninni Wahlström, the theoretical boundaries of three concepts of knowledge relevant to curricula and teaching are explored. The knowledge concepts of transactional realism (pragmatism), Bildung and social realism are examined both regarding their historical traditions and what can be understood as their characteristic differences. While Bildung means offering the world to students by focusing on content with which the learner can engage, transactional realism presents the world as incomplete and unresolved, focusing on inquiry, reflective thinking and interactive communication. Social realism, however - starting from a division between mind and object, theory and practice - describes the world to students by focusing on scientific knowledge. The three concepts of knowledge are used for a critical analysis of the transnational educational framework, 'Education 2030,' developed by the Organisation for Economic Co-operation and Development (OECD). 
In Chapter 3, 'Equity in Education - Equal Opportunities for What?,' Ninni Wahlström draws attention to another important concept, the notion of equity. Drawing on Nancy Fraser's concepts of redistribution, recognition and representation; 'the principle of parity of participation'; and Amartya Sen's and Martha Nussbaum's conceptualisation of the capability approach, the chapter elaborates a framework combining curriculum theory with the concept of equity. Equity is explored both from an institutional framework of justice, following Fraser, and from an individual perspective of actually achieved experiences and outcomes of education, based on the concept developed by Sen and Nussbaum. The purpose of this analysis is to develop a framework for how the understanding of equity can constitute an important concept for studies on education at various levels of a school system. The two general approaches to justice are discussed more specifically from the perspective of education. The particular dimensions of education that have become important for the development of an equitable school system are clarified through a cohesive framework based on the analytical levels of curriculum theory.

Chapter 4, 'Exploring the Importance of Teacher Feedback: Connecting Truthfulness and Student Learning' by Jeff Frank, offers a philosophical perspective on thinking about feedback as an important way of reflecting on the task of education. Though undertheorised in the philosophy of education literature, a conceptualisation of feedback is needed to avoid falling into the trap of equating a high-performing school with results on standardised tests. Frank argues for the usefulness of Bernard Williams' ideal of truthfulness as a way to view the ends of education and describes what it would mean for teachers to appreciate their feedback as promoting truthfulness and - thus - a more substantive understanding of learning and high performance. The chapter aims at helping the reader to see the gaps that exist in the quality of feedback students experience and the impact this has on their learning. This chapter also offers an invitation to theorise about feedback: its uses, impacts and place in the education of teachers.

Related to the question of feedback, Bettina Vogt focuses on students as co-authors of curriculum events in differing classroom contexts in Chapter 5, 'The Students' Role in Standards-Based Education: Some Critical Reflections on Pedagogical Implications.' The purpose of the chapter is to reveal the pedagogical implications of a standards-based curriculum in relation to the students. The primary questions in the chapter are how the students' role as co-authors can be understood and what this role means in educational processes when the standards-based curriculum, intended to enable equal conditions for teaching and learning, is enacted in different kinds of classrooms. The chapter builds on theoretical concepts from Wolfgang Klafki's critical-constructive Didaktik, which provides the theoretical framework through which the students' role can be illuminated and its pedagogical implications explored and problematised. Empirically, the chapter draws on data collected in two learning environments, and the empirical examples 
illustrate how the students' role becomes limited in different ways in the two classrooms, with pedagogical implications for both equity and democracy.

With a shift in focus to the construction of curriculum, Daniel Sundberg, in Chapter 6, 'Curriculum Coherence: Exploring the Intended and Enacted Curriculum in Different Schools,' discusses the term curriculum coherence as a policy idea. A core assumption has been that a strengthened coupling of curriculum elements - goals, content, assessment criteria, textbooks, teachers' professional development, and so forth - according to set standards will improve goal attainment and student performance. A second core assumption has been that clear, precise and detailed achievement standards will benefit equality and equity and have a levelling effect on differences in student achievement in high- versus low-performing schools. However, these assumptions ignore some critical factors identified in educational research, as well as basic socio-political conditions for curriculum enactment in different schools and classrooms. The chapter discusses some significant aspects for achieving curriculum coherence and the potential of the concept for addressing the challenges of the elusive teaching gap and increasing knowledge segregation in policymaking and teaching practices.

In Chapter 7, 'Principal Agency - Educational Leadership at the Intersection Between Past Experiences and Present Environments,' Katarina Ståhlkrantz takes her starting point in the importance of the leadership of the school by exploring school leaders' goals and visions about what values, knowledge, and skills they want to lead towards in their roles as principals. Drawing on a theoretical pragmatism approach within curriculum theory and its underlying transactional realism framework, principal agency about the curriculum is empirically analysed from a temporal perspective. The empirical material consists of interviews with principals from school settings representing both low- and high-performing schools. Diverse contexts and school leadership practices create differences in principal agency. The question of 'educational leadership for what?' - that is, towards what values, knowledge and skills principals should lead - allows alternative considerations of what versions of curriculum students will be offered - beyond the language of performance, outcomes and standards.

As stated in the title for Chapter 8, 'Teaching Repertoires and Student Perceptions of Knowledge in High- and Low-Performance Classrooms,' Daniel Alvunger analyses teaching repertoires and perceptions of knowledge in the subjects of natural sciences and the subject of Swedish in various teaching environments. To some extent, the different contextual features of the two classrooms influenced the students' conceptions of knowledge, but in general, the students shared a common understanding of knowledge as being theoretical, abstract, hierarchically structured and practical in terms of creativity and developing problem-solving, cooperation, critical thinking and communication skills. While the knowledge requirements of the curriculum shape students' understanding of knowledge, they also consider the value of knowledge as it relates to their future adult and professional life. Based on the analysis, it is concluded that the classroom dynamics created by 
situational, contextual, social and cultural factors influence the way student access to knowledge is enabled or restrained.

The students' perspectives are placed at the centre in Chapter 9, 'Pedagogical Segregation from Students' Perspectives.' In this chapter, Catarina Schmidt explores the teaching factors affecting pedagogical segregation on a local level within this specific school, the student's perspectives on this and how this segregation can be understood. The analysis reveals that the students' perspectives involve not only their views of the ways the teaching is conducted, in this case, through whole-class teaching followed by individual work, but also their awareness of when they are learning alongside when the teaching is conducted in repetitious and non-dialogic ways, accompanied by low expectations and messy classroom situations. The students expressed an awareness of those better teaching-learning alternatives accessible in other classrooms in their own school and in other school contexts. In conclusion, the students were aware of being denied equal opportunities to access upper secondary school, preparing them for citizenship and working life.

Finally, in Chapter 10, 'Knowledge, Curriculum and Teaching on Matters That Concern - A Concluding Discussion,' Jeff Frank, Catarina Schmidt, Daniel Sundberg, Bettina Vogt, and Ninni Wahlström argue for the need for theoretically based conversations to close the elusive performance gap between diverse educational environments. They conclude that the encounter between the teaching content, the social learning environment and the student is central for the student's opportunities to develop new knowledge, a sense of citizenship and one's individual potential. The teacher's democratic stance in the authoring of teaching content in the classroom makes a difference for what content and kind of participation the student gets the opportunity to co-author of and thus what opportunities the students are offered to learn. Furthermore, they suggest that the much-debated concept of 'powerful' in connection with knowledge might be misleading as a basis for curriculum and teaching and suggest a shift from 'matters of facts' to 'matters of concern,' as well as a shift from powerful knowledge to meaningful knowledge as the basis for curriculum and teaching, if we really want various groups of students to direct their interest towards the teaching content of common concern and become involved in their own education.

\section{Note}

1 The research project Exploring the elusive gap: Equity and knowledge segregation in teaching processes, financed by the Swedish Research Council [2017-03501].

\section{References}

Alexander, R. (2001). Culture and pedagogy: International comparisons in primary education. Blackwell.

Anyon, J. (2014). Radical possibilities. Public policy, urban education, and a new social movement (2nd ed.). Routledge. 


\section{Ninni Wablström}

Bellack, A. A., Kliebard, H. M., Hyman, R. T., \& Smith, F. L. (1966). The language of the classroom. Teachers College Press.

Biesta, G. (2014). Pragmatising the curriculum: Bringing knowledge back into the curriculum conversation, but via pragmatism. The Curriculum Journal, 25(1), $29-49$.

Burman, A. (2021). Dissensus. Drömmar och mardrömmar $i$ demokratins idéhistoria. [Dissensus. Dreams and nightmares in the history of democracy ideas]. Natur \& Kultur.

Carr, W., \& Hartnett, A. (1996). Education and the struggle for democracy: The politics of educational ideas. Open University Press.

Cherryholmes, C. (1988). Power and criticism. Poststructural investigations in education. Teachers College Press.

Cohen, D. K., Raudenbush, S. W., \& Ball, D. L. (2003). Resources, instruction, and research. Educational Evaluation and Policy Analysis, 25(2), 119-142. doi:10.3102/01623737025002119

Deng, Z., \& Luke, A. (2008). Subject matter. Defining and theorizing school subjects. In F.M. Connelly, M. F. He, \& J. A. Phillion (Eds.), The SAGE handbook of curriculum and instruction (pp. 66-87). Sage Publications.

Dewey, J. (1991). Common sense and science. In J. A. Boydston (Ed.), John Dewey. The later works, 1949-1952 (Vol. 16, pp. 242-256). Southern Illinois University Press. (Original work published 1949).

Dewey, J. (2008). Democracy and education. In J. A. Boydston (Ed.), John Dewey. The middle works, 1899-1924 (Vol. 9, pp. 3-370). Southern Illinois University Press. (Original work published in 1916).

Doyle, W. (1992). Curriculum and pedagogy. In P. W. Jackson (Ed.), Handbook of research on curriculum (pp. 486-516). Macmillan.

Fraser, N. (2004). Institutionalizing democratic justice: Redistribution, recognition, and participation. In S. Benhabib, \& N. Fraser (Eds.), Pragmatism, critique, judgment: Essays for Richard J. Bernstein (pp. 125-147). MIT Press.

Fraser, N. (2017). From progressive neoliberalism to Trump-and beyond. American Affairs, 1(4).

Gunter, H. M., Grimaldi, E., Hall, D., \& Serpieri, R. (2016). NPM and educational reform in Europe. In H. M. Gunter, E. Grimaldi, D. Hall, \& R. Serpieri (Eds.), New public management and the reform of education. European lessons for policy and practice (pp. 3-17). Routledge.

Hansen, D. T. (1995). The call to teach. Teachers College Press.

Jackson, P. W. (1990). Life in classrooms. Teachers College Press.

Jungar, A.-C. (2017). Populism $i$ Norden. Från marginalen mot den politiska mittfaran [Populism in the Nordic countries. From the margins to the political center]. Report. The think-tank agenda (Finland).

Klette, K., Svein, L., Anmarkrud, Ø., Arnesen, N., Bergem, O. K., Ødegaard, M., \& Zachariassen, J.-R. H. (2005). Categories for video analysis of classroom activities with a focus on the teacher. University of Oslo.

Levitsky, S., \& Ziblatt, D. (2018). How democracies die. Broadway Books.

Lundgren, U. P. (1981). Model analysis of pedagogical processes. Liber/Gleerup.

Molinari, L., Mameli, C., \& Gnisci, A. (2013). A sequential analysis of classroom discourse in Italian primary schools: The many faces of the IRF pattern. British Journal of Educational Psychology, 83, 414-430. doi:10.1111/j.2044-8279.2012.02071.x

Mudde, C., \& Kaltwasser, C. R. (2017). Populism. A very short introduction. Oxford University Press. 
NAE. (2021). The Swedish National Agency for Education. Statistics of grades. Retrieved July 20,2021, from https://www.skolverket.se/skolutveckling/statistik

Nussbaum, M. C. (2007). Frontiers of justice: Disability, nationality, species membership. Harvard University Press.

OECD. (2012). Equity and quality in education. Supporting disadvantaged students and schools. OECD.

Olssen, M. (2009). Neoliberalism, education and the rise of global common good. In M. Simons, M. Olssen, \& M. A. Peters (Eds.), Re-reading education policies: A handbook studying the policy agenda of the 21st century (pp. 433-457). Sense Publishers.

Roberts, D. A. (2007). Scientific literacy/science literacy. In S. K. Abell, \& N. G. Lederman (Eds.), Handbook of research on science education (pp. 729-780). Routledge.

Sen, A. (1999). Development as freedom. Oxford University Press.

Swedish Research Council. (2017). God forskningssed [Good research practice]. The Swedish Research Council.

Wahlström, N. (Ed.). (2019). Classroom research-Methodology, categories, and coding. Linnaeus University Press.

Wahlström, N. (2020). Democracy and curriculum-The task still before us. European Educational Research Journal, 19(4), 351-363. doi:10.1177/1474904119889795

Wahlström, N. (2021). School and the democratic hope: The school as a space for civic literacy. Keynote presented at the European Education Research Conference 2021, Geneva/virtual, September 6-10.

Wahlström, N., \& Sundberg, D. (Eds.). (2018). Transnational curriculum standards and classroom practices: The new meaning of teaching. Routledge.

Wells, G. W., \& Arauz, M. (2006). Dialogue in classroom. Journal of the Learning Sciences, 15(3), 379-428.

Youdell, D. (2011). School trouble. Identity, power and politics in education. Routledge.

Young, M. (2013). Overcoming the crisis in curriculum theory: A knowledge-based approach. Journal of Curriculum Studies, 45(2), 101-118. 


\title{
2 Policy, Knowledge and Promoting a Democratic Stance
}

\author{
Ninni Wablström
}

In recent years, the mission for schools to provide good conditions for students to acquire knowledge has been emphasised in international and national educational policies - not least based on international knowledge measurements such as Programme for International Student Assessment (PISA) and comparisons of results. This focus on knowledge has been interpreted in different ways in different international and national policy arenas. Meanwhile, the role of schools in maintaining democracy in Western countries has largely been taken for granted. Extensive research (e.g. Grek, 2019; Lingard \& Lewis, 2017; Lingard \& Ozga, 2007) has shown that, for example, the education policy stated by the Organisation for Economic Co-operation and Development (OECD) has centred mainly on competencies for future working life needed for nations to cope with global competition. Because of the economic implications of education, the OECD actively engages in education policy issues at the transnational arena. Socioeconomic considerations characterise the OECD's views on both the aim of education and the governance of schools. Different countries have been influenced by this dominating international discourse when framing their own national education policies in their own unique ways (Wahlström, 2020a). However, there have been significantly fewer studies on the translations from policy to the concepts of knowledge that form the basis for curricula. Curriculum reforms do not start from zero. Instead, transnational reforms add and change earlier traditions of knowledge and school conceptions when new policy ideas enter historical knowledge traditions and education cultures in different countries. The framework Education 2030 is a recent example of overarching goals that might potentially influence the policy of curricula in several Western countries. Therefore, curriculum research needs to take an interest in both policy reforms and knowledge traditions.

In this chapter, the purpose is to explore the boundaries of three different concepts of knowledge and how different elements of a transnational education framework, Education 2030, become adaptable, or unadaptable, to a certain knowledge concept. The notion of citizenship education is specifically highlighted in the analysis of both the transnational policy framework and the different concepts of knowledge. In the first section, the OECD framework of Education 2030 (OECD, 2018) is introduced. In the next section, the historical traditions and characters of three different concepts of knowledge with relevance for curricula and teaching are presented together with an analysis of the policy framework in relation to the different knowledge 
concepts. In the third and final section, the character of the policy framework and the educational implications of connections and boundaries between the different knowledge concepts are discussed.

\section{The OECD Framework of Education 2030}

The OECD looked ahead to 2030 and launched a framework titled The Future of Education and Skills 2030. According to the OECD (2018) itself, the framework is an attempt to offer a response to the overarching question of how education 'can equip learners with agency and a sense of purpose, and the competencies they need, to shape their own lives and contribute to the lives of others' (p. 2). It sounds like a reasonable democratic basis for a national compulsory education, but is it what it purports to be? Moreover, what forms of knowledge does the framework implicitly advocate?

The aim of the OECD framework Education 2030 is to support national governments to find answers to two questions: 'What knowledge, skills, attitudes and values will today's students need to thrive and shape their world?' and 'How can instructional systems develop these knowledge, skills, attitudes and values effectively?' (OECD, 2018, p. 2). Thus, the central pedagogical questions are the what and the how of future education. As is often the case in international policy documents, the main argument for the proposed policy is challenges attributed to the rapid change of society. The OECD identified environmental, economic and social challenges. The environmental challenges include climate change and the handling of natural resources. The economic challenges raise the question of what it means to be human when biotechnology and artificial intelligence are gaining influence. Finally, the social challenges consist of issues related to migration, urbanisation and inequalities in life chances and living standards. The framework Education 2030 distinguishes four different types of knowledge: disciplinary knowledge on subject-specific concepts and detailed content; interdisciplinary knowledge, which is transferring concepts and content across subjects; epistemic knowledge, which represents an understanding of how expert practitioners work and think, helping students use this understanding for solving community problems; and procedural knowledge, which focuses on the how question and helps students identify and solve problems (OECD, 2019b).

The OECD (2018) claimed that an overarching purpose for meeting these challenges can be summarised with the term well-being. The OECD's concept for stimulating well-being is 'inclusive growth.' In addition to preparing students for working life, Education 2030 argues for the need to 'equip students with the skills they need to become active, responsible and engaged citizens' (OECD, 2018, p. 4). A core concept for the 2030 framework is 'student agency,' which aims to express students' engagement in society in working for its improvement (OECD, 2019a). Student agency also denotes the need of students to play an active role in deciding what to learn and how to learn. The assumption is that the emphasis on agency, as well as co-agency, helps individual learners develop agency in the broader terms of being an 
engaged citizen. An inference drawn in the framework is that a personalised learning environment, supporting and motivating each student, is crucial for evolving agency. The OECD has suggested a constrained curriculum to ensure the depth and the quality of students' learning. The knowledge concept suggested is competencies, comprising 'the mobilisation of knowledge, skills, attitudes and values to meet complex demands' (OECD, 2018, p. 5). For learners to develop in this direction, the term transformative competencies has been introduced. It suggests that students should be able to act creatively, reconcile tensions and take responsibility. According to the OECD (2018), the assessment methods need to be expanded and renewed to also cover outcomes and actions that cannot be measured today.

\section{Three Different Concepts of Knowledge}

In a sense, there are as many versions of knowledge in classrooms as there are teachers, because each teacher has his or her own unique way to select and prioritise teaching content and to decide which teaching approach best suits each different element of a subject matter. However, to conceptualise the meaning of knowledge and its implications for curricula and teaching practices, there is a need to distinguish between some distinct basic forms of the concept of knowledge. During the 2000s, the question of knowledge has been at the centre of the debate about curriculum policies, not least since Michael Young $(2008 \mathrm{a}, 2013)$ revitalised the discussion of the concept of knowledge as a necessary basis for curriculum reforms. Young's claim for the conceptualisation of knowledge as 'social realism' has both received support (Mitchell \& Lambert, 2015; Wheelahan, 2010) and inspired arguments for other traditions of knowledge that should form the groundwork for schools' knowledge bases (Biesta, 2014; Deng, 2020; Wahlström, 2020b). In the following, three traditions of knowledge are introduced and compared in relation to the proposed framework of Education 2030. The focus is on the what and the how of education, because these aspects of knowledge conceptualisations are highly integrated. A third aspect of the analysis is the kind of citizenship education that the different forms of knowledge allow for.

\section{The Knowledge Concept of Social Realism}

Theorist of sociology of education Michael Young (2008b) noted that the what of education was not really questioned until the 1970s. The curriculum theory question of what is educationally worthwhile knowledge was mainly taken for granted. With the 'new sociology' in the 1970s, this obviousness became questioned (Young, 1971). One characteristic of the new sociology was the introduction of aspects of power and ideology into the discussions on the knowledge base of curricula and content selection. The 'new' in sociology at the time was the argument that curricula reflected a social and political discourse representing certain values, ideas and interests, rather than something given. Thirty years later, Young (2008b) stated that 
the new sociology treated knowledge as interchangeable, underestimating the need to identify the social basis of knowledge structures themselves. The structural differentiation establishes boundaries between theoretical and practical knowledge and between curricular and everyday knowledge. These structures, Young (2008b) argued, have educational implications because the social structures of knowledge also represent necessary conditions for the acquisition of knowledge.

Instead of viewing knowledge in education as a social construction, Young, in the 2010s, argued for what he described as social realism. There is, Young (2008b) argued, a fundamental distinction between skills and competencies on the one hand (vocational education) and acquiring knowledge on the other. Drawing on the sociologist Emile Durkheim, the distinction between knowledge and experience is one of structural differentiation, which means that knowledge and experience are based on different forms of social organisation in society. Young placed this analytical distinction between knowledge and experience as a principled basis for distinguishing between school knowledge and other knowledge achieved outside school. School knowledge primarily has its roots in the academic disciplines and is characterised by its differentiation. Young's conclusion was that the fundamental educational problem is the discontinuity between the culture of curricula and the culture of the students. Thus, the educational question is how to make knowledge (that counts) accessible for the majority of students. Young (2008b) termed his theory of social realism a knowledge-based approach to curriculum, which implies that curriculum in itself should be understood as an independent social institution, separate from the needs of teachers, students and policy-makers. Social realism, thus, can be interpreted as a counter-movement to a perceived international trend where the priorities of schooling are displaced from a focus on acquisition of knowledge students otherwise do not have access to, to a focus on the school's role to equip young people as future citizens in a broader meaning.

Social realism is based on the assumptions that the main role of school is to constitute a place for knowledge transmission, that some knowledge is more worthwhile than other knowledge and that differences between different forms of knowledge must constitute the basis for curricula. To this point, Young (2008b) formulated his now well-known expression of 'powerful knowledge.' The knowledge is powerful in the sense that it gives intellectual power to those who have access to it. In modern societies, such knowledge is specialised knowledge developed within different knowledge domains. Specialised knowledge constitutes the groundwork for reliable explanations about the world and provides the learners with an intellectual language, facilitating for engaging in public debates on moral, political and other issues. While context-dependent knowledge comprises everyday knowledge and common sense, context-independent knowledge is conceptual, specialised knowledge that is not related to particular cases. Knowledge that is independent of context is developed in communities of experts in fields such as science and technology and, because of its context independence, forms the 
basis for generalisations. Teachers with specialised knowledge are required for the teaching of the school subjects. For social realists, the acquiring of specialised knowledge, based on differentiation from other forms of knowledge and vertically structured in reaching higher levels of abstraction, forms the basis for education. For social realists, there is a close relation between academic disciplines and school subjects, which connect university-based subject specialists with their school-based colleagues.

\section{The Policy of Education 2030 from a Social Realist Perspective}

If the policy framework of Education 2030 should be implemented in a curriculum based on the knowledge concept of social realism, only minor parts of the policy would fit in. The what question is most obvious. A small number of topics should be introduced in each grade to promote depth and quality of students' learning. Moreover, topics should be sequenced in a way that represents the logic of the academic disciplines in order for the students to develop their learning from basic to more abstract concepts. Disciplinary knowledge constitutes the foundation in an imaginary hierarchy with its subject-specific concepts and detailed content in specific disciplines (OECD, $2019 \mathrm{~b}$ ). So far, it is a logic of social realism that is emphasised. However, social realism has less to say about the question of how. Their main concern is that students get access to knowledge through the organisation of the national school systems and the content and structure of curricula, rather than about how the qualities of individual learning processes can actually be understood.

Young (2008a) took his point of departure in Durkheim's sociology of knowledge when developing the knowledge concept of social realism. Durkheim's starting point was the social reality of religion in primitive societies. The collective representation of religion was based on a collective meaning and not on individual minds. Durkheim thought that these collective representations constituted the 'paradigm of all advanced forms of theoretical knowledge' (Young, 2008a, p. 4l). He made a clear distinction between the profane and the sacred orders of meaning, where profane referred to people's knowledge from their everyday lives and sacred to the world of religion, built on abstract understandings. The sacred system implies an objectivity because of its collective character and its social meaning external to individual perceptions. According to Young (2008a), Durkheim argued that the systems of the sacred were relatively stable over time and represented features of knowledge and truth. Thus, for Durkheim, religion appeared to be a model for abstract thoughts of modern science and social solidarity. The systems of the sacred, as well as the systems of theoretical knowledge, are characterised by their development within a social community and their separation from the practical everyday life. Since the concepts have developed beyond the systems of the practical, they can be used for making connections between objects and events. Moreover, these abstract concepts make it possible to anticipate future consequences by formulating 
hypotheses. According to Young (2008a), Durkheim's sociology of knowledge distinguishes between the sacred and the profane, or between theory and common sense, in all societies. The theoretical concepts get their power from being unobservable. However, Durkheim said little about the process of developing knowledge.

Drawing on the roots of Durkheim's sociology of knowledge in social realism, the distinctions between theory and practice and between thought and action in social realism are emphasised. It is theoretically based knowledge (i.e. clearly structured specialised knowledge) that is understood as a starting point for understanding the world. According to social realism, the concept of competence in curricula can be related to policies of 'technical instrumentalists' and the needs of the economy (Young, 2008a, p. 20). Thus, core concepts from Education 2030 - such as transformative competencies, interdisciplinary knowledge and epistemic knowledge - have little to do with a knowledge-based curriculum from a social realist perspective.

The citizenship education that social realism opens up is an informed citizen taking part in common deliberations based on powerful knowledge in terms of specialised knowledge. It represents a perspective of academic rationalism of curricula (Deng \& Luke, 2008). The assumption is that access to abstract theoretical knowledge is essential for an effective democracy (Wheelahan, 2010). The emphasis is on the citizenship of the adult.

\section{The Knowledge Concept of Transactional Realism}

In the same way as an organism always finds itself in a certain environment and tries to master that environment in order to survive, so too is the individual always already in an environment with which he or she communicates, interacts and adapts. There is not an individual interacting with an environment outside. Instead, transaction requires accepting the two in a common contingent system, focusing on different elements in different situations. For Dewey, the distinction between internal and external was not an ontological distinction - only a methodological one (Garrison, 2001). When thinking in terms of life functions, the distinction between outer and inner becomes blurred and unhelpful because it does not reflect the reality of living organisms. 'The higher the organism is in the evolutionary scale, the more complicated are the transactions in which it is involved' (Dewey \& Bentley, 1991, p. 129). Dewey denied dualities between man and the world, between inner and outer and between subject and object. According to Dewey, there are no gaps to overcome; there are only new relationships to establish in an already common environment.

In relation to the process of transaction, Dewey did not distinguish between common sense and science. The difference between the two is instead a difference of reflective inquiry, of thinking. As Garrison (1994) pointed out, to insist on the perspective of transaction is to insist that we are participants in an ongoing development of the world, rather than spectators of a finished world. This means that there is no way to step outside our existence in the 
world; we will always act as part of the physical and social world, influencing and being influenced by it.

Considering the dependence of life in even its physical and physiological aspects upon being parties in transactions in which other human beings and "things" are also parties, and considering the dependence of intellectual and moral growth upon being a party in transactions in which cultural conditions partake - of which language is a sufficient instance - the surprising thing is that any other idea has ever been entertained.

(Dewey, 1991b, p. 243)

Even if Dewey was surprised that other understandings of human conditions for living and developing could be expressed, other ideas have dominated the knowledge debate. In the quotation cited earlier, Dewey stated that through the processes of transactions, the human being exists, and through these processes, each individual develops habits (common sense), knowledge and moral values (growth). This is why Dewey did not distinguish between common sense and knowledge and why he used the concept of experience instead of knowledge. They are all outcomes of transactions with the individual acting as a part.

An experience is a result of acting and its consequences. There are two phases in experiences: one active and one passive phase. We act on something and undergo the consequences of our action. Through experiences, relationships with other humans and physical things are established; we know something about them. The term of transaction implies that every experience affects the one who has acted and undergone the experience and that the outcome of an experience affects subsequent experiences because there is a principle of continuity intrinsic in every experience. The space of thinking occurs in the intersection between an action and its consequences. In this way, habits are established - that is, attitudes and knowing necessary for handling all the conditions which we meet in living (Dewey, 199la). For an experience to be reflective, there needs to be intentional thinking for discovering specific connections and relationships between our actions and the consequences we undergo. Consequently, reflective experiences contain an uncertain or problematic situation, a tentative interpretation of the situation, a careful consideration to clarify the problem, a provisional inference of how to solve the situation and an acting based on the provisional inference and, finally, the conclusions drawn from the consequences of the acting. Already attained knowledge deepens reflective thinking and the quality of the experience. For an experience to be educative, it needs to enhance and deepen succeeding experiences (Dewey, 1991a). Using the concept of experience in a context of meaning making and gaining knowledge has caused a lot of trouble, not the least for Dewey himself, because experience is usually thought of as being a personal or subjective concern. However, Dewey (1991b) insisted that when 
you want to emphasise the interconnectedness of all concerns and affairs, the concept of experience 'serve[s] the purpose better than any word that is yet available' (p. 248, footnote).

An objection often expressed is that when a person gains knowledge in terms of experiences, it is not possible for him or her to know anything for sure because experiences are thought of as being predominantly subjective. Dewey's $(1917 / 1985)$ answer was that the concept of experience is an expression of humans' transactions with a 'genuinely objective world' (p. 6). Humans are already involved with reality in their environment through constantly ongoing transactions; thus, the philosophical problem is not how individuals can achieve knowledge about reality, as in the philosophy of consciousness. Instead, the philosophical problem is, according to Dewey, how we can learn something from the transactions with the realities in our environment. To do that, we need to act together with other humans to get a shared intersubjective world, and the way we get something in common is through the process of communication. The term communication should not be understood as passing on information but rather as a practical coordination of our own interactions with others to be able to create meaning of the world. Knowledge is fallible because we can never be sure that the actions and conclusions developed in the past will be adequate for the problems we will meet in the future (Biesta \& Burbules, 2003). The meaning of experience does not constitute the difference between common sense and science - between the designations 'water' and ' $\mathrm{H} 2 \mathrm{O}$ ' - so what demarcates the two, then? Actions in terms of transactions are involved in both. However, while transactional inquiries in common sense are important for the needs of everyday life, transactional inquiries in science are conducted for the sake of advancing the system of knowings and knowns. The distinction lies in what is done and known (development of new knowledge), why it is done and known (the advancement of knowing) and where (within academy) and by whom (scientists) it is done and known. The outcomes of science are abstractions and theories, even if the scientific work in itself is based on practical work - testing, reading, writing, thinking - a work usually labelled as intellectual (Dewey, 1991b).

\section{The Policy of Education 2030 from a Transactional Realist Perspective}

In Education 2030, the disciplinary knowledge lays the groundwork for interdisciplinary knowledge, relating concepts from one discipline to another. Moreover, disciplinary knowledge is understood in this framework as raw material, from which new knowledge can be developed. This view of knowledge echoes John Dewey's argument of knowledge as retrospect if not combined with reflecting on challenges in actual and future situations. 'The value of knowledge is subordinate to its use in thinking' because 'we live not in a settled and finished world, but in one which is going on, and where our main task is prospective' (Dewey, 1916/2008, p. 158). Interdisciplinary 


\section{Ninni Wablström}

knowledge fits more easily in the tradition of transactional realism. In the OECD interpretation of epistemic knowledge, the understanding of how experts within disciplines think and work was emphasised. This kind of knowledge is expected to help students understand how knowledge can be developed and applied to different situations, which is similar to the experiential form of knowledge represented in transactional realism. Procedural knowledge has to do with knowledge of methods and thinking for problem-solving - that is, what steps and actions are needed for reaching a solution to a problem. While the concepts of disciplinary, interdisciplinary and epistemic knowledge have answered the didactic question of what, procedural knowledge represents an answer to the didactic question of how.

The overarching goal of education as a response to challenges in society formulated in Education 2030 could be understood in accordance with a curriculum based on transactional realism. Even the meaning of transformative competencies - in terms of being creative, reconciling tensions and dilemmas and taking responsibility - could constitute a potential answer to education as moral growth. However, if 'a personalised learning environment' (OECD, 2018, p. 4) represents a cognitive and constructivist view of the self-authoring learner gaining new knowledge through the internalisation of the inner schemes of knowledge that are already known, the learner is an autonomous individual separated from context, unlike the transactional individual in transactional realism. In the latter, individuals make meaning of the world through a common participation in communication with others. In transactional realism, knowledge emerges through transactional processes, in the intersection between an individual, other humans and objects.

The citizenship education that transactional realism opens up for is the unpacking of the what in education regarding the relationships between facts and different aspects of their consequences for individuals and society. Regarding transactional realism, Dewey (2008, p. 370) claimed that all education, to be called education, aims at developing individuals' moral character and the social aims of society. He expressed moral responsibility in the very last sentence of his text Democracy and Education: '[i]nterest in learning from all the contacts of life is the essential moral interest.' It is a social reconstructionist perspective of curricula built on experiential knowledge (Deng \& Luke, 2008), represented by transactional realism. The focus is on the students as citizens, connecting their own experiences with others' experiences in terms of knowledge.

\section{The Knowledge Concept of Bildung}

The idea of Bildung has its roots in the neo-humanist tradition flourishing in Germany in the period between 1770 and 1830. In English, Bildung can be understood in terms of 'culture' and 'cultivation.' The Bildung theorists were interested in the question of how to link the individual with his or her cultural heritage - in their case, texts from ancient Greece and Rome. 
The engagement in and learning from culture was seen as a reciprocal process of actualising the individual character of the self and of re-understanding the meaning and wisdom embedded in human cultural expressions. In such educative experiences, both the subject and the subject matter are transformed. In Wilhelm von Humboldt's theory of Bildung, there was no split between the individual and humanity at large. In each human self, there is an embryo of the universal humanity as an inner destiny. The idea of Bildung is for the individual to interact in educative ways with things and persons with varied cultural and individual expressions as a way of reaching an inner freedom of the self (Løvlie, 2002). Because the self is always already involved in the world, the individual should not be understood as a separate satellite. As Løvlie and Standish explained (2002, p. 319), 'Bildung starts with the individual embedded in a world' where self and the other 'are already connected in their common, self-expressive nature.' For neo-humanists, education takes the form of character formation through encounters with the arts, literature and philosophy. However, education is never about the individual alone; it is always about the relation between the self and the wider world, the culture, through transformation. In this process of transformation of the self, there is always a simultaneous process of transformation of culture. Thus, the term Bildung is about self-transformation through the relationship between the self and a historical and cultural world.

In the history of education, two views of Bildung became predominant in the 19th century: Bildung as self-formation and Bildung as the acquisition of an institutionalised canon of cultural traditions. Therefore, Bauer (2003) argued that the understanding of the meaning of Bildung needed to go back to the 'classic' meaning of Bildung from the mid-18th century to be relevant in educational discussions today. During that period, the term Bildung was conceptualised as creative, critical and transformative processes that changed the relationship of self and world during a historical period of changing social and material conditions. Klafki (2000) also emphasised that terms such as self-determination, emancipation and autonomy from the classic texts needed to be read together with terms such as humanity, humankind, humanness, objectivity and the general from the same texts.

This means that reasonableness, capacity for self-determination, and freedom of thought and action are attained only in the processes of acquiring and examining the content of something that does not at first come from the person himself or herself, but is the objectification of activities in the culture - and this in the widest sense: in the objectification of activities in which possibilities of human self-determination, the development of human reason, human freedom, or else their opposites, have taken shape.

(Klafki, 2000, p. 88)

In short, the content of Bildung is focused on the question of what objectification of human history is best suited to support the individual's Bildung. 


\section{Ninni Wablström}

In education, the development of the uniqueness of each person can be realised only in communication with others, 'where they - in their individuality bring themselves into such communication and give each other recognition' (Klafki, 2000, p. 93). The meaning of self-determination is to take a moral responsibility and to provide a readiness for moral action.

The concept of Didaktik in the German-speaking European countries connects to the basic ideas of Bildung in terms of developing one's own unique self. Thus, the task of school education is to introduce a content for students which promotes and expands their Bildung in terms of individuality and sociality. This means that Didaktik - with its triadic relation between content, teacher and learner - can provide students with tools to help students open up the world and be open to the world, but Didaktik and teaching cannot provide the students with Bildung in any direct way. Therefore, at the centre of Didaktik is the content, the tool to the world. Any content needs to be understood in terms of how this specific content can contribute to a student's understanding of mankind, of the world or of him or herself. In Didaktik, the central focus is the encounter between a unique individual and specific content. Thus, the meaning and the value of the content cannot be expressed by the teacher alone; it can be understood only in a student's interpretation of the content through the student's interactions with the content and the teacher (Hopmann, 2007).

\section{The Policy of Education 2030 from a Perspective of Bildung}

In both transactional realism and Bildung, the intersubjective nature of knowing is emphasised. The learner is always already included in a social and physical context the individual interacts with, is influenced by and develops their knowledge in relation to. In transactional realism, this context is the environment, with an overarching understanding of the need to form communities for encountering the inevitable challenges of any society. In Bildung, the common context is constituted by the cultural environment. Thus, in these two understandings of knowledge, the self and the other are already connected in a common context. In both concepts, an individual learns from contact with both the past and the present, through direct communication and through text, art and other media. In Bildung, knowledge emerges in terms of an individual's self-cultivation and self-determination. The purpose of the cultivation of oneself is to develop a sense of moral responsibility for oneself, as well as in relation to others and to a common society. In this aspect, Bildung resonates with the term learner agency in Education 2030, as

a personalised learning environment that supports and motivates each student to nurture his or her passions, make connections between different learning experiences and opportunities, and design their own learning projects and processes in collaboration with others.

(OECD, 2018, p. 4) 
The central interest in Bildung and Didaktik is the content - more particularly, the meaning of the content for the individual student. In this way, a personalised concept of learning agency can make sense. The emphasis is on disciplinary and interdisciplinary knowledge, including culture and the arts. The focus is not so much on epistemic knowledge - that is, learning from the practices of the experts - as on how insights from the historical and current cultural environments can provide insights for dealing with the present and future world. The important aspect is that the content contains an important or engaging message to each student, helping students develop their inner potential and take moral responsibility when acting in the world.

The citizenship education addressed in the knowledge concept of Bildung is the understanding of Bildung as a creative and transformative process, which changes the relationships between the self and a changing social and material world (Bauer, 2003). Thus, there are certain similarities between Bildung and transactional realism: the intersubjective meanings of cultivation and experience, the contingent and searching quality of knowing, the interest for others from a position that is not one's own and the transformation of individuals and society by seeing things with new eyes and asking new questions (Wahlström, 2007). However, the emphasis on self-determination points at an individualised curriculum based on humanism (Deng \& Luke, 2008), which makes citizenship education more obscure in comparison to the individual self-actualisation. Citizenship education based on Bildung has its central interest directed towards reciprocal moral growth for individuals and culture. As in transactional realism, the focus is on the students as citizens here and now.

\section{Three Concepts of Knowledge - Three Relations to the World}

Unlike in the framework of key competencies (OECD, 2005, p. 7), where it was stated that '[a]ll OECD societies agree on the importance of democratic values,' there is no explicit value base in democracy in Education 2030. The justification for the latter framework is the environmental, economic and social changes. A new concept in comparison with the framework for key competencies (OECD, 2005) has been accentuated in Education 2030: well-being. Well-being is used as an overarching goal for both material resources - such as income, earnings and housing - and for quality of life, including health, civic engagement, social life, security, education and environment. In fact, the term well-being seems to cover almost all aspects of life. Education for well-being is said to prepare people not only for work but also to 'become active, responsible and engaged citizens' (OECD, 2018, p. 4). What is missing is a much-needed analysis of what is meant by wellbeing in relation to school and curricula. A concept covering all aspects of life risks becoming blank, without power to point out any direction for priorities and values in education. It also risks being interpreted as objective well-being in economic terms rather than being perceived as subjective well-being (Tesar \& Peters, 2020). Thus, it raises the question about who 
and what decides if education is conducive for individual and social well-being? The term well-being can be understood as an expansion of the former educational goals for coping with working life (see OECD, 2005) to future goals of covering all parts of life. To the question 'What kind of citizen?', the answer is a personally responsible adult citizen (Westheimer \& Kahne, 2004). Thus, the policy concept of well-being is not a new term for democracy or social justice; it rather points in an individual direction of 'being well' in one's own life.

In the analysis of a proposed policy framework for education in relation to actual concepts of knowledge, the different characters of policy goals and goals of knowledge become clear. While the former express what we want from the world, the latter explain what we can know about the world. There are both gaps and connections between the three different concepts of knowledge analysed in this chapter. Both transactional realism and Bildung have philosophical roots, while social realism is rooted in a sociological tradition. Both transactional realism and Bildung take their starting points in the whole, in the individual as already embedded in the environment (transactional realism) or culture (Bildung), by which both humans and environment/culture are being transformed through their interactions. Social realism, however, starts off from a division between mind and object, theory and practice.

Young (2008b) referred, in his concept of social realism, mainly to Emile Durkheim's lectures on sociology and pragmatism in Paris in 1913. In these lectures, the target of criticism was pragmatism - but rather the pragmatism of William James than of John Dewey (Rusche \& Tilman, 2007). According to Young (2008b), Durkheim made a clear distinction between knowledge and experience, which can be traced back to the distinction between the sacred and the profane systems of meaning. While Dewey argued that consciousness emerges when agents confront action-problematic situations, Durkheim insisted that thought and action were opposed and that action could not give rise to consciousness (Gross, 1997). Another critique of pragmatism arose by understanding the word 'practical' in a narrow sense, in terms of what is useful for success in the everyday world. In Durkheim's and other critics' views, practice has nothing to do with the operations of thought. For pragmatists, however, theories are practical in the sense that they create a coherent organisation of ideas in our minds, through which the knower can move efficiently. Moreover, a problematic situation does not relate only to a physical problem; it may relate to intellectual or moral problems that need to be problematised. For pragmatists, theory comes late in inquiry as the gradual accumulation of knowledge, while Durkheim thought of theory as being a driving force in advancing knowledge which should be introduced at an early stage as an active instrument for discovering the causal network that underlies phenomena (Rusche \& Tilman, 2007). Where transactional realism goes beyond dualisms, social realism strives to maintain boundaries and structures. What transactional realism and social realism have in common is the belief that knowledge is socially 
constructed and fallible. What separates them is the meaning of experience and the degree to which scientific knowledge can be understood as being independent of context.

The kind of knowledge underpinning curricula becomes important in relation to how education can contribute to developing an interest of society and the handling of its challenges. Bildung offers the world to students by focusing on content with which the learner can engage. It is not possible to predict in advance what they will learn. Transactional realism presents the world as incomplete and unresolved, focusing on inquiry, reflective thinking and interactive communication. The goals of education are preferably formulated during the process of learning. Social realism describes the world to students with a focus on scientific knowledge. Learning goals are predictable, and access to knowledge represents the crucial link to the common world.

\section{References}

Bauer, W. (2003). On the relevance of Bildung for democracy. Educational Philosophy and Theory, 35(2), 211-225. doi:10.1111/1469-5812.00020

Biesta, G. (2014). Pragmatising the curriculum: Bringing knowledge back into the curriculum conversation, but via pragmatism. The Curriculum Journal, 25(1), 29-49. http://dx.doi.org.proxy.lnu.se/10.1080/09585176.2013.874954

Biesta, G. J. J., \& Burbules, N. C. (2003). Pragmatism and educational research. Rowman \& Littlefield.

Deng, Z. (2020). Knowledge, content, curriculum and Didaktik beyond social realism. Routledge.

Deng, Z., \& Luke, A. (2008). Subject matter: Defining and theorizing school subjects. In F. M. Connelly; M. F. He, \& J. A. Phillion (Eds.), The SAGE handbook of curriculum and instruction (pp. 66-87). Sage Publications.

Dewey, J. (1985). The need for a recovery of philosophy. In J. A. Boydston (Ed.), John Dewey. The middle works, 1899-1924 (Vol. 10, pp. 3-48). Southern Illinois University Press. (Original work published 1917)

Dewey, J. (1991a). Experience and education. In J. A. Boydston (Ed.), John Dewey. The later works, 1925-1953 (Vol. 13, pp. 2-62). Southern Illinois University Press. (Original work published 1938)

Dewey, J. (1991b). Common sense and science. In J. A. Boydston (Ed.), John Dewey. The later works, 1925-1953 (Vol. 16, pp. 242-256). Southern Illinois University Press. (Original work published 1949)

Dewey, J. (2008). Democracy and education. In J. A. Boydston (Ed.), John Dewey. The middle works, 1899-1924 (Vol. 9, pp. 3-370). Southern Illinois University Press. (Original work published 1916)

Dewey, J., \& Bentley, A. F. (1991). Knowing and the known. In J. A. Boydston (Ed.), John Dewey. The later works, 1925-1953 (Vol. 16, pp. 3-279). Southern Illinois University Press. (Original work published 1949)

Garrison, J. (1994). Realism, Deweyan pragmatism, and educational research. Educational Researcher, 23(1), 5-14.

Garrison, J. (2001). An introduction to Dewey's theory of functional "trans-action": An alternative paradigm for activity theory. Mind, Culture, and Activity, 8(4), 275-296. doi:10.1207/S15327884MCA0804_02 
Grek, S. (2019). Facing 'a tipping point'? The role of the OECD as a boundary organisation in governing education in Sweden. Education Inquiry, 1-21. doi:10. $1080 / 20004508.2019 .1701838$

Gross, N. (1997). Durkheim's pragmatism lectures: A contextual interpretation. Sociological Theory, 15(2), 126-149.

Hopmann, S. (2007). Restrained teaching: The common core of Didaktik. European Educational Research Journal, 6(2), 109-124. doi:10.2304/eerj.2007.6.2.109

Klafki, W. (2000). The significance of classical theories of Bildung for a contemporary concept of Allgemeinbildung. In I. Westbury, S. Hopmann, \& K. Riquarts (Eds.), Teaching as reflective practice: The German Didaktik tradition (pp. 85-107). Routledge.

Lingard, B., \& Lewis, S. (2017). Placing PISA and PISA for schools in two federalisms, Australia and the USA. Critical Studies in Education, 58(3), 266-279. doi:1 $0.1080 / 17508487.2017 .1316295$

Lingard, B., \& Ozga, J. (2007). Introduction: Reading education policy and politics. In B. Lingard, \& J. Ozga (Eds.), The RoutledgeFalmer reader in education policy and politics (pp. 1-8). Routledge.

Løvlie, L. (2002). The promise of Bildung. Journal of Philosophy of Education, 36(3), 467-486.

Løvlie, L., \& Standish, P. (2002). Introduction: Bildung and the idea of a liberal education. Journal of Philosophy of Education, 36(3), 317-340.

Mitchell, D., \& Lambert, D. (2015). Subject knowledge and teacher preparation in English secondary schools: The case of geography. Teacher Development, 19(3), 365-380. doi:10.1080/13664530.2015.1042024

Organisation for Economic Co-operation and Development. (2005). The definition and selection of key competencies: Executive summary.

Organisation for Economic Co-operation and Development. (2018). The future of education and skills: Education 2030.

Organisation for Economic Co-operation and Development. (2019a). Student agency for 2030.

Organisation for Economic Co-operation and Development. (2019b). Knowledge for 2030.

Rusche, D., \& Tilman, R. (2007). The aims of knowledge: Emile Durkheim's critique of American pragmatism. European Legacy, 12(6), 695-713. doi:10.1080/10848770701565049

Tesar, M., \& Peters, M. A. (2020). Heralding ideas of well-being: A philosophical perspective. Education Philosophy and Theory, 52(9), 923-927. doi:10.1080/001 31857.2019.1696731

Wahlström, N. (2007). Do we need to talk to each other? How the concept of experience can contribute to an understanding of Bildung and democracy. Educational Philosophy and Theory, 42(3), 293-309. doi:10.1111/j.1469-5812.2008.00441.x

Wahlström, N. (2020a). Current school reforms in transnational policy landscapes. In W. Pink (Ed.), Oxford research Encyclopedia of education. Oxford University Press. doi:10.1093/acrefore/9780190264093.013.841

Wahlström, N. (2020b). Tracing implications of transnational policy in curriculum events. The Curriculum Journal, 31(4), 587-604. doi:10.1002/curj.62

Westheimer, J., \& Kahne, J. (2004). What kind of citizen? The politics of educating for democracy. American Educational Research Journal, 41(2), 237-269.

Wheelahan, L. (2010). Why knowledge matters in curriculum: A social realist argument. Routledge. 
Young, M. (Ed.). (1971). Knowledge and control: New directions for the sociology of education. Collier Macmillan.

Young, M. F. D. (2008a). Bringing knowledge back in: From social constructivism to social realism in the sociology of education. Routledge.

Young, M. (2008b). From constructivism to realism in the sociology of the curriculum. Review of Research in Education, 32(1), 1-28. doi:10.3102/00917 32X07308969

Young, M. (2013). Overcoming the crisis in curriculum theory: A knowledge-based approach. Journal of Curriculum Studies, 45(2), 101-118. doi:10.1080/002202 72.2013.764505 


\section{Equity in Education Equal Opportunities for What?}

\section{Ninni Wablström}

In transnational policy strategies, organisations such as the European Union (EU) and the Organisation for Economic Co-operation and Development (OECD) are well aware of every nation's need for both well-educated citizens and a sense of cohesion in society. The OECD (2018a, p. 3), for example, stated thus: 'we are committed to helping every learner develop as a whole person, fulfil his or her potential and help shape a shared future built on the well-being of individuals, communities and the planet' as a response to the identified environmental, economic and social challenges which are in front of us. Both broad visions and high goals are expressed in political visions and frameworks for education as a policy field. However, what would actually be required to make visions a reality is a completely different matter. In this chapter, I take the term every learner as a starting point for an analysis of how the research field of curriculum theory can include the concept of equity as a substantial perspective for the understanding of education at different levels of a national school system, from both institutional and individual perspectives. In the introductory section, the multifaceted meaning of the concept of equity is exemplified. In the two following sections, the two frameworks of justice - the capability approach and the principle of parity of participation - are introduced. In the fourth section, a perspective of equity for compulsory education is elaborated. In the fifth and final section, the combination of two concepts of equity is discussed for the covering of different perspectives of equity in a national school system.

\section{The Contingent Meaning of Equity}

There is a clear distinction between the concepts of equality and equity in education. Equality refers to offering the same resources and opportunities for all individuals across a school system. Despite differences in gender, socioeconomic class or ethnicity, all students should have the same access to public resources and welfare services, such as schooling. The aim of equality is achieved when opportunities are equal for all groups of students. In contrast, equity represents a system for redistribution of common goods to compensate for inequalities and to enhance the chances for each individual to get the same opportunities as other individuals in society. An equitable system provides compensating resources for those who need further support so that each student can reach his or her social and intellectual potential. Since education should be adapted to students' individual needs, justice is

DOI: $10.4324 / 9781003218067-3$ 
linked to quality of education (Jurado De Los Santos et al., 2020). From a neoliberal point of view, equity is about getting the opportunity to choose one's own path to enter the working life. From a social justice point of view, in contrast, equity is about receiving the resources needed for compensation for structural or other inequalities. While the neoliberal view of equity is centred on educating citizens as a workforce, the social justice view of equity is centred on educating citizens to get equal chances in life.

In a literature review on educational research on equity, the meaning of equity in different periods was categorised. In the years around 2010, educational research on equity was mainly linked to mathematics and gender. During the following four years (2012-2016), equity was related to gender, social justice and race in educational research. In the two years thereafter, research on equity focused on school improvement, access to education, student disabilities, race and teacher attitudes (Jurado De Los Santos et al., 2020). The research overview shows that the concept of equity is balancing between aspects of social justice on the one hand and aspects of outcomes-based governing of the school on the other hand.

When the OECD has compared different national school systems from an aspect of equity, the indicators are based on the relationship between students' knowledge outcomes and socioeconomic statuses. A school system exhibits a higher degree of equity when the differences between students' outcomes can be explained by other factors than socioeconomic positions - that is, when socioeconomic differences affect students' results only to a small extent. According to the OECD (2018b), the impact of socioeconomic factors varies between countries; however, no country has a totally equitable school system. The OECD has admitted that equity is a complex concept. Nevertheless, the OECD (2018c) claimed that its Programme for International Student Assessment (PISA) measures equity in education through two related principles: inclusion and fairness. Inclusion means that all students, particularly those from disadvantaged backgrounds, have access to high-quality education and attain at least a basic level of approved skills. Fairness refers to the realising of every student's potential by removing obstacles to equal access to educational resources and school environments. Thus, in the OECD educational policy, there is a field of tension between the meaning of equity as reaching a minimum level of knowledge and as realising one's individual potential.

In Swedish educational policy, two policy concepts differ from the terms used internationally. Instead of the internationally most commonly used concept of competence, the concept of ability is used throughout the Swedish curricula. In addition, the concept of equivalence in Sweden replaces the international designation of equity. The concept of equivalence has a longstanding tradition in Swedish educational policy tradition. In the middle of the 20th century, the term equivalence denoted the fact that all Swedish schools had the same economic resources distributed by the state in a staterun school system. From 1991 onwards, after the decentralisation of the responsibility of the Swedish schools to municipalities and private school 
providers, the meaning of the concept of equivalence shifted over time. Broadly speaking, equivalence means that all students work in accordance with the same curriculum goals and that all students have access to a quality of education leading to at least the basic level of approved knowledge. In the preparatory work for the current Education Act, the Swedish government has explained that '[a]ll school organisers must therefore offer education of such quality that children, young people and adults are given equivalent opportunities to achieve the goals of the education' (Government Proposal 2009/10:165, p. 203). This explanation indicates that schools should offer education of equivalent, but not necessarily identical, quality and value. When the government applies the concept of equivalence to the national grading system (Government Proposal 2009/10:165), the meaning instead designates uniformity.

During the past decade, the Swedish policy has focused strongly on equivalence of grading. The assumption is that if teachers differ in their assessments of the same national tests, there is a lack of adequate equivalence in the national grading system. A possible solution to the problem of discrepancies between different teachers' assessment, as discussed by the Swedish National Agency for Education (NAE, 2020), was that teachers should not be allowed to assess their own students in national tests and that the outcomes of national tests should have a regulatory effect on the grades the teacher may give the students. The trend to interpret the concept of equivalence in terms of uniformity risks constraining teachers' professional agency and the public trust in the teacher profession. Taken together, the concept of equivalence tends to move along a scale of interpretation, from corresponding value in the one pole of a continuum to uniform value at the other pole.

A conclusion to be drawn from this brief overview is that policy concepts chosen at the international and national policy levels are neither neutral in their interpretation nor interchangeable. The selected concepts imply underlying assumptions concerning the meaning of a fair education system. A search on the combination of education and equity on the Web of Science resulted in 9,498 hits (in April 2021), while the combination of education and equivalence resulted in only 992 hits. These results imply that choosing 'national' concepts of equity both permits 'own' interpretations and makes it possible for Sweden to stand to the side in the international public mainstream debate.

\section{A Problematisation of the Meaning of Equity in Education}

In an overview of the historical meaning of equity in England, Unterhalter (2009) distinguished between equity from below, equity from above and equity from the middle. By tracing the meaning of equity back to the 14th century, Unterhalter noted that the term equity signifies a virtue people do or perform. Equity from below is about everyday relations of respecting each other across our differences. 'Equity from below thus takes seriously aspects of 
personal heterogeneity both in circumstances and in conceptions of a good life' (Unterhalter, 2009, p. 418). In the 16th century, an additional meaning of equity emerged in terms of law regulations of natural rights handled in specific courts. Equity from above represents a legal regulation of ideas of rights and fairness. From the 18th century, finally, a third meaning of equity was added to the former two through the emergence of capitalism. At that time, economic resources became linked to social arrangements, where equity was not an expression of individual virtues but rather the flow of money in society.

The three meanings of equity can be applied to education at three different levels: first, equity from below concerns treating all individuals respectfully and on equal terms in a school's daily activities. Equity from above is manifested in the regulations that govern a school's education, while equity from the middle is associated with resources and the efficiency of education (Unterhalter, 2009). These three interrelated levels can contribute to analyses of equity in national school systems by highlighting aspects of equity significant at different levels. In the following, two different approaches of equity are introduced. The capability approach understands equity mainly from the perspective of the individual, while the principle of participation interprets equity from a societal perspective.

\section{Education and the Capability Approach}

With some modification, you can, with Martha Nussbaum (2011, p. 59), pose the questions 'What are students actually able to do and to be?' and 'What real opportunities for activity and choice has society given them?' According to Nussbaum, the capability approach developed by Amartya Sen (1999) and herself is closely allied with the international human rights movement. The capability approach grounds its justifications of rights on the fact of being born, and it articulates a clear relationship between human rights and human dignity as well as between human rights and duties. Nussbaum $(2007,2011)$ differed to some extent from Sen in her view of the connection between human rights and the capability approach; Nussbaum linked the capability approach more closely to human rights than Sen (2005) did. The controversy between Nussbaum and Sen revolved around the issue of formulating a list with ten points regarding central capabilities that each government must assure its residents reach. Nussbaum (2007) argued that capabilities should be understood as ways of realising a life with human dignity and that the list of the ten central human capabilities includes the different areas of life in which people typically engage. In Nussbaum's (2011) suggested list, education was included under the item Senses, imagination, and thought, based on the argument that the capacity to think and reason needs to be informed and cultivated by an adequate education. Sen's (2005) objection to a list of key capabilities was based mainly on his emphasis on the importance of public reasoning. The framework of capabilities, Sen argued, helps evaluate opportunities for different 
groups and individuals through continued public reasoning. Thus, it is a question for public debate if there is a need for a list of rights or not and, if so, what items a list should include. Another objection from Sen (2005) was that even if human rights and human capabilities in a sense have common motivations, they also differ in some distinct ways. Many aspects of human rights can be adequately discussed from a capability perspective. While the opportunity aspect of freedom belongs to the area of individual capabilities, this approach has less to say about processes of fairness and equity at a social level.

The basic idea of the capability approach is to highlight the individual's opportunity to actually achieve the combination of functionings he or she has reason to value. Here, functionings means what a person is able to do or to be. A central aspect of the capability approach as an analytic framework is its sensibility for individual differences of opportunities. Such differences emerge, for example, as a consequence of physical or mental heterogeneities, variations in social resources, environmental differences and positions related to social contexts. The meaning of freedom is linked to the freedom to choose among desirable functionings and the freedom to combine these functionings in a set of capabilities that the individual values. Thus, a capability reflects the alternative combinations of possible functionings, and without these alternative opportunities, there is no freedom (Sen 1999, 2005). Freedom includes an 'ethical individualism' in the sense of a normative consideration of the effects for each individual affected, since individuals are the primary moral concern. Accordingly, evaluating capabilities, rather than outcomes or resources, shifts the attention of analysis from average values to the evaluation of 'real' individuals' opportunities to choose what they have reason to value. The difference between capability and functioning can be described as a difference between potential and outcome. Two students can reach the same knowledge outcomes (functionings), but the process to get there or the opportunity to use the outcomes for the future may differ a lot between the two students, which means that their potentials (capabilities) differ. The reason to evaluate capabilities instead of functionings is that a focus on capabilities reveals differences related to social justice. According to Walker and Unterhalter (2007), the opportunities for individuals to reach functionings and form capabilities can be amplified by social resources and social arrangements. Sen termed these combinations of social resources and individual potentials conversion factors, while Nussbaum used the term combined capabilities.

To examine aspects of education from a capability approach, Unterhalter and Brighouse (2007) developed a model based on three different values embedded in education. First, education has an instrumental value that concerns what individual students have the chance to learn at school and the implications of achieving certain levels of knowledge. A second, overlapping field is the intrinsic value that emphasises the potential for self-development and self-realisation through education. The intrinsic values highlight desirable 
functionings in terms of personal development that cannot be directly linked to improved material or meritocratic prospects. Positional values, finally, are about an individual's success relative to others.' Achieved grades is a typical example of a positional value because it can enable a student to continue to study in a programme he or she values. Positional values also comprise 'cultural' values such as gender and ethnicity, revealing otherwise often invisible forms of discrimination.

The capability approach does not offer detailed indicators for measuring. The evaluation rather includes students' personal experiences and stories of freedom to achieve the functionings they are striving for and to form the set of capabilities they have reason to value. The central interest is evaluation of effects of social structures for each individual or group of individuals. The policy from above is not only about offering access to education. It should also provide resources that make it possible for each individual to actually come to school - for example, by the arrangements of school transport or resources for material equipment. What it means to experience equity from below is clarified when listening to individual stories about opportunities to gain access to and be able to succeed within the education that the individual appreciates.

In Table 3.1, the three different values of education developed by Unterhalter and Brighouse (2007) are combined with functionings of education - that is, the actual outcomes that can be achieved through schooling - alongside the capabilities to which the combination of different functionings can lead.

Table 3.1 A framework for analysis from the perspective of capability approach based on Unterhalter (2009) and Unterhalter and Brighouse (2007)

Analysis of equity from an individual perspective: the capability approach on education

\begin{tabular}{llll}
\hline & Functionings & Capabilities \\
\hline $\begin{array}{l}\text { Instrumental } \\
\text { values }\end{array}$ & $-\quad \begin{array}{l}\text { real access to adequate } \\
\text { education }\end{array}$ & - & $\begin{array}{l}\text { education leading to } \\
\text { expanded opportunities } \\
\text { in life }\end{array}$ \\
Intrinsic values & $-\quad \begin{array}{l}\text { access to education } \\
\text { involving elements } \\
\text { of engagement, } \\
\text { critical reflections and } \\
\text { deliberations }\end{array}$ & $-\begin{array}{l}\text { education as an expansion } \\
\text { of personal growth }\end{array}$ \\
Positional values & $-\quad \begin{array}{l}\text { access to formal } \\
\text { competence and } \\
\text { positions } \\
\text { cultural recognition }\end{array}$ & - & $\begin{array}{l}\text { cultural recognition } \\
\text { freedom to participate in } \\
\text { community } \\
\text { freedom to combine } \\
\text { different aspects of life }\end{array}$ \\
\hline
\end{tabular}


The capability approach is relevant when exploring what aspects of reality primarily influence students' individual experiences of school and how individual students consider their actual chances of success in their education. While the capability approach creates a 'thick' account of matters of concern for reaching equity from an individual perspective, it has less to say about the policies, processes and structures that improve equity and remove obstacles in the education system as a whole. In contrast, Nancy Fraser (2008) has developed a multidimensional social theory of justice focused on an institutional level, which includes the allocation of resources, recognition across social and cultural differences and participation on equal terms in community.

\section{Education and the Principle of Parity of Participation}

The conceptualisation of redistribution, recognition and participation within political philosophy offers a complementary framework for analyses of equity, taking the institutional dimension into consideration (Fraser, 2004). The terms justice and equity are here understood as synonymous, although Fraser primarily used the term justice.

Fraser $(2004,2008)$ suggested the principle of parity of participation for the understanding of justice. In this principle, Fraser brought together two dimensions included in the meaning of justice: redistribution and recognition. Redistribution concerns distributive justice in terms of economic resources where inequality results in poverty, class differences and large differences in financial resources for different groups in society. Recognition concerns the cultural status order of society where inequality results in disrespect, cultural imperialism and status hierarchy. According to Fraser $(2004,2008)$, the two dimensions of redistribution and recognition are intertwined in reality but analytically separated. A critical approach to recognition includes an understanding of recognition that can be defended only because it can be combined with a social policy of equality, Fraser (2003) argued. Hence, the dimensions of redistribution and recognition should be understood as interrelated and with a need for balance between the two. The third dimension, representation, denotes a political dimension of justice alongside the economic and cultural ones (Fraser, 2008). Representation includes both the first-order level in terms of political voice and democratic accountability and a meta level on how boundaries and frames are drawn in society. Taken together, the three dimensions of redistribution, recognition and representation aim at viewing justice as a principle of parity of participation (Fraser, 2008). A principle of parity of participation requires social arrangements that enable people to interact with one another as peers in social life. Two conditions are required to meet the principle. First, the distribution of material resources needs to ensure participants' mutual independence and opportunities to have a 'voice.' Second, 
institutionalised values need to encompass equal respect for all and ensure equal opportunities for participants to achieve social appreciation. Fraser (2004) understood recognition as a question of social status that invites each individual to act as partners on equal terms in social interactions. Thus, misrecognition means social subordination by preventing individuals from participating as peers in social interactions. Fraser termed this meaning of recognition a status model of recognition, in which equity of recognition is understood as reciprocal recognition and status equality. Misrecognition, however, is understood as subordination conveyed by institutionalised patterns of cultural value that impede parity of participation. The principle of parity of participation aims at offering an analytic vocabulary leading, in turn, to removing obstacles in social arrangements. However, how individual social situations should be judged in terms of justice is a question for continuous public debates and deliberations.

Understanding equity from a perspective of redistribution, recognition and participation means moving the focus beyond individual capabilities to institutionalised conditions. Redistribution in the context of education is about access to qualified teachers and material equipment such as schoolbooks and computers with internet connection. As Lingard and Keddie (2013) emphasised, distributive principles are also included in the dimension of intellectual quality of education. An emphasis on intellectual demandingness and rigour in education, as critical reflections and deep understanding in the study of a subject, creates environments that support distributive justice in the sense that less privileged students can achieve intellectual qualities and grades to eventually gain greater access to the material benefits in society. The dimension of recognition is embedded in the creation of a learning environment which supports relevant and meaningful learning for all students, including those who experience themselves or are perceived by others as marginalised. Social values in relation to social class, ethnicity, gender, disability, sexuality and their intersectionality are subjects of critical reflections in terms of both teaching content and frames of reference that students bring to class. The recognitive perspective seeks to destabilise inequitable status hierarchies of cultural value. The dimension of participation was transferred by Lingard and Keddie (2013) to the area of education by emphasising the need to create democratic and inclusive spaces in learning environments where respectful relations are encouraged. These spaces reflect representative justice insofar as all students have the right to have a voice and get the opportunity to develop their sense of autonomy.

In Fraser's three-dimensional model of parity of participation through equitable distribution of resources and social status in terms of recognition, equity in education can be analysed from an institutional level (the policy, regulation and organisation of schooling), the programmatic level (the structure and content of curriculum and guidelines) or at a classroom level (the actual classroom activities). See Table 3.2. 
Table 3.2 A framework for analysis of equity in education, based on Fraser's (2004) principle of parity of participation

Analysis of equality: the principle of parity of participation

\begin{tabular}{|c|c|c|c|}
\hline & $\begin{array}{l}\text { Distribution of } \\
\text { resources (the } \\
\text { what of justice) }\end{array}$ & $\begin{array}{l}\text { Recognition of } \\
\text { cultural and } \\
\text { social status (the } \\
\text { who of justice) }\end{array}$ & $\begin{array}{l}\text { Participation as } \\
\text { peers (the how in } \\
\text { justice as action) }\end{array}$ \\
\hline Societal level & 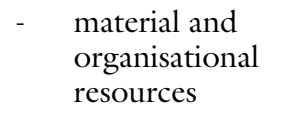 & $\begin{array}{l}\text { the status in } \\
\text { society }\end{array}$ & $\begin{array}{l}\text { - a sense of } \\
\text { autonomy within } \\
\text { community }\end{array}$ \\
\hline Programmatic & $\begin{array}{l}\text { - access to norms } \\
\text { and knowledge } \\
\text { representing } \\
\text { cultural capital }\end{array}$ & $\begin{array}{l}\text { the status } \\
\text { of different } \\
\text { cultures in } \\
\text { curricula and } \\
\text { regulations }\end{array}$ & $\begin{array}{l}\text { recognition } \\
\text { of everyone's } \\
\text { entitlement to } \\
\text { have a voice }\end{array}$ \\
\hline $\begin{array}{l}\text { Classroom } \\
\text { level }\end{array}$ & 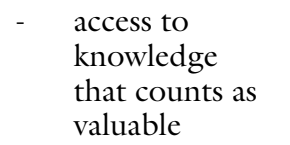 & $\begin{array}{l}\text { - } \quad \text { the individual } \\
\text { status }\end{array}$ & $\begin{array}{l}\text { commitment of } \\
\text { showing mutual } \\
\text { respect }\end{array}$ \\
\hline
\end{tabular}

\section{Evaluation of Equity - The Need for 'Thick' Investigation}

Knowledge goals have increasingly been replaced by formulated standards and knowledge requirements in curricula because the concept of goal is assumed to be less powerful regarding the control of school. The logic of a performance-based curriculum is easy to understand: the curriculum includes standards for what knowledge the students should reach, and then you measure whether the requirements have been achieved. It speaks to common sense that it should be possible to guarantee certain knowledge to the students and to hold the school accountable for how well the requirements have been achieved. Evaluations in accordance with this approach look at the students' performances at a specific time, the same for all students, which makes it possible to compare students' performances synchronically across schools and diachronically over time. National and international knowledge tests are based on this performance-based logic. The input of the evaluation is in the school activities throughout a country, while the output is the students' knowledge achievements at a certain point of time. Even if criticism of the simplified logic of the model has been known for a long time (Entwisle \& Conviser, 1969), it is still commonly used, with the PISA survey as one of the most prominent examples.

Classroom studies from high- and low-performing schools, which form the basis of the chapters in this book, tell an entirely different story. The 'input' in terms of the schools' social and economic resources, quality of education and proficiency in using the language vary a lot between schools and classrooms. The similarity in terms of uniformity is represented only when it comes to 
the measurement of knowledge in national tests; in that phase all are evaluated according to the same measuring instrument. While the parameters differ largely at the input phase, they are identical on the evaluation at the output phase of the model. These knowledge tests give an indicator on something, but it is unclear on what. Is it the need for clearer standards, for more resources, for better-qualified teachers, for less migration? The politicians who are supposed to respond with policy actions to the test results can cherry-pick among different desirable causes and actions in line with their party ideologies. However, if we really want to learn more about the input phase that is, conditions influencing the daily work of the school before the tests we need to complement a simple input-output model with other means for evaluation. Based on the assumption that fair inputs lead to fair results, it seems reasonable that such methods include the dimension of equity.

The concept of equity in education is currently not sufficiently addressed and developed in the European research field of curriculum theory. During the 1960s and 1970s, Bernstein (2000) developed a rigorous framework of the pedagogic device, which is useful for detailed studies on discourses of knowledge and access to different forms of knowledge for different social groups from a structural perspective (e.g. Wahlström et al., 2020; Loughland \& Sriprakash, 2016). However, the concept of equity is not explicitly emphasised. In contrast, curriculum research in North America has shown a longstanding interest for questions of equity, specifically with a focus on lived curriculum from a personal perspective within a phenomenological research tradition. According to this perspective, it is in the lived experience of curricula, rather than the planned, that a curriculum is felt, enacted and reconstructed (e.g. Pinar, 2011; Craig, 2020). Australian researchers have discussed equity in relation to the structure of curriculum content (Luke et al., 2013). They argue that education systems should hold on to their meritocratic ideals - that students should have the opportunity to reach their learning potential, regardless of socioeconomic or other contextual or individual differences. The relation between a school system and its students and their families and communities 'should be based on the democratic right to achieve at least a threshold level of knowledge, skills and dispositions that will enable effective and useful citizenship' (Luke et al., 2013, p. 14). To enhance equity, the technical form of curricula must support teacher professionalism at all levels, which means that curricula should provide a map rather than a standardised and prescriptive template, since the latter risks constraining a teacher's informed professionalism.

With reference to Luke et al. $(2013$, p. 35), in order to promote justice, syllabus documents should preferably include the following components: (i) core knowledge, skills and competences as aspirational targets; (ii) a professional vocabulary for standards; (iii) a delimited and well-defined testing-and-examination system; (iv) development of teacher professional competence for the enhancement of local school- and classroom-based curriculum-planning-and-assessment practice; and (v) a strong equity focus on the learning needs and challenges for students from socioeconomically marginalised communities. From a curriculum theory perspective, a basic 
assumption concerning equity is that a curriculum needs to support, but not take over, the role of the teacher as the ultimate representative of equitable education at the school and classroom level. This means that equity cannot be understood as identical resources for all students but rather as an adaptation to the needs of individual students to achieve basically the same knowledge. Crucial formulations of guidelines for equitable curriculum in this respect are as follows:

- 'aspirational targets' instead of standardisation and knowledge requirements

- an emphasis on common professional vocabularies and standards for teaching and assessment practices rather than standardised tests

- a clearly expressed responsibility for teachers to conduct classroom activities characterised by mutual respect and to take the needs of the students as their starting point for teaching

\section{Equity on Different Levels in a National School System}

Within curriculum theory, the basic levels of analyses of school policies and their implications are the societal level, the programmatic level and the local classroom level (Deng \& Luke, 2008; Wahlström, 2020). The societal level denotes the general opinion in society concerning the purpose and benefits of school, education and knowledge, which ultimately sets the limits of what kind of educational policy reforms become possible to implement in a society. The societal level is permeated by social, historical and cultural traditions that define the direction towards the future; that is why it is complicated to transfer an educational policy from one country to another. National politicians and policy-makers operate at the societal level. When national policies are decided at the societal level, they are implemented on the programmatic level in terms of, for example, the Education Act, curricula, guidelines and distribution of resources. At the local school and classroom levels, finally, the policy is recontextualised into actual teaching and learning activities. The levels of analysis in curriculum theory correspond well with Unterhalter's (2009) framework for analyses of equity from above, from the middle and from below. Depending on the focus of evaluation, the aspect of equity can be analysed at different levels in a national school system.

The principle of parity of participation developed by Fraser $(2004,2008)$ and the capability approach developed by Sen $(1999,2005)$ and Nussbaum $(2007,2011)$ have different analytic perspectives on justice. While Fraser's conceptualisation of equity in terms of redistribution, recognition and participation explores the institutional dimensions and their implications at different levels of a school system, the capability approach examines the consequences of educational policy for individuals at each level from a bottom-up perspective. Due to their different points of departure in the institutionalised rules and patterns and in the individuals' experiences of the system, respectively, the two approaches of evaluation of equity complement each other. In Table 3.3, the different levels of equity (Unterhalter, 2009) and different 
Table 3.3 A framework of curriculum theory and equity based on an institutional perspective in the principle of parity of participation (Fraser, 2004) and on an individual perspective in the capability approach (Sen, 2005; Nussbaum, 2011)

\begin{tabular}{|c|c|c|c|c|c|c|}
\hline \multirow[t]{2}{*}{$\begin{array}{l}\text { Curriculum } \\
\text { theory and } \\
\text { equity: }\end{array}$} & \multicolumn{2}{|c|}{$\begin{array}{l}\text { Instrumental values (what } \\
\text { the student gets the opportunity } \\
\text { to learn from education) }\end{array}$} & \multicolumn{2}{|c|}{$\begin{array}{l}\text { Intrinsic values (who the person } \\
\text { gets the opportunity to become) }\end{array}$} & \multicolumn{2}{|c|}{$\begin{array}{l}\text { Positional values (how and where the } \\
\text { student has the opportunity to participate) }\end{array}$} \\
\hline & $\begin{array}{l}\text { The principle } \\
\text { of parity of } \\
\text { participation }\end{array}$ & $\begin{array}{l}\text { The capability } \\
\text { approach }\end{array}$ & $\begin{array}{l}\text { The principle of parity } \\
\text { of participation }\end{array}$ & $\begin{array}{l}\text { The capability } \\
\text { approach }\end{array}$ & $\begin{array}{l}\text { The principle of parity } \\
\text { of participation }\end{array}$ & The capability approach \\
\hline $\begin{array}{l}\text { Societal level } \\
\text { 'From above' }\end{array}$ & $\begin{array}{l}\text { Equitable } \\
\text { distribution } \\
\text { of material, } \\
\text { cultural and } \\
\text { knowledge } \\
\text { resources }\end{array}$ & $\begin{array}{l}\text { Real access to } \\
\text { high-quality } \\
\text { education for } \\
\text { each student }\end{array}$ & $\begin{array}{l}\text { A policy for a broad } \\
\text { view of knowledge, } \\
\text { including } \\
\text { democratic and } \\
\text { aesthetic aspects }\end{array}$ & $\begin{array}{l}\text { Access to a } \\
\text { broad view of } \\
\text { knowledge for } \\
\text { each student, } \\
\text { including } \\
\text { democratic and } \\
\text { aesthetic aspects }\end{array}$ & $\begin{array}{l}\text { An education system } \\
\text { based on meritocracy } \\
\text { and social equality }\end{array}$ & $\begin{array}{l}\text { Actual access to formal } \\
\text { competence based } \\
\text { on meritocracy and } \\
\text { social equality }\end{array}$ \\
\hline $\begin{array}{l}\text { Programmatic } \\
\text { level } \\
\text { 'From the } \\
\text { middle' }\end{array}$ & $\begin{array}{l}\text { A rigorous view } \\
\text { of academic } \\
\text { knowledge } \\
\text { 'for all' in } \\
\text { curricula }\end{array}$ & $\begin{array}{l}\text { Actual access } \\
\text { to academic } \\
\text { knowledge }\end{array}$ & $\begin{array}{l}\text { Curriculum as a } \\
\text { framework for } \\
\text { professional planning } \\
\text { and assessment } \\
\text { of academic and } \\
\text { aesthetic subjects }\end{array}$ & $\begin{array}{l}\text { Adaptation of } \\
\text { teaching in } \\
\text { academic } \\
\text { and aesthetic } \\
\text { subjects to each } \\
\text { student }\end{array}$ & $\begin{array}{l}\text { Recognition of equal } \\
\text { social status for } \\
\text { different groups: } \\
\text { in relation to curricula, } \\
\text { guidelines and } \\
\text { regulations }\end{array}$ & $\begin{array}{l}\text { Positional and cultural } \\
\text { recognition for } \\
\text { each individual in } \\
\text { relation to curricula, } \\
\text { guidelines and } \\
\text { regulations }\end{array}$ \\
\hline
\end{tabular}


values of education (Unterhalter \& Brighouse, 2007) are combined with an analytic framework developed within curriculum theory (Deng \& Luke, 2008). Both frameworks of equity are represented at each level, because it is not the level of analysis in itself but rather whether the analysis concerns institutional or individual aspects that determines which approach is most suitable for the analysis. Each approach delivers different kinds of answers at each level.

\section{Equity - An Urgent Concept in Educational Policy and Curriculum Theory Research}

To promote belief in each student and intrinsic learning for all, evaluation of equity at different levels of the school system is of profound significance. The aspect of equity in education can be examined and discussed from both institutional and individual perspectives. Three different values of education are emphasised. The instrumental value accentuates the worth of knowledge and of being knowledgeable in a subject for future possibilities. The intrinsic value considers education as an end in itself, emphasising personal experiences and engagement through the teaching and learning activities. The positional value of education, finally, includes both the cultural recognition of being equal as peers and students at school and equal opportunity of future education or employment for the students.

Drawing on the model of justice developed by Fraser $(2004,2008)$, the economic, cultural and political dimensions of justice together constitute a three-dimensional framework of a principle of parity of participation. In an educational context, redistribution is about fair distribution of material resources for schooling and about meeting the needs of disadvantaged students through appropriate and adapted resources. Redistribution of resources also comprises high-quality teaching across different schools in a national school system. The concept of recognition draws attention to fair access to schools regardless of socioeconomic or cultural status and addresses the problem of school segregation. Representation, which Fraser (2004) also termed participation, entails a fair and equal right for all students to participate on equal terms in schoolwork, classroom discussions and fora for student discussions on school issues. The principle of parity of participation addresses the educational arrangements, aiming at elucidating possibilities and obstacles in school as an institution.

In an evaluation on educational equity for each individual, the capability approach of freedom and justice developed by Sen $(1999,2005)$ and Nussbaum $(2007,2011)$ is more suited. The focus in the capability approach is what actual functionings students have the opportunity to achieve regarding the instrumental, intrinsic and positional values of education. Does each student have a real opportunity to learn the knowledge stipulated in the curriculum? Does each student get the opportunity to actually develop his or her personal potential through the meeting with different subject matters and different forms of teaching? Does each student get an equal right to cultural and 
social recognition and access to further education? However, it is not the individual functionings - that is, what different knowledge and skills the individual has achieved - that are central in the capability approach. Rather, the central interest is captured in the question of whether the combination of functionings in education and social life leads to a set of capabilities which offers each individual the opportunity to live the kind of life he or she has reason to value.

There is an advantage in utilising both institutional and individual perspectives, either separately or in combination, to explore factors of equity in school systems beyond knowledge tests easy to measure. Due to the complementing perspectives of the two frameworks, a starting point in the individually based capability approach will probably lead over to issues of redistribution and recognition when it comes to measures. The opposite is also true. In order to take measures implemented at the organisational level seriously, they should also be evaluated at the individual level to give an idea of whether the measures have had the intended effect. From a curriculum theory perspective, the starting point for equity in education is the belief in the students and their ability to contribute with their experiences for the shaping of good learning environments. To really follow up the educational situation from an individual viewpoint, regarding what functionings a student has achieved and plan to achieve and to relate the outcome of these individual functionings with the student's desired capabilities, provide deep insights into what factors are important for developing equitable knowledge conditions from a student perspective. Based on an understanding of learning as an interactive - rather than as an intrinsic - development, improving qualities in the teaching and learning environment have great potentials to make a difference for the individual student.

Within a curriculum theory tradition, the aspect of equity can be explored and discussed from an institutional/societal level, from a programmatic level of regulations and guidelines, from a classroom level or from a combination of these levels. At each level, equity can be interpreted from the perspective of the individual or from the perspective of school as an institution. In international and national education policy introduced in the beginning of the chapter, the interest of equity is directed towards institutionalised arrangements in the school system. It is clear that the OECD (2018a) educational policy shows an interest in the aspect of redistribution of economic resources across the school system. This aspect is also possible to evaluate and compare within and across national school systems. There is also an international policy interest in education as an arena for self-actualisation, balancing the economic value of education for a nation with a personal dimension of individual benefits. Both aspects can be linked to the instrumental and positional values of education. In the case of Sweden, focusing on equivalence in education, the redistribution aspect of resources and the instrumental values of education are at the centre of the debate. However, what is consistently subordinated in the education policy debate is the intrinsic value of education. Neither is the social and cultural equality of students within and between schools sufficiently addressed. 


\section{Ninni Wablström}

\section{References}

Bernstein, B. (2000). Pedagogy, symbolic control and identity: Theory, research, critique. Rowman \& Littlefield.

Craig, C. (2020). Curriculum making, reciprocal learning, and the best-loved self. Palgrave Macmillan.

Deng, Z., \& Luke. A. (2008). Subject matter: Defining and theorizing school subjects. In F. M. Connelly, M. F. He, \& J. A. Phillion (Eds.), The SAGE handbook of curriculum and instruction (pp. 66-87). Sage Publications.

Entwisle, D. R., \& Conviser, R. (1969). Input-output analysis in education. The High School Journal, 52(4), 192-198.

Fraser, N. (2003). Från omfördelning till erkännande? Rättvisedilemman i en "postsocialistisk" tid [From redistribution to recognition? The dilemma of justice in a "post-socialist" time] (pp. 175-212). Daidalos.

Fraser, N. (2004). Institutionalizing democratic justice: Redistribution, recognition, and participation. In S. Benhabib, \& N. Fraser (Eds.), Pragmatism, critique, judgment: Essays for Richard J. Bernstein (pp. 125-147). MIT Press.

Fraser, N. (2008). Scales of justice: Reimagining political space in a globalizing world. Polity.

(Government Proposal. 2009/10:165). Den nya skollagen - för kunskap, valfribet och trygghet [The new Education Act - for knowledge, freedom of choice and security].

Jurado De Los Santos, P., Moreno-Guerrero, A-J., Marín-Marín, J-A., \& Soler Costa, R. (2020). The term equity in education: A literature review with scientific mapping in Web of Science. International Journal of Environmental Research and Public Health, 17(10), 3526. doi:10.3390/ijerph17103526

Lingard, B., \& Keddie, A. (2013). Redistribution, recognition and representation: Working against pedagogies of indifference. Pedagogy, Culture \& Society, 21(3), 427-447. doi:10.1080/14681366.2013.809373

Loughland, T., \& Sriprakash, A. (2016). Bernstein revisited: The recontextualisation of equity in contemporary Australian school education. British Journal of Sociology of Education, 37(2), 230-247. doi:10.1080/01425692.2014.916604

Luke, A., Woods, A., \& Weir, K. (2013). Curriculum, syllabus design and equity: A primer model. Routledge.

Nussbaum, M. C. (2007). Frontiers of justice: Disability, nationality, species membership. Harvard University Press.

Nussbaum, M. C. (2011). Creating capabilities: The human development approach. Harvard University Press.

Organisation for Economic Co-operation and Development. (2018a). The future of education and skills: Education 2030.

Organisation for Economic Co-operation and Development. (2018b). Equity in education: Breaking down barriers to social mobility.

Organisation for Economic Co-operation and Development. (2018c). PISA 2018 results (Volume II): Where all students can succeed.

Pinar, W. F. (2011). The character of curriculum studies: Bildung, currere, and the recurring question of the subject. Palgrave Macmillan.

Sen, A. (1999). Development as freedom. Oxford University Press.

Sen, A. (2005). Human rights and capabilities. Journal of Human Development, 6(2), 151-166. doi:10.1080/14649880500120491 
NAE. (2020). Likvärdiga betyg och meritvärden. Ett kunskapsunderlag om modeller för att främja betygens och meritvärdenas likvärdighet [Equivalent grades and merit values: A knowledge base about models to promote equivalence of grades and merit values].

Unterhalter, E. (2009). What is equity in education? Reflections from the capability approach. Studies in Philosophy and Education, 28(5), 415-424. doi:10.1007/ s11217-009-9125-7

Unterhalter, E., \& Brighouse, H. (2007). Distribution of what for social justice in education? The case of education for all by 2015. In M. Walker, \& E. Unterhalter (Eds.), Amartya Sen's capability approach and social justice in education (pp. 6786). Palgrave Macmillan.

Wahlström, N. (2020). Tracing implications of transnational policy in curriculum events. The Curriculum Journal, 31(4), 587-604. doi:10.1002/curj.62

Wahlström, N., Adolfsson, C-H., \& Vogt, B. (2020). Making social studies in standards-based curricula. Journal of Social Science Education, 19, 66-81. doi:10.4119/ jsse-2361

Walker, M., \& Unterhalter, E. (2007). The capability approach: Its potential for work in education. In M. Walker, \& E. Unterhalter (Eds.), Amartya Sen's capability approach and social justice in education (pp. 1-18). Palgrave Macmillan. 


\title{
4 Exploring the Importance of Teacher Feedback
}

\section{Connecting Truthfulness and Student Learning}

\author{
Jeff Frank
}

Feedback is central to teaching and learning, and yet feedback's central role doesn't receive a great deal of attention in the philosophical literature in education. ${ }^{1}$ This is unfortunate because a teacher will not develop into the teacher they hope to become unless they devote significant attention to the role that feedback plays in their teaching practice. In the first part of this paper, I explore the centrality of feedback in teaching and learning, largely through a conceptual analysis of how feedback operates in classrooms. In the second part, I explore the connections between a teacher reflecting on feedback and their teaching practice, largely by drawing on Bernard Williams's thinking on truthfulness. Finally, in the third part of the paper, I suggest that a teacher who is thoughtful about their approach to feedback is in a better position to promote deeper learning than a teacher who is not. I conclude with recommendations for teacher education and teacher professional development. ${ }^{2}$

As other chapters in this volume make clear, it is imperative that we understand what accounts for gaps in performance between classrooms that are deemed high-performing and those that are deemed low-performing. While countless explanations of this gap have been offered in the literature ${ }^{3}-$ everything from teachers holding lower expectations for students, to assuming a deficit perspective when thinking about the students and their home culture(s), to providing instruction that fails to engage and appropriately challenge students - what connects all of these explanations is the significance of the teacher's intervention to close existing gaps. In this chapter, I suggest that the use of truthful feedback is a key element in appropriately challenging and educating every student, and I also suggest that this is something that a teacher has control over, even in an era marked by standardisation of curriculum and assessment.

Thinking about feedback is important, because it offers us a lens to view the ends of education in a new light (Harðarson, 2012, 2018). As schools, principals and teachers come under exceeding pressure to increase student performance, we need a better understanding of the purposes of education so that we don't narrow the ends of education and demoralise teachers (Santoro, 2018). When we consider the uses of feedback in the classroom, we are given an opportunity to theorise the purposes of education in ways that invite

DOI: $10.4324 / 9781003218067-4$ 
us to consider how feedback can give teachers increased agency to engage in the type of teaching that they value and that promotes deeper learning for their students. And when we do this, teachers can more wholeheartedly stand behind their teaching practice, which will have the saltatory effect of re-moralising teachers while increasing the learning and engagement of students. This offers one way of closing the gaps between high- and low-performing schools without sacrificing our values and ideals in the process.

\section{The Role of Teacher Feedback in the Life of Classrooms}

Philip W. Jackson's (1990) Life in Classrooms remains remarkable for its ability to draw a reader's attention to those everyday aspects of classroom life that evade notice and critical attention, precisely because they are so commonplace. One aspect of classroom life that often escapes attention is the ubiquity of feedback a teacher offers. Especially in the early years of a child's life in school, teacher feedback is omnipresent. Sit there, sit like that, don't talk, colour like this, don't say that, listen, eyes up here, the blocks go like that, that book isn't on your level, choose another, and so on. Though much of a teacher's feedback is spoken, much isn't. A teacher points, a teacher raises an eyebrow, a teacher throws their hands up, a teacher frowns, a teacher beams with encouragement, and a teacher glares. Finally, students receive feedback that the teacher may not intend or be fully in control of. A teacher's disapproval based on a student's social position or identity category feeds back into a student's sense of welcome, belonging or acceptance in the classroom, and this impacts their sense of agency and engagement.

Already we can begin to see the centrality of feedback in the life of a classroom, along with important distinctions. Some feedback is about learning, some is about behaviour. Some feedback is explicit and spoken, while some is implied and unspoken. Feedback can be biased, and teachers can unintentionally communicate approval or disapproval in explicit and implicit ways. Though biased feedback may not be intended by the teacher, it has power nonetheless. A teacher's dismissive glance at a group of young girls during math time may communicate that boys are more capable when it comes to math. Praising one child's jacket or new outfit may alienate the child in a second-hand coat.

It is important to consider another level of analysis. Some feedback is formal. Students receive comments on their work along with grades. Children receive comments on their report cards, also often accompanied by grades. As well, teachers facilitate assessments that they didn't create - everything from daily diagnostic computer work (Frank, 2020) to standardised tests but they communicate the results of those assessments to students and their caregivers and use these assessments when planning instruction.

Finally, it is common to talk about assessment of learning, versus assessment for learning, versus assessment as learning (Earl, 2003). These distinctions often track onto distinctions between formative and summative assessment, and they also track onto discussions of authentic assessments, high-stakes 
assessments and standardised assessments. The key point in all these distinctions is to help get clear on the ways that assessment is primarily intended to measure or account for learning, and when assessment is meant to promote, deepen and extend learning.

This discussion and these distinctions are not meant to suggest that a philosopher of education, using conceptual analysis, can resolve problems of practice from their armchair. Rather, the foregoing analysis is meant to suggest that these different senses of feedback are deeply interconnected and that it is useful for a teacher to work to get clear - for themselves - how feedback works in their classroom.

To take up one key distinction, it is often very useful for a teacher to consider which assessments and standards originate outside of their classroom, and then think about how important those standards and assessments are to their sense of what it means to be a teacher. A related point: it is also often important for a teacher to understand how circumscribed their freedom is when it comes to what must be taught and what types of assessment must be administered. A set of standards connected to a standardised test is not a curriculum, let alone a script, but they are often taken that way (Wiggins \& McTighe, 2005). Put another way, two teachers can use the same set of standards and have their students achieve high scores on a mandated standardised test but get to that goal in very different ways. One teacher can spend a great deal of time encouraging memorisation and doing test preparation, while another teacher can promote deeper learning that leads to passionate engagement and an ongoing interest in the material learned (Martinez \& McGrath, 2014; Mehta \& Fine, 2019).

A key difference in these classrooms is the way a teacher uses feedback to express what is valued. In the test preparation classroom, a teacher's feedback will often be closely tied to outcomes. In the deeper learning classroom, teacher feedback will be tied to the process of engagement and will encourage thinking (Ritchart, 2015). What is equally important is that a teacher's behavioural feedback will also often be tied to their instructional goals. In a classroom where memorisation is prized, one set of behaviours will be cultivated. In a classroom where thinking is the goal, other behaviours will be nurtured.

This discussion may feel a bit too abstract and disconnected to the complexities of practice (Lampert, 2001). The point, though, is to suggest that teachers become as mindful as possible about the scope of their freedom so that they can think about their hopes for the work of teaching. Unless a teacher is aware of the type of practice they hope to enact in their classroom and through their work, it is far more likely that the feedback the teacher uses will be the product of history and habit, not something that the teacher very intentionally uses to create the type of classroom environment that they are genuinely proud of and that stands up to their own sense of what a classroom should be and do.

To summarise, feedback is ubiquitous and multifaceted in every classroom. A teacher is always already giving feedback, even if they aren't fully 
aware of this fact. Ignoring a student or not doing something is still expressive and plays a role in communicating who, how and what a teacher values. In classrooms where there are strong external pressures in the form of mandated curriculums, mandatory assessments and zero-tolerance discipline policies, the type of feedback a teacher provides is heavily constrained. In a culture marked by structural injustices, teachers are often unaware of their own biases and the ways that these biases impact the types of feedback they give to students and what this feedback communicates (Harber et al., 2019).

It is for these reasons that teachers need to devote significant attention to the place of feedback in their classroom, working to discover the types of constraints they face and freedom they have, while also undertaking to unlearn ways of thinking and being that are biased and harmful to their students (Cochran-Smith, 2000). This work is difficult, because it touches on who the teacher is as a person (Hansen, 1993, 2018), and the work is often moral, epistemic, and political at the same time (Frank, 2013). As such, developing an approach to feedback is something each teacher must do for themselves. Though recommendations are useful, what is ultimately needed is for each teacher to develop an orientation to giving feedback that is aligned with their own sense of teaching and its values while also remaining responsive to everything that challenges those values. In the next section, I make the case that Bernard Williams's thinking on truthfulness provides resources that teachers might draw on as they develop this orientation to their work.

\section{Truthfulness and Teacher Development}

In this section, I don't offer a detailed discussion of Bernard Williams's (2002) increasingly relevant book Truth and Truthfulness, let alone attempt to offer an overview of his work as a philosopher (Fricker, 2020). Instead, my goal is more modest. I am interested in discussing the importance of truthfulness when it comes to providing feedback, where truthfulness is understood in terms of accuracy and sincerity. Both Shirley Pendlebury (2008) and David Cooper (2008) discuss the importance of accuracy and sincerity for teaching, but neither connect their discussions to a teacher's orientation to offering feedback.

I turn to Williams in this paper because I believe that a spirit of truthfulness is at risk, especially in the United States. Many Americans continue to believe - despite overwhelming evidence - that Donald Trump won the 2020 Presidential election in a 'landslide.' What is worse, they were willing to attack America's Capitol based on this false belief. As well, many Americans engage in conspiracy thinking, even about things as tragic as school shootings that leave families and communities utterly devastated. Bernard Williams is well aware that asserting something as truth isn't simple, especially in a world learning the lessons of standpoint theory and responsive to neo-pragmatist and postmodern approaches to truth. Subjectivity and bias will certainly colour our best attempts at objectivity and truth, but this doesn't mean that any opinion or assertion is as good as any other or that it is impossible to assert 
matters of fact like who won a contested election. We don't need a simplistic approach to truth in a post-truth era, and this is not what Williams offers. Instead, Williams suggests that the best hope for truth is to cultivate a spirit of truthfulness, where truthfulness is an aspiration guided by the virtues of sincerity and accuracy.

To understand truthfulness, we need to understand these two virtues. Williams describes sincerity as saying what one means, and accuracy as accepting reality as a check on one's beliefs, especially in cases where reality challenges beliefs that one sincerely holds. In our time, especially in the United States, I worry that we are alienated from the virtues of sincerity and accuracy. Schools, for example, are often so focused on 'getting results' and pursuing success very narrowly understood (Frank \& McDonough, 2020), that questions of sincerity don't even arise. When external measures of success are pursued, or when we don't even wonder about the difference between success as defined by others and success as we take it to be (Siegel \& Bryson, 2018), it is extraordinarily difficult to act with sincerity. And while most schools still aspire to the virtue of accuracy, they are embedded in cultures that are flooded with disinformation (Rauch, 2020). More, there are individuals who are so invested in their preferred vision of reality that they'd rather cling to that false vision rather than acknowledge or accept any truth that challenges their beliefs. As such, even though schools may aspire to accuracy, teachers may find it challenging to teach in a spirit of truthfulness when embedded in a community that is often wilfully living in misbelief (Buchanan, 2018).

The virtues of sincerity and accuracy are as important as they are at risk in our time, and there are many ways to use Williams's insight to think about education. ${ }^{4}$ In this paper, I narrow my focus to truthfulness and feedback, and I begin by exploring the opposite of truthful feedback. We might think of feedback that lacks truthfulness as feedback that is insincere and inaccurate. Feedback is insincere when it doesn't connect to meaningful learning goals. For example, if I am teaching to a test and not teaching something that I genuinely think is valuable for students to learn, much of my feedback is likely to be inauthentic. Feedback is inaccurate when it is misleading. If I lower standards for some children - either intentionally or through unconscious bias - and assert that their work is strong when it is not, I provide inaccurate feedback. In my experience, I see teachers struggling with authenticity and accuracy, and one hope for this paper is that it offers teachers ways of reclaiming both virtues so that they might provide more truthful feedback.

To take a step in this direction, I want to offer a concrete example of moving from standards to feedback. For the purposes of this paper, I will draw on my own experience as a teacher educator, and I will use the framework of Understanding by Design, a common approach to instructional design in the United States. The selection of Understanding by Design is not as important as the way it helps us think through the process of moving from instructional goals to assessment, and finally to instruction (Wiggins \& McTighe, 2005). ${ }^{5}$ The first stage of Understanding by Design asks a teacher 
to specify their learning goals. Though many teachers have external standards they must be responsive to, they generally have freedom in how those standards get translated into goals. In the United States, the Common Core Standards have generated a great deal of controversy. I sidestep that controversy, and - instead - use a Common Core Standard to illuminate what I mean by teacher instructional freedom. Here is a grade 9-10 standard from English Language Arts, specifically reading literature:

\section{CCSS.ELA-LITERACY.RL.9-10.9}

Analyze how an author draws on and transforms source material in a specific work (e.g. how Shakespeare treats a theme or topic from Ovid or the Bible or how a later author draws on a play by Shakespeare). ${ }^{6}$

As you can see, the standard is under-determined. While schools or states may specify which texts must be taught or which source material must be used, in many cases a teacher will have a great deal of freedom when it comes to how to interpret the standard. Here accuracy and sincerity come into play. A teacher must accurately interpret what the standard is asking, but they also must sincerely consider how the standard speaks to them as a teacher of their particular students, in their particular context at this particular time in history. So long as the teacher is accurately interpreting the standard, they have freedom to teach from their own passions and interests and what they take their students' passions and interests to be.

This may not seem to immediately connect to feedback, but it does. The teacher who takes the time to accurately and sincerely reflect on the purposes of the standard is in a better position to respond to the student question, often unasked: Why does this matter? Why do I need to learn this? A teacher who takes the time to accurately and sincerely interpret the standard is positioned to wholeheartedly get behind their teaching and send the message - explicitly and implicitly - that they are teaching something that matters, both because it meets the external learning standards and because it speaks to something the teacher cares about or believes students do - or should - care about.

In the case of the Common Core Standard discussed earlier, you can imagine a teacher picking several poems they care about that draw from a shared source material and then you can also imagine them using those poems to get students excited about poetry and the message the source material is trying to convey. Now, there may be schools and states that take away a teacher's freedom in relation to standards, and this may lead a teacher to seek another place to teach or to exit the profession completely (Santoro, 2011). But in many cases, the freedom to interpret standards exists, and when it does, teachers can think through what it means to accurately and sincerely interpret their standards in ways that make them meaningful for students.

Stage two of Understanding by Design is moving from standards to planning assessment. Here, again, the teacher is mindful of the external tests their students are mandated to take, just as they will think about the types 
of assessments that are most responsive to their own sense for what is most interesting and important about the standard. Where one teacher may simply have students practice examples of the type of external assessments they will take, another teacher will use their most truthful interpretation of the standard to create assessments aligned with that interpretation. For example, a teacher may give students source material from the New Testament, and then have them read speeches by Martin Luther King, Jr. or the non-fiction of James Baldwin or the fiction of Toni Morrison, asking the student to find examples of how these works respond to or modify the source material in ways that the student finds most meaningful or interesting. Or the teacher can have students work in the other direction. They can provide contemporary literature that draws on source material and have the students find and engage with the source material in order to understand the contemporary literature and the source material. A key distinction I am trying to make clear is that the assessments can be mechanical and relatively unthinking, or assessments can call on students to engage and think more deeply. A teacher who gives a list of Bible verses or Shakespeare plays and has students draw a line or fill in a bubble to connect the literature that uses the source material is giving an assessment that is responsive to the standard but that doesn't ask the students to think. By contrast, a teacher who has students find material on their own that is responsive to source material, or who engages deeply with the source material so that students can see that source material at work in contemporary material, is using assessment to prompt and deepen thinking.

Here we can also see how feedback becomes more or less truthful. A teacher who has students match source material to a specific work is generally - only going to tell a student: that is right, that is wrong. There is less room to have a conversation. By contrast, a teacher who uses assessment to promote thinking invites students into conversation. These teachers are interested in the types of source material that connects with students, and they use feedback to connect students from the source material to specific works that the students may find interesting. Feedback in this classroom is about connections and draws on the virtues of truthfulness. Is the student accurately connecting source material to specific works, and are they sincerely interested in the connections they are making? A whole world of feedback opens in these types of classrooms, and this feedback serves to deepen thinking and engagement.

This brings us to the third stage of Understanding by Design, instruction. Once a teacher interprets the standard and uses this interpretation to develop assessments that are accurately and sincerely aligned with the standard, they develop learning opportunities that position students to be successful on the assessments. Again, if a teacher simply gives students an assessment that looks like what the student will see on a standardised test, feedback often comes in the form of judgment: this is right, this is wrong. Learning opportunities are designed so that more students are right than wrong. By contrast, when teachers design assessments that are meant to promote thinking, the teacher is less in the role of a judge and more in the 
role of conversation partner (Lear, 2009). The feedback the teacher provides works on the levels of accuracy and sincerity. The teacher wants the students to find things that allow them to think deeply and accurately about complex ideas that don't admit of simple right and wrong answers. In addition, the teacher wants students to care about what they are reading, and the teacher wants students to develop their own tastes and interests. Instead of having every single student meet the standard by showing how Martin Luther King, Jr. complicates and extends ideas from the New Testament, these teachers want students to find source material that speaks to them and contemporary works that also engage their interest. To get to this type of classroom, the teacher appreciates the ways feedback can draw students closer to the material they are learning while empowering students to embrace their developing interests and passions.

There is always room to think more intentionally about the types of learning we hope to facilitate and then think about how we can get there through our feedback. In order to do this, we might engage in a process like Understanding by Design, or any process that allows us to think deeply about our instructional goals. Importantly, just as standards can become overly determinative, even something like assessment for learning can become constraining if a teacher isn't mindful of the differences between deeper learning and something like learnification, where the sole goal of teaching is to get results (Biesta, 2010, 2012).

When I think about what makes my life as a teacher fulfilling, I often find myself reflecting on the role that feedback plays in my practice. Feedback is at the centre of my teaching because I see it as key to setting a conversational tone that allows students to make connections that open new interests and opportunities for learning. For example, I have my students write response papers so that I can write feedback that honours their current interests while drawing connections to my subject that I hope they will become interested in. I try to do the same thing in the classroom. I ask questions or do activities that - when effective - provoke student questions that suggest new lines of interest and inquiry that are true to the subject I teach and resonant with a student's genuine interests. In this way, I see feedback as a key path to meaningful teaching and deeper learning, but I think a teacher will only see feedback in this light if they are given opportunities to critically reflect on the type of teacher they hope to become, while considering the role feedback plays in developing into this teacher. When feedback is limited to correcting students and pointing them to the one correct response, possibilities of teaching and learning are also limited. By contrast, when feedback invites a conversation between teacher, student, and subject matter, teaching and learning become exciting and expansive. ${ }^{7}$

It is this expansive vision of teaching and learning that called many of us to the work of being a teacher (Hansen, 1995), and in the next section, I look at the mutually deepening connection between a commitment to accurate and sincere feedback and a commitment to promoting deeper engagement and thinking in the classroom. Seeing our classroom as a place 


\section{Jeff Frank}

of conversation and connection will transform how we see the purposes of learning and feedback, and this - in turn - will allow us to reflect on what we hope our classroom to become and how feedback will move us closer or further away from that hopeful vision.

\section{Feedback and Deeper Learning}

The previous two sections highlight how interconnected everything is in a classroom. A teacher who wants to encourage deeper thinking on the part of students needs to rethink curricular goals, assessment, instructional practices, and much else. Everything hangs together, and changes in one aspect of classroom practice have a ripple effect. Once a teacher begins to think about standards in terms of accuracy and sincerity, they come to see how many things would need to change in order for an ethos of curricular truthfulness to take root. While this can make changes to instructional practice feel impossibly complex, I also find this realisation can be empowering. That is, one realises that conditions don't need to be perfect in order to start the process of change. Rather, if a teacher begins changing one or two aspects of their practice, then other aspects of their practice will slowly change with it. Again, instead of feeling as if one must wipe the slate clean or have everything in order, a teacher can choose an aspect of their teaching practice to work on, knowing that this will eventually ripple out to touch all aspects of their classroom.

This is especially the case when we think about truthfulness and feedback. A teacher who aims to give truthful feedback to students - that is, feedback that is both accurate and sincere - realises that so much would need to change in order for them to provide this type of feedback. When an assignment is poorly constructed, it is hard to give meaningful feedback. When an assignment is too easy or disconnected from student interests or content worth engaging with, a teacher will often find it hard to give good feedback.

By contrast, when a teacher starts with the type of feedback they want to give, this can help them design meaningful work for students. For example, if I want to be able to point students in the direction of interesting readings, or make interesting connections through my feedback, the assignments I give must be open-ended enough to facilitate this type of feedback. If I give an assignment where only one correct answer is possible, it is often much harder to provide conversation-continuing feedback. But if I choose assignments where I look forward to seeing where students take their work, then I am in a position to suggest new areas of inquiry and provide feedback that draws them closer to my content area or the main themes of my course.

What I am looking to create is a virtuous cycle. When I picture the type of conversation I want to provide in my feedback, this allows me to think deeply about the type of work I need to facilitate for my students. As I become more mindful of the type of student thinking and engagement I hope to promote, I find that the quality of student work increases. Students become more engaged and more thoughtful. When this happens, the quality of my own 
feedback to students can improve. I can ask them better questions, and this helps them think more deeply. This - in turn - allows us to have better conversations in class, and it also allows me to learn more about what students are interested in and how I can connect this to my curriculum.

There is a great deal of attention being devoted to moving away from the 'game of school' and to the promotion of deeper learning (Mehta \& Fine, 2019), and I see feedback as key to promoting the goals of deeper learning. What may be even more important, feedback is something that a teacher is largely in control of. Though they may be given standards, and though their success as a teacher may be tied to the results of standardised tests given to their students and that are outside of the teacher's control, teachers can become more mindful of the type of feedback they want to provide students. As they think about the freedom they have to provide feedback they can sincerely get behind, they can also think about the type and quality of feedback they currently provide, and how they might alter that feedback so that it promotes student thinking and engagement. Once they begin doing this, they are positioned to see the ways that changing their relationship to feedback touches on all aspects of their classroom life. When they begin to think about offering feedback as facilitating a conversation, then they will rethink their learning goals, their assessments, and their instructional practices.

I don't want to suggest that any of this is simple, but I do see this process as initiating a virtuous cycle. When teachers think about the quality of the conversation they hope to facilitate through their feedback, they begin providing students work that allows this conversation to happen. When students learn how interested they are in having these types of conversations, it calls on the teacher to provide deeper learning experiences that allow them to provide even more truthful and meaningful feedback. I would like to believe that when teachers are given the space and opportunity to consider this fact, they will be motivated to start small and begin the process of taking stock of all of the ways that feedback does and doesn't work in their classroom. And when they do this, they are on the path to promoting deeper learning for their students. Giving teachers that space and opportunity is what I turn to in my conclusion.

\section{Conclusions: The Role of Feedback in the Education of Teachers}

In this conclusion, I briefly suggest and sketch out one way of promoting critical reflection on feedback as a means to cultivating student engagement and thinking while also allowing teachers to teach in ways that are responsive to their vision of what good teaching should be and do. I believe reflecting on feedback should begin in teacher education programs, and it should receive increased emphasis in teacher development.

I don't think focusing on feedback is a simple solution or a panacea, but I believe that giving teachers an opportunity to focus on feedback in their 
classroom will allow them to start the work of slow improvement right away. Here are some steps that they might take:

- Do a feedback inventory. Try to describe - though not yet judge - all the feedback given in a week.

- After listing all the feedback, code the feedback as positive, negative, neutral, using the standards of student engagement and thinking, along with a teacher's own vision of good practice, as guides.

- Begin mapping out steps that one can take to give better feedback, drawing on ideals of accuracy and sincerity.

- Critically reflect on how to make this a continuous process and a virtuous cycle.

- Look for ways to connect with other teachers, forming professional learning communities focused on feedback and doing instructional design that leads to feedback that promotes deeper learning.

Teachers can start this work in their teacher education program. They can describe all the ways that feedback works in the classrooms they observe, and then they can also think about what they would do - when they have their own classroom and during student teaching - to make feedback work for students and given their developing vision of what good practice looks like. Getting in the habit of reflecting on feedback from their teacher education program will help them stay in this habit - and advocate for its importance once they become teachers.

Of course, changes at the policy level and changes in how teachers are evaluated and supported by school leaders will make it easier for teachers to do their work well, but one of the main reasons I focus on feedback is because teachers often have room to improve this aspect of their practice almost immediately. Simply asking the question - Is this the type of feedback I want to give; does it work for students and my own vision of teaching? can be the start of a slow but rewarding transformation. For example, when I realised that the written comments I gave to my students were valued by my students more than almost any other aspect of my instructional practice, I devoted as much time as possible to giving accurate and sincere feedback. When I did this, students shared more in their response papers, and this allowed me to adjust my instruction and feedback so that it was more responsive to what my students were interested in. ${ }^{8}$ Most important, it helped me promote what I valued in the classroom: student engagement and thinking. Focusing on feedback allowed me to facilitate connections between my students and my subject area, and for this reason I think it is worthwhile to give teachers opportunities to reflect on the role of feedback in their classrooms. Again, this isn't a simple solution or a panacea, but I think it offers one path to improvement that teachers can immediately begin walking down.

Returning to a theme of the opening section, teachers need to be mindful of their unintentional biases when providing feedback. Feedback is a place where we can welcome students or make them feel as if they don't belong 
(Frank, 2021). It is important to realise that even if one intends to provide supportive and honest feedback, what matters is that a student receives the feedback in that spirit. ${ }^{9}$ In a society marked by structural injustices, teachers need to be especially mindful of how students interpret their feedback. As well, a teacher needs to balance sincerity - what they are genuinely interested in - with a sense of accuracy. When it comes to structural injustices, this means selecting material that resonates with the truths of how their students experience the world. It is too easy for a teacher to select material that they find important or interesting, assuming that this will have universal appeal. Luckily, if teachers provide students with opportunities for genuine thinking, and create a trusting environment where students feel comfortable speaking accurately and sincerely, then they will learn when they need to modify their curricular material and instructional activities. Importantly, this doesn't mean cancelling or rejecting anything, though it does mean a willingness to listen and think together about the truth. When feedback is grounded in a spirit of truthfulness, it is far more likely that these necessary conversations will happen. And it is these types of conversations that we need now, and it is these types of conversations that will make classrooms lively and engaging places that have the potential to transform students, teachers, and our world for the better.

\section{Notes}

I I argue the point here, but in one might consult Biesta and Stengel's (2016) wonderful and very comprehensive handbook chapter on the philosophy of teaching. In this handbook, chapter feedback is not discussed, and formative assessment is not a focus. Though philosophers of education are critical of assessment practices (Egelandsdal \& Riese, 2020; Rømer, 2019), philosophically informed approaches to feedback and formative assessment are rare (Frank, 2017). My hope in this paper is to put feedback at the center of teaching as a way of empowering teachers to take ownership over a central aspect of their work.

2 As will become clear, this paper is written from the standpoint of an American, and examples will be drawn from the American context. At the same time, every effort will be made to demonstrate how these ideas related to feedback might transcend that context.

3 Including, very importantly, problematising the very idea of an achievement gap and helpfully reframing it as a 'debt' (Ladson-Billings, 2006).

4 For example, I think it will be especially useful to think about how truthfulness helps us approach curriculum design and teaching controversial issues in the classroom.

5 Again, I will use UbD as a framework in this paper, but many other approaches to instructional planning will work here.

6 Retrieved from http://www.corestandards.org/ELA-Literacy/RL/9-10/

7 I see this as connected to David Hawkins's (1974) thinking on the teaching triangle. For an excellent recent discussion of Hawkins's work, see Rodgers (2020).

8 For a beautiful discussion of how a teacher uses feedback to connect with students, see Tovani (2011). For another inspiring discussion, see Berger (2003).

9 For an extremely interesting discussion, and one that hasn't received the attention in deserves in education (especially because it speaks directly to the practice of teaching), please see Potter (2002). 


\section{Jeff Frank}

\section{References}

Biesta, G. (2010). Good education in an age of measurement. Paradigm.

Biesta, G. (2012). Giving teaching back to education. Phenomenology \& Practice, 6(2), 35-49. https://doi.org/10.29173/pandpr 19860

Biesta, G., \& Stengel, B. (2016). Thinking philosophically about teaching. In D. H. Gitomer, \& C. A. Bell (Eds.), Handbook of research on teaching (5th ed., pp. 7-68). American Educational Research Association.

Berger, R. (2003). An ethic of excellence. Stenhouse.

Buchanan, A. (2018). Prisoners of misbelief: The epistemic conditions of freedom. In D. Schmidtz, \& C. E. Pavel (Eds.), The Oxford handbook of freedom (pp. 508-524). Oxford University Press.

Cochran-Smith, M. (2000). Blind vision: Unlearning racism in teacher education. Harvard Educational Review, 70(2), 157-190. https://doi.org/10.17763/haer. 70.2.e77x215054558564

Cooper, D. E. (2008). Teaching and truthfulness. Studies in Philosophy and Education, 27(2-3), 79-87. doi:10.1007/s11217-007-9091-x

Earl, L. (2003). Assessment as learning. Corwin.

Egelandsdal, K., \& Riese, H. (2020). Never mind the gap: Formative assessment confronted with Dewey's and Gadamer's concept of experience. European Journal of Education, 55(1), 3-14. doi:10.1111/ejed.12378

Frank, J. (2013). Mitigating against epistemic injustice in educational research. Educational Researcher, 42(7), 363-370. doi:10.3102/0013189X12457812

Frank, J. (2017). Bound to the mimetic or the transformative? Considering other possibilities. Education and Culture, 33(1), 23-40. doi:10.5703/educationculture. 33.1 .0023

Frank, J. (2020). Against technology-mediated personalized learning: Resources from John William Miller and Henry Bugbee to support parental resistance. Ethics and Education, 15(1), 98-112. doi:10.1080/17449642.2019.1700445

Frank, J. (2021). Belonging in college: John William Miller on liberal education's promise of freedom. Soundings, 104(2-3), 260-274. doi:10.5325/soundings. 104.2-3.0260

Frank, J., \& McDonough, J. (2020). Core practices and philosophy of education: Balancing effectiveness with goodness. Teachers College Record, 122(4), 1-22. https://eric.ed.gov/?id=EJ1268390

Fricker, M. (2020). Bernard Williams as a philosopher of ethical freedom. Canadian Journal of Philosophy, Early View, 1-15. doi:10.1017/can.2020.43

Hansen, D. T. (1993). From role to person: The moral layeredness of classroom teaching. American Educational Research Journal, 30(4), 651-674. doi:10.3102 $/ 00028312030004651$

Hansen, D. T. (1995). The call to teach. Teachers College Press.

Hansen, D. T. (2018). Bearing witness to the fusion of person and role in teaching. In N. Wahlström, D. Alvunger, \& D. Sundberg (Eds.), Teachers matter-But how? (pp. 7-23). Routledge.

Harber, K. D., Reeves, S., Gorman, J. L., Williams, C. H., Malin, J., \& Pennebaker, J. W. (2019). The conflicted language of interracial feedback. Journal of Educational Psychology, 111(7), 1220-1242. doi:10.1037/edu0000326

Harðarson, A. (2012). Why the aims of education cannot be settled. Journal of Philosophy of Education, 46(2), 223-235. doi:10.1111/j.1467-9752.2012.00847.x 
Harðarson, A. (2018). The teacher is a learner: Dewey on aims in education. Educational Philosophy and Theory, 50(5), 538-547. doi:10.1080/00131857.20 17.1395735

Hawkins, D. (1974). I, thou, it. In D. Hawkins (Ed.), The informed vision: Essays in teaching and learning (pp. 48-62). Agathon Press.

Jackson, P. W. (1990). Life in classrooms. New York: Teachers College Press. (Original work published 1968).

Ladson-Billing, G. (2006). From the achievement gap to the education debt. Educational Researcher, 35(7), 3-12. doi:10.3102/0013189X035007003

Lampert, M. (2001). Teaching with problems and the problems of teaching. Yale University Press.

Lear,J.(2009).UniversityofChicago:Aimsofeducationaddress. Retrievedfromhttps:// college.uchicago.edu/student-life/aims-education-address-2009-jonathan-lear

Martinez, M. R., \& McGrath, D. (2014). Deeper learning. New Press.

Mehta, J., \& Fine, S. (2019). In search of deeper learning. Harvard University Press.

Pendlebury, S. (2008). Accuracy, sincerity and capabilities in the practice of teaching. Studies in Philosophy and Education, 27(2-3), 173-183. doi:10.1007/ s11217-007-9088-5

Potter, N. N. (2002). How can I be trusted? Rowman and Littlefield.

Rauch, J. (2020). Trump's firehose of falsehood. Persuasion [online]. Retrieved from https://www.persuasion.community/p/trumps-firehose-of-falsehood

Ritchart, R. (2015). Creating cultures of thinking. Jossey-Bass.

Rodgers, C. (2020). The art of reflective teaching: practicing presence. Teachers College Press.

Rømer, T. A. (2019). A critique of John Hattie's theory of visible learning. Educational Philosophy and Theory, 51(6), 587-598. doi:10.1080/00131857.20 18.1488216

Santoro, D. (2011). Teaching's conscientious objectors. Teachers College Record, 113(12), 2670-2704. https://eric.ed.gov/?id=EJ988304

Santoro, D. (2018). Demoralized. Harvard Education Press.

Siegel, D., \& Bryson, T. (2018). The yes brain. Bantam Books.

Tovani, C. (2011). So what do they really know? Stenhouse.

Wiggins, G., \& McTighe, J. (2005). Understanding by design (2nd ed.). ASCD.

Williams, B. (2002). Truth and truthfulness. Princeton University Press. 


\title{
5 The Students' Role in Standards-Based Education \\ Critical Reflections on Pedagogical Implications
}

\author{
Bettina Vogt
}

In a wider sense, this chapter is about the pedagogical implications of a standards-based curriculum for the equity task of education. More concretely, the students' role will be in focus in this chapter and how their role can be understood when the standards-based curriculum is enacted in different kinds of classrooms. By this, the chapter intends to shed light on those groups of actors in the school system who are at the centre of all educational efforts and whose broad intellectual, personal and social development the curriculum ultimately addresses. In the research literature, the student's role in teaching processes is often associated with concepts such as 'student voice' or 'student agency.' In sum, these two interrelated concepts can be said to refer to the ethical and equity dimensions of students' unique perspectives on their education and on their real possibilities of exerting influence over the conditions, limitations and ways in which their education takes shape (Arnot \& Reay, 2007; Cook-Sather, 2006, 2020; Manyukhina \& Wyse, 2019). However, in this chapter, the question of the students' role will be approached from a somewhat different angle and will be critically explored by integrating perspectives from critical curriculum studies, pedagogy and General Didaktik. Consequently, the purpose of the chapter is to contribute with theoretically relevant conceptualisations regarding the students' role in teaching processes, which is the ways in which the pedagogical relation in the didactical triad of student, teacher and content can be understood when the students' role is the prime focus. However, before diving deeper into this, some introductory remarks on curriculum standardisation and classroom practices are necessary to contextually frame the chapter.

\section{Curricular Standardisation and Classroom Practices}

For quite some time, the curricular standardisation of education has profoundly changed the ways in which education is not only governed and organised but also perceived and realised. Although standards-based curricula can look different in different contexts, there are common denominators, such as the stipulation of externally set standards that concretise knowledge expectations and the alignment of different curriculum elements, such as content, aims and assessment (Sundberg \& Wahlström, 2012). On the one

DOI: $10.4324 / 9781003218067-5$ 
hand, the usual line of argumentation for legitimising curricular standardisation is that it increases educational equality since it prescribes knowledge expectations that are the same for all students. Moreover, standardisation is seen to be a necessary basis for the 'efficient' organisation of teaching and learning processes by also providing reliable data for monitoring and accountability purposes (Bellmann \& Waldow, 2012).

On the other hand, the functionalities of educational systems are complex and multi-layered, with many factors mutually influencing each other on the system's different levels. Based on previous research, we know that standards-based curricula evidently result in various and sometimes unintended side effects. Regarding the Swedish case, the contributions in Wahlström and Sundberg (2018) show that teaching under the standards-based curriculum for compulsory school, with its clear and uniform knowledge expectations, has become more outcome-oriented and promotes whole-class teaching in order to ensure that all students can reach the pre-set performance goals. Moreover, the focus on standards and the constant presence of grading criteria and learning aims also has consequences for students' well-being and their self-image as learners, with their level of performance becoming a part of who they 'are' (Hirsh, 2020; Vogt, 2017). This can be understood as the constant awareness that students have regarding their own capacities in relation to the clear and explicit communication of the externally set expectations of what one is supposed to know and be able to do with that knowledge in order to reach a certain performance level and, thereby, to achieve a certain grade. Taken together, it can be said that curricular standardisation has diverse consequences for the didactical architecture in classrooms in terms of shifts concerning what the central fundamental elements of the work undertaken in the classroom are and how teachers and students position themselves in relation to those elements. Against this background, the question regarding the students' role and its interdependencies in the social system of the classroom becomes vital. How can the students' role be understood in teaching processes under the conditions of a standards-based curriculum, and what are the pedagogical implications for students being part of different learning environments?

\section{Students as Co-Authors of Curriculum Events}

As the findings from many classroom studies suggest - and here, Philip W. Jackson's Life in Classrooms can be named as a prominent classic example (Jackson, 1968/1991) - the transformation of the curriculum into concrete teaching and learning can be considered as inevitably embedded in a socially situated context. As such, teachers and students are mutually involved in communicative processes when making meaning of the curriculum. Occasions of institutionalised teaching and learning, then, can be seen as the 'pedagogical transformation of curriculum,' denoting 'curriculum events.' From a discursive point of view, these curriculum events '[consist] of written, oral, and behavioral "texts" that must be interpreted and acted 
upon [by students, B.V.] toward some purpose' (Doyle, 1992, p. 508). When teaching, teachers 'author' these curriculum events and young people, in the role of students, become 'co-authors' by contributing to these discursive 'texts'.

For the questions in focus in this chapter, this has several implications: first, this denotes a widened understanding of the curriculum concept, where the curriculum as a programme necessarily needs to be transformed into concrete classroom practices. This transformation must not be seen as a topdown process (where the general and predetermined content and aims would simply be applied and put into practice in whatever classroom by whatever individuals involved) but as a communicative, contextually embedded and locally framed process of joint meaning-making. This is, in the present chapter, the specific ways in which the standards-based curriculum is perceived and realised in different learning environments. Second, the notion of the socially and communicatively framed transformation of the curriculum also means that the students do not only 'take part' in teaching in terms of acquiring the curriculum-prescribed knowledge and skills; instead, students' active role in this meaning-making process is emphasised, and students, as actors in explicit and implicit ways, contribute to shaping curriculum events as a sort of social and communicative interplay between themselves, the teacher and the content. Here, it is important to underline that the focus is not on students' learning in and of itself as a sort of cognitive process but on how students participate in creating and making meaning of those events. This theoretical position regarding the students includes them being seen as 'productive processors of reality' (Hurrelmann, 1988), a term that refers to the pedagogical notion of the student as being a subject whose process of individuation (Selbstwerdung) is realised in interaction with the 'world.' The school, and especially the classroom, belongs to this 'world,' and it is one of the major arenas for young peoples' enculturation and socialisation. In school, students do not merely acquire units of knowledge in terms of learning content; they also learn something about society and develop an idea of the value that this knowledge has for themselves and for the shared common good, what can be done with that knowledge and how social life in this world can be organised.

From a pedagogical point of view, this implies that in school, as a societal institution, pedagogical opportunities are required through which students experience how the relevance of their role in the joint meaning-making processes of teaching is acknowledged and practically lived and supported.

\section{Pedagogy and General Didaktik: A Conceptual Frame of Students' Co-Authorship Role in Teaching Processes}

As outlined earlier, regarding its theoretical orientation, the chapter draws upon conceptual formations and ideas from the fields of critical curriculum research and pedagogy, as well as from the tradition of General Didaktik. Here, the guiding thought is that a carefully chosen combination of 
certain conceptualisations from these three fields allows for a framework that enables the capture of students' co-authorship in its pedagogical and didactical dimensions against the backdrop of critical curriculum theory. Or, stated differently, it is at the point where these three fields converge that students' co-authorship is seen to be situated and where it can be traced in its diverse forms and with the inherent complexity that characterises pedagogical relationships. Below, I will, therefore, first explain what the view of pedagogy applied herein means for the concept of teaching, in relation to which students' co-authorship is seen to take place. In a second step, I will present how a conceptual apparatus related to a critical-constructive Didaktik may enable us to trace the specific character of the students' role and how the students' role in standards-based education can be explored and problematised.

\section{Pedagogy: Teaching as an Act and as Discourse}

In this chapter, regarding the pedagogical perspective of teaching, inspiration is mainly found in the work of Robin J. Alexander (2001), who suggests that the concept of teaching includes both the act of teaching itself and the discourse that is linked to that act. Hence, classroom teaching involves both social action and meaning-making dimensions; it refers to what teachers do and, ultimately, why they do what they do. Teaching, understood as an act and discourse, is about 'what one needs to know, and the skills one needs to command, in order to make and justify the many different kinds of decisions of which teaching is constituted' (Alexander, 2004 , p. 11). From such a framing of the teaching concept, it follows that teaching means more than the mere 'techniques' used in order to direct a learning process towards the acquisition of certain kinds of knowledge content. Teaching, understood from this broader view of what happens in classrooms when teachers and students interact, denotes education (Alexander, 2008), which connects the knowledge and skill aspects of teaching to the pedagogical justifications of the previously mentioned processes regarding the students' subjectification.

These processes are framed by the curriculum, which can by no means be seen to represent a neutral basis for what knowledge - and in which ways that knowledge - should be taught and learnt in classrooms. Rather, the curriculum carries certain and sometimes implicit kinds of assumptions, ideas and values about knowledge and learning, which matter for how the pedagogical task is perceived and realised. By understanding teaching as consisting of 'curriculum events' (Doyle, 1992), the pedagogical transformation processes can be traced when teachers and students jointly 'make' the curriculum with respect to how they make meaning of it and what kinds of meanings they ascribe to it. The process of students' co-authoring of curriculum events must, therefore, not be understood as isolated but as embedded in this joint meaning-making of the curriculum and as framed by the pedagogical context in which it occurs. 


\section{General Didaktik and Bildung Orientation}

General Didaktik can be explained as denoting a general theory of teaching (Rucker, 2020). Institutionalised teaching, as it takes place in schools, is here seen as the complex relationships that occur between the teacher, content and the student, which is usually illustrated in the form of the so-called didactic triangle. In a simplified way, the tradition of General Didaktik could be said to address the core questions of teaching, which are the 'what,' the 'how,' the 'why,' the 'for whom' and, above all, the 'what for' of teaching. The 'what for' of teaching, which is what the teaching is fundamentally purposed to lead to for the students and under which conditions it can be pedagogically justified, is superordinated to and ultimately determines the answers regarding the questions of what content to teach to whom and what methods should be employed to teach that content. Due to the complexity of the relationships and the teachers' necessary critical reflection regarding the purpose of their teaching, teaching also becomes a question of pedagogy (Hudson, 2006). It could be said that teaching refers to different dimensions of a broad range of pedagogically relevant problems that can be related to, for example, instruction, content, learning, methods, aims, purposes, assessment, or sanctions (Klafki, 2007).

However, within General Didaktik, different models can be traced, where the bildungs-oriented Didaktik represents the most influential one, as it has had a lasting impact on the development of Central and North European educational thinking and is continuously modified and refined, also in relation to the curriculum (Gundem \& Hopmann, 1998; Krogh et al., 2021; Uljens \& Ylimaki, 2017; Westbury et al., 2000). One way of understanding the bildungs-oriented General Didaktik is that it purposes to '[clarify] the basic structure of teaching under the claim of Bildung' (Rucker, 2020, p. 52). Regarding the concept of Bildung, one has to be aware that there is no overall, general definition of what is meant by Bildung, as the concept is multi-faceted and characterised by more or less different nuances in meaning (Hopmann, 2007). In the following, it is outlined how Bildung - as a central educational category - is to be understood in this chapter, what it consists of and what it implies in relation to the students' role when looking at this category from a certain kind of Didaktik model, namely, the critical-constructive Didaktik model.

\section{Critical-Constructive Didaktik}

Originally developed in a German-speaking context, which is characterised by a long tradition of human-science pedagogy, Wolfgang Klafki (2007) provides a theoretical model of General Didaktik that is bildungs-oriented, but which goes beyond the hermeneutic Didaktik tradition, as Klafki's (2007) critical-constructive Didaktik model is also influenced by the critical works that emerged in light of the Frankfurt School. The conception of a bildungs-oriented Didaktik that Klafki's model is based upon refers to 
Bildung as the students' abilities (Fähigkeiten) in terms of (i) self-determination (Selbstbestimmung), which means the ability to make autonomous, well-informed and morally justifiable decisions; (ii) co-determination (Mitbestimmung), which means the ability to participate in joint decision-making processes; and (iii) solidarity (Klafki, 1995). Those abilities (or perhaps it would be even more correct to speak of capabilities in this context) are seen as the basic principles that a human and democratic society constitutively rests upon (Klafki, 1995, 2007). The term critical in Klafki's model denotes the critical-communicative dimensions of teaching, which either enable or impede the conditions that are necessary for those abilities to be developed. In addition, the model also entails an action-oriented (handlungsorientierten) and empirically informed approach to teaching, here described as the 'constructive' part of Klafki's theory, addressing the practical as well as the reflexive aspects of teaching and learning with regard to those abilities. Altogether, what is highlighted in Klafki's (2007) work and what is a recurrent theme in his writing is the issue of how Didaktik, as a research framework and as a conceptual background for teachers' professional reflexive orientation, can help us to problematise, illuminate and change societal conditions that lead to, for example, cultural, economic and social inequality. In school, as a societal institution, and in the classroom, as a social unit of the same, these inequalities intentionally or unintentionally risk becoming reproduced to the further disadvantage of those students who already lack different kinds of privileges and opportunities. Therefore, the kind of teaching that takes the ethical responsibilities of the societal and democratic task of education seriously takes students' different backgrounds, potentials and needs into account and enables a learning environment that is rich in offering opportunities for all students to develop their capabilities of self- and co-determination and solidarity. This implies that students need to be given the opportunity to meet and critically examine different kinds of knowledge content and to position themselves clearly and with growing personal autonomy regarding the questions that society poses to each individual, both now and in the future. Hence, the broad Bildung of each student denotes a process, as it also stands for the results of those educative processes.

The idea of Bildung, understood as outlined earlier, represents the central category for guiding teachers' professional decision-making regarding the concrete teaching content and in which ways to teach that content. The necessity and essential pedagogical relevance of such a central category like Bildung is given if

... our pedagogical efforts for the next generation (...) shall not fall apart into a loose vis-à-vis, or even into against each other directed, countless single activities, and if the pedagogical support, the measures, activities and individual efforts to learn shall become or remain justifiable and responsible.

(Klafki, 2007, p. 44 $4^{1}$ 
Hence, a superordinated category such as Bildung is needed that provides teachers and students with the necessary orientation regarding the overall purposes of education that are able to transcend the here and now of the classroom and the mere learning content, as such. From that follows what Klafki calls the primacy of objectives (Primat der Zielentscheidung) (Klafki, 2007). The primacy of objectives means that decisions regarding teaching content and methods always have to be justified in relation to the overall purpose, not in a deductive sense but as a critical-reflective practice that is embedded in discursive negotiation processes regarding the extent to which the offered teaching enables each student's self-determination, co-determination and solidarity under the pedagogical conditions of the specific classroom.

Hereby, the essential pedagogical programme of the critical-constructive view of teaching is contoured so that it can be seen to represent a general action-oriented frame for all students' education. This perspective also has consequences for one of the central aspects in school that relates to the school's socialisation task, namely, to prepare students to live in a performance-based society. From a critical-constructive Didaktik angle and when the focus is on the students' role, this includes, for example, reflections on what the students' 'performance' (Leistung) is seen to represent, what kinds of demands on student performance are justifiable from a pedagogical and ethical point of view and also what counts as valuable performance in this context. If the students' abilities of critical awareness, creativity, communication and empathetic solidarity are the primary purposes, then, in school, no demands can be made in terms of student performance that hinder

... young people from developing their self- and co-determination abilities, their critical and decision-making abilities - which also includes their ability to validly dissociate from certain societal performance demands.

(Klafki, 2007, p. 228, author's translation)

Consequently, a successful Bildung process would also include young people's ability to position themselves, in a well-founded and critical way, as being against the contexts, structures, institutions, people and ideas that enabled their Bildung, and to challenge and question them if necessary.

In relation to a critical-constructive approach to teaching, one thus has to differentiate between performance demands that are externally imposed on schools and a pedagogical performance principle (pädagogisches Leistungsprinzip). Pointedly, and in light of such a pedagogical performance principle, the focus is not on the student as a kind of supplier of externally and pre-set standardised expectations; instead, the students' role refers to the development of capabilities, which relates to an individual development based on the students' unique starting points and needs. This represents the students' individual performance - an individual performance that is exclusively 'owned' by the students themselves and which teaching can only support and help to initiate. 


\section{The Students' Role in Two Different Learning Environments}

In the following, these ideas and conceptual frames are related to the analytical observations that could be made in two different classrooms regarding the students' role in the didactical relationships between students, teachers and content, as well as the pedagogical implications that follow from this. Here, the two different classrooms, which are attended by students in year eight in two Swedish compulsory schools, represent different kinds of learning environments in which the students' role takes shape in curriculum events. However, it is important to note that the focus is not on an empirical comparison of the classrooms per se, but on the context-sensitive examination of the previously named aspects in relation to exemplifying excerpts of different pedagogical environments.

The empirical examples ${ }^{2}$ in this chapter are taken from a set of data that was collected during the school year 2018/2019. The data set includes 16 video-filmed classroom observations of science classes in a year eight classroom, as well as eight semi-structured interviews with the science teachers and eight group interviews with the students. Also, fieldnotes and additional materials were collected, such as lesson plans and materials handed out during lessons, and they were analysed through abductive and integrated coding procedures, including a fine-grained coding scheme for the lessons (Wahlström et al., 2019). In relation to this chapter, the guiding initial questions for analysis were about how the character of and the conditions for the students' role could be conceptualised, relating to the didactical relationships that characterised the curriculum events that the students were an active part of.

\section{Introducing the Two Learning Environments}

The first classroom is part of Larch Tree School, which is located on the outskirts of a medium-sized Swedish city. The school has an international profile, and the majority of the students have a migration background, as well as parents with post-secondary education. There is an explicit pedagogical idea for the school, which is, amongst others, about having high expectations for all the students to succeed with their studies. This aim permeates the work realised in this school on every level and is mirrored in a comprehensive and optimised set of pedagogical and didactical structures for how teaching and learning are organised and for how the results are continuously monitored and, if necessary, adjusted on the group and individual levels. For this school, students' performance, as measured in so-called merit points that are based on students' grades in year nine, is clearly above the national average.

The second classroom is a part of the Oak Tree School. The school is located on the outskirts of a bigger Swedish city, with the neighbourhood being characterised by challenging socio-economic conditions and a high degree of cultural diversity. The majority of students in this school come from homes with migration experiences, and most of the students' parents do not have 
post-secondary education. According to the principal, the school has struggled with low goal attainment for a long period of time, and it has had to handle a broad variety of social problems besides the school's core task of teaching. In addition, there are also difficulties in finding enough certified and more experienced teachers. In this school, the students' merit points are clearly below the national average, and the majority of students have difficulties in achieving the minimal standards for entering upper secondary school.

\section{The Students' Role in the Larch Tree Classroom}

Before the science classes in Larch Tree School start, students have to wait for the teacher to unlock the classroom door while placed in two rows outside the classroom. When entering the classroom, students quickly and quietly move to their seats, standing behind their chairs and waiting for the teacher to welcome them and to allow them to sit down. After this, the teacher always introduces the content and the structure of the day's lesson. Here, the knowledge requirements often play a central role, which are the criteria for different grading levels expressed in the syllabus, and the result expectations of the lesson and the learning task are communicated. In addition, the teaching content in science classes follows the school's detailed plan for what to teach in science in the different years in order to ensure that all of the content prescribed in the syllabi is effectively covered during lessons.

Overall, science classes in Larch Tree School are characterised by a so-called result-oriented knowledge conception (Wahlström et al., 2019), which means that knowledge in this classroom is first and foremost conceptualised in terms of learning outcomes and students' performance. This becomes visible in the classroom discourse for the observed lessons, as well as in the interviews and the additional material collected (see also Vogt, 2021 for a more detailed presentation).

For example, at the beginning of every new task, students are handed out plans for the new working unit, including the learning objectives for each lesson with different levels of difficulty, which are related to different grading levels that can be achieved during this lesson. In a biology class, for example, one lesson was about the cells and organ system, and the students needed to show that they 'could label an animal cell' to get a pass, whereas the highest performance level required the students to 'describe how the organ system works together.' After each lesson, students are supposed to track their learning outcomes of the day by checking off which grade-related level their performance matched with during the lesson, how they would explain the achieved level, and what they needed to do in order to improve their performance regarding the content in question. In the student interviews that were conducted, it became visible that the students were positive towards this kind of learning support. For example, in one interview, a student said:

This helps a lot, because instead of thinking about what we have learnt, you can simply look and check what you know. Well, like, you only have 
to look for yourself, checking, and if you know something, then you can skip it. (...) If I am going for a D, I know that this is what I need to know. ${ }^{3}$

In sum, those local documents can be seen as didactical artefacts that frame the lessons and mirror a kind of result-oriented standardisation of teaching processes, where knowledge and its acquisition are conceptualised and communicated as easily measurable units that can be broken down into fragments of learning and where the value of the learning mainly lies in the grading level achieved. For the students, this implies the effective organisation of their learning processes, with the aim of ensuring that they, at the end of the term, can achieve the desired grade.

For the science teacher, this didactical standardisation equals a sort of necessary pedagogical structure to enable working with the science syllabi in an effective manner. It helps the teacher to cover all of the content prescribed in the syllabi, which are perceived as overcrowded, as well as preparing students for getting the focus right in order to achieve good results in the standardised tests. In the interviews, the teacher often underlines how important it is that the students understand the rules of the classroom, what the expectations are regarding their learning and the requirements for achieving good results. This conception is, for example, mirrored in the following interview excerpt, where the teacher explains how new groups of students are introduced to the teacher's science classroom:

(...) as I am used to saying: You are here to work! You are not here to socialise, but you do this, and you do that. (...) And then, I probably should not do this, but I throw up my year nine results from the national test and say: These people did EXACTLY what I said. And they had Ds in year six and now they got Bs in the national test. And I can show them the analysis that I have done, from the department. (...) And there you go. It's up to you. (...) I guarantee, if you do what I say, you'll get the results.

The result-oriented conception that is illustrated in the quote just cited, and which includes an idea of teacher-structured guidance for effectively directing students' learning towards expected results, also has implications for the teaching repertoires used during lessons. Here, the observed science lessons were mainly characterised by teacher-led whole-class teaching, where rote learning and high-frequency Initiate-Response-Evaluation sequences (so-called I-R-E sequences, where the teacher asks closed questions about facts and concepts that students have to answer and which could be either 'right' or 'wrong') were the dominant forms for teaching. Against the background of the importance of providing students with the possibility of achieving good test results and due to the content overcrowded curriculum, the teacher summarises how teaching science 'is fast food teaching. You're constantly moving from one thing to the next. Fact after fact after fact after 
fact.' This conception leads to the conclusion that the frames and possibilities for deeper learning are limited, where students' subject-related interests, their own meaning-making and a critical examination of the content could be provided with more space:

That's not student-led. (...) You know, where I can't just: oh, you want to learn about this? So, we will spend the next three weeks doing this. I don't have the time. I have to get these things taught.

Taken together, the ways in which teaching and learning are perceived and jointly realised by the teacher and the students in this environment are characterised by a focus on performance and results. Here, student performance seems to be more about externally defined performance measurements in terms of standards and national tests, rather than it representing a pedagogically informed idea of performance in terms of aiming at the students' content-related Bildung, as well as their social and personal growth. If put pointedly, it could be said that the students' role is concurrently one of both a consumer and a supplier. On the one hand, students simply consume the pre-structured knowledge units and teaching procedures for efficiency reasons, and, on the other hand, they are supposed to deliver the science facts, the concepts and the evidence of having the ability to operate with those facts in a prescribed and quite instrumental manner, which is required for achieving the expected high results. Thereby, the didactical space for and the pedagogical value of learning and discovering something that deepens one's understanding of the world and how one can position and locate oneself in relation to this - in ways that allow for a critical and moral examination becomes constrained.

\section{The Students' Role in the Oak Tree Classroom}

In the Oak Tree science classroom, the door is often still open when lessons begin, with students going in and out of the classroom. When the teacher starts talking, some of the students sit down and listen, while others are moving around in the room, talking to their friends or checking their mobile phones. Then the teacher introduces the lesson topic, sometimes followed by a short repetition of the last lesson's science concepts. Lessons are mainly held in a teacher-led whole-class setting, with rote teaching and $\mathrm{I}-\mathrm{R}-\mathrm{E}$ sequences as the dominant teaching repertoires. The structure of the lessons is quite repetitive, mostly consisting of rote teaching at the whiteboard, watching short films and then answering questions on copied papers. In addition, there are many disruptions due to classroom management issues and when students leave the classroom during teaching and come back again.

Overall, science lessons in the Oak Tree classroom are characterised by a focus on theoretical concepts and facts, and there are almost no references made to any of the formulations in the syllabi during lessons. The dominating knowledge conception that comes to the fore in the analysed lessons is 
an essentialistic one, meaning that the lessons are mainly characterised by a vertical knowledge approach emphasising the discipline-oriented dimensions of the subject ( see also the chapter by Schmidt in this book; Wahlström et al., 2019). This essentialistic approach to knowledge also becomes visible in the teacher interviews, where the teacher underlines that it is the subject-specific concepts that build students' knowledge, for example, including content such as 'What is motion, what is acceleration? What is energy, what is force? That's the most important.' The teacher's pedagogical idea behind the teaching is to prepare students for their future lives and the standards they will have to meet later on in upper secondary school. Hence, what students have to learn today is what is formulated in the performance standards that point out what is to be mastered in the future:

INTERVIEWER: If you reflect on what students need to know, what is important, how do you choose?

TEACHER: Knowledge requirements. In some way, these are the frames. Because I have worked at the upper secondary level, I know what it is about and about their future.

For the teacher, the purpose of the students' science learning is about learning the basics of the sciences and getting the facts and concepts right for their future learning path. The teacher's conception of the basic character of what is to be learnt is also communicated to students during lessons. In one chemistry lesson, for example, which was about photosynthesis, the teacher talked about the written test, which the lesson was intended to prepare the students for. As was the case for all the other working units, the teacher handed out copied papers with the most important facts and concepts that the students had to learn:

TEACHER: Everybody got those? This is very simple. It's only these that will come up in the test. It's not so many pages. It's only ten pages (...). You receive this. This is enough for passing the test. It's not so many pages when you think about it. (...)

STUDENT: Are we not supposed to have a book?

TEACHER: We will not have a book at all. It's only this [holding up the papers] we will use. If you received a book, then you can return it. (...)

The teacher's conception regarding the content's simplicity that is exemplified in the excerpt just cited also implies that the content is reduced with regard to its material amount ('only ten pages') as well as its content-related character and extent ('We will not have a book at all. It's only this we will use'). What is communicated to the students here is that this reduction in content corresponds to a didactical adjustment to the teacher's expectations about what they are supposed to achieve ('This is enough for passing the test').

However, the teacher's intention of preparing students for upper secondary level in a basic way is challenged on an everyday basis due to classroom 


\section{Bettina Vogt}

management issues and students' difficulties in understanding the content in the way they are taught, which, for example, becomes visible in a lesson about Ohm's law:

The teacher asks one of the students to read a question aloud from one of the copied papers. Students in the back of the classroom are not listening and are talking with each other.

TEACHER: Listen, do you want to participate in the lesson?

STUDENT A: No one has said anything! [upset]

TEACHER: You are supposed to participate.

STUDENT A: I do participate! [upset]

TEACHER: What do you mean student B?

STUDENT B: I don't have it.

TEACHER: Well, you have it in front of you. The question.

STUDENT B: Which question?

TEACHER: Question eight.

STUDENT B: I cannot answer the question.

TEACHER: Yes well, you cannot/. You do not know/. You cannot solve this equation?

STUDENT B: Well (...). I don't understand anything. I have not understood anything!

TEACHER: Ehm. No, you don't understand anything/. You might study at home. [The teacher turns towards a student in the front row and poses the question to this student instead.]

From a student's perspective, situations such as the one here have to do with classroom management issues that often make ordinary teaching difficult. However, besides those vital pedagogical aspects, the most important point for the students is that they perceive the teaching to be carried out in a way that 'is much like university' and not like the teaching they 'have been used to over the years.' That makes it hard for them to really understand and to engage with the content that the teacher offers to them, as explained by one student during an interview: 'The teacher uses very/. The teacher does not explain that well. Most of us do not understand during the lessons, and others just ignore the teacher.'

Taken together, also in the Oak Tree science classroom, teaching and learning the sciences is mostly perceived and realised as the teacher-led instruction about facts and concepts, where the subject-related concepts that are offered to the students appear as a given body of basic knowledge, with a limited didactical space for students' own meaning-making based on their starting points for learning. Here, the focus does not lie so much on the results in the here and now in terms of the highest possible grades but on equipping students with the basic knowledge needed for coping with the standards for upper secondary school. However, the teaching that takes place does not engage the students, and there is, if at all, only a loose didactical relationship 
between the teacher and the content, on the one hand, and the students, on the other hand. Since the students have difficulties in understanding the content and the teaching offered does not succeed in engaging them, in the end, they do not get in touch with the content in a way that could be supportive of their personal and social capabilities and their opportunities for a critical and autonomous examination of the world.

\section{Concluding Remarks}

In this chapter, the focus has been on the students' role in teaching processes and, thereby, explicit attention has been paid to the group of actors that are at the very centre of all educational efforts. The students' role in teaching processes has been addressed in relation to differing learning environments in times when the answer on the questions regarding the purposes of education and educational equity often seems to be about the stipulation of coherent and measurable standards and equal opportunities for all students to achieve those standards. By approaching the students' role from an integrated perspective of pedagogy, critical curriculum theory and Didaktik, this role can be explored as embedded in the didactical relationships between teachers, content and students that constitute teaching in relation to its communicative and educational dimensions. Essentially, teaching is understood as the pedagogical act of the joint meaning-making of teachers and students regarding a certain content, which reaches beyond mere instruction, learning and measurable outcomes and in which the students' role becomes vital with regard to the students' broader educational opportunities that are either enabled or limited.

In the two different learning environments that provided the empirical examples for this chapter, the same patterns of pedagogical implications can be traced but which appear in different ways. It could be said that teaching, if its overlying purpose becomes limited to, for example, learning outcomes and the achievement of standards, has consequences for the didactical relationships between the student, the teacher and the content, and thereby also for the kind of student role that becomes possible in the classroom. If the teaching content, prescribed in the syllabi and translated into concrete teaching in different classrooms under different conditions, does not transcend itself - beyond its short-term and direct utility - and if students are not given opportunities to position themselves towards the teaching they are a part of in a truly meaningful way, then the didactical space in which the students' critical and autonomous approach to the world can flourish is critically narrowed. A too one-sided understanding of performance, in terms of the achievement of externally prescribed standards and the absence of a clear pedagogically justifiable idea of performance, risks to affect education for both high-performing and lower performing groups of students. Here, both groups of students are refused adequate opportunities to develop their capabilities of self-determination, co-determination and solidarity, which then also implies a wide range of conceivable consequences for the school's 


\section{Bettina Vogt}

democratic task. Overall, and from an equity perspective, this is particularly serious for students in low-performing classrooms, since they are not only disadvantaged with regards to their opportunities to achieve high grades in relation to prescribed performance standards and thereby to benefit from the formal chances that are related to the access to further educational tracks. On top of that, they are also refused a pedagogical classroom environment that would allow the students to take a role in their education in which their broad personal and social capabilities, as well as their academic potential, can become visible and grow. Against this background, thus, it can indeed be questioned to which extent and in which ways a performance-oriented standardisation of education that comes along with a plethora of unintended challenges for teaching and learning, and of which only a few could be outlined in this chapter, will be of help for solving the profound pedagogical and societal problématiques that characterise today's classroom realities in many different learning environments.

\section{Notes}

1 All translations in this chapter are the author's.

2 In the excerpts, pseudonyms are used and personal pronouns are replaced by neutral pronouns, for example, the teacher, the student et cetera.

3 In Sweden, the grading scale consists of six grading levels from A to F, with A being the highest grade and F standing for a not-passed grade.

\section{References}

Alexander, R. (2001). Culture and pedagogy: International comparisons in primary education. Blackwell Publishers.

Alexander, R. (2004). Still no pedagogy? Principle, pragmatism and compliance in primary education. Cambridge Journal of Education, 34(1), 7-33. doi:10.1080/0305764042000183106

Alexander, R. J. (2008). Essays on pedagogy. Routledge.

Arnot, M., \& Reay, D. (2007). A sociology of pedagogic voice: Power, inequality and pupil consultation. Discourse: Studies in the Cultural Politics of Education, 28(3), 311-325. doi:10.1080/01596300701458814

Bellmann, J., \& Waldow, F. (2012). Standards in historischer Perspektive. Zur vergessenen Vorgeschichte outputorientierter Steuerung im Bildungssystem. Zeitschrift für Pädagogik, 58(2), 139-142. https://www.pedocs.de/volltexte/ $2015 / 10545 / \mathrm{pdf} /$ ZfPaed_2_2012_Bellmann_Waldow_Standards_in_ historischer_Perspektive.pdf

Cook-Sather, A. (2006). Sound, presence, and power: "Student voice" in educational research and reform. Curriculum Inquiry, 36(4), 359-390. doi:10.1111/ j.1467-873X.2006.00363.x

Cook-Sather, A. (2020). Student voice across contexts: Fostering student agency in today's schools. Theory Into Practice, 59(2), 182-191. doi:10.1080/00405841.2 019.1705091

Doyle, W. (1992). Curriculum and pedagogy. In P. W. Jackson (Ed.), Handbook of research on curriculum: A project of the American Educational Research Association (pp. 486-516). Macmillan; Maxwell. 
Gundem, B. B., \& Hopmann, S. (Eds.). (1998). American university studies. XIV: Vol. 41. Didaktik and/or curriculum: An international dialogue. P. Lang.

Hirsh, A. (2020). When assessment is a constant companion: Students' experiences of instruction in an era of intensified assessment focus. Nordic Journal of Studies in Educational Policy, 80(2), 1-14. doi:10.1080/20020317.2020.1756192

Hopmann, S. (2007). Restrained teaching: The common core of Didaktik. European Educational Research Journal, 6(2), 109-124. doi:10.2304/eerj.2007.6.2.109

Hudson, B. (2006). Approaching educational research from the tradition of critical-constructive Didaktik. Pedagogy, Culture \& Society, 11(2), 173-187. doi:10.1080/ 14681360300200171

Hurrelmann, K. (1988). Social structure and personality development: The individual as a productive processor of reality. Cambridge University Press.

Jackson, P. W. (1991). Life in classrooms. Teachers' College Press. (Original work published 1968)

Klafki, W. (1995). Didactic analysis as the core of preparation of instruction. Journal of Curriculum Studies, 27(1), 13-30. doi:10.1080/0022027950270103

Klafki, W. (2007). Neue Studien zur Bildungstheorie und Didaktik: Zeitgemäße Allgemeinbildung und kritisch-konstruktive Didaktik [New studies on the theory of Bildung and Didaktik: Contemporary General Bildung and critical-constructive Didaktik]. Beltz.

Krogh, E., Qvortrup, A., \& Graf, S. T. (Eds.). (2021). Didaktik and curriculum in ongoing dialogue. Routledge.

Manyukhina, Y., \& Wyse, D. (2019). Learner agency and the curriculum: A critical realist perspective. The Curriculum Journal, 30(3), 223-243. doi:10.1080/0958 5176.2019 .1599973

Rucker, T. (2020). Teaching and the claim of Bildung: The view from general didactics. Studies in Philosophy and Education, 39(1), 51-69. doi:10.1007/ s11217-019-09673-0

Sundberg, D., \& Wahlström, N. (2012). Standards-based curricula in a denationalised conception of education: The case of Sweden. European Educational Research Journal, 11(3), 342-356. doi:10.2304/eerj.2012.11.3.342

Uljens, M., \& Ylimaki, R. M. (2017). Bridging educational leadership, curriculum theory and Didaktik. Springer International Publishing.

Vogt, B. (2017). Just assessment in school: A context-sensitive comparative study of pupils' conceptions in Sweden and Germany [Doctoral thesis]. Linnaeus University Press.

Vogt, B. (2021). Supportive assessment strategies as curriculum events in a performance-oriented classroom context. European Education Research Journal. Online first, 1-18. https://journals.sagepub.com/doi/10.1177/14749041211030387

Wahlström, N., \& Sundberg, D. (Eds.). (2018). Transnational curriculum standards and classroom practices: The new meaning of teaching. Routledge.

Wahlström, N., Alvunger, D., Schmidt, C., Sundberg, D., \& Vogt, B. (2019). Coding scheme for analysing classroom discourse and conceptualisations of knowledge. In Wahlström, N. (Ed.), Classroom research: Methodology, categories and coding (pp. 39-43). Linnaeus University Press.

Westbury, I., Hopmann, S., \& Riquarts, K. (Eds.). (2000). Teaching as a reflective practice: The German Didaktik tradition: Routledge. 


\title{
6 Curriculum Coherence \\ Exploring the Intended and Enacted Curriculum in Different Schools
}

\author{
Daniel Sundberg
}

In recent decades, curricula have held a central place in European and national education policy. Not least, curricula have become targets for politicians' ambitions to improve the goal attainment and results of educational systems and schools. Internationally, a policy movement has emerged around standards- and results-focused curriculum constructions, with the intention of driving the quality development of school activities and teaching towards aligning with the available international and national outcome measures and quality indicators (Desimone, 2013; Honig \& Hatch, 2004; Sundberg \& Wahlström, 2012). In this type of curriculum construction, the emphasis is placed on clear knowledge requirements ('performance standards') that can be evaluated at the individual, classroom, school and national levels. International agenda setters, such as the Organisation for Economic Co-operation and Development and the European Union, have gained increasing influence in national curriculum discourses on the structure, focus and content of curricula (Karseth \& Sivesind, 2010). However, several research studies have indicated that standards-based curriculum constructions are designed according to a linear top-down model with centrally prescribed and specified knowledge requirements that are rarely applied locally in accordance with the intentions. Several national, cultural/pedagogical and political traditions and systems, as well as local conditions, affect how the curricula are understood, interpreted and translated into different teaching practices that also accommodate tensions between different knowledge views and ideologies (Bernstein, 2000; Buchmann \& Floden, 1992; Wahlström \& Sundberg, 2018).

The idea of policy alignment has nevertheless become a guiding principle for policy-makers around the world in the past few decades to overcome the gaps between policy and practice. In this chapter, curriculum coherence, as an example of policy alignment, is examined and analysed while exploring the interplay between the intended and the locally enacted curriculum. Two general models and types of definitions are identified, theoretically discussed and empirically explored regarding how they play out in different teaching practices. The first will I refer to as a coordinative approach, in which curriculum reforms are driven by formal standardisation (i.e. a system perspective). Curriculum coherence is foremost considered in terms of linking learning materials, teacher preparation, monitoring and supervision and so forth to national curricula - which, in turn, promotes some registers of teachers' DOI: $10.4324 / 9781003218067-6$ 
teaching repertoires. In contrast, the second, what I will call an integrative approach, is related to how goals, content and knowledge requirements and assessment are consistent across intended and enacted curricula (i.e. substantial consistency). Curriculum coherence concerns, via an epistemic and content-related framing, how various institutionalised background ideas and assumptions about knowledge, learning and assessment are linked to the intended curriculum and its various elements.

In this chapter, the two main approaches to curriculum coherence are explored and investigated with the Swedish standards-based curriculum reform as an example. The Swedish curriculum follows the transnational and European policy trend in several regards, focusing on uniform and specified standards and knowledge requirements in the curriculum in order to obtain measurable results, performance and performance indicators. The design also attempts to achieve a strong linkage of the various elements in the curriculum chain: the selection of content, organisation and assessment. This means, for example, that the standards are clearly adapted to the grading criteria (Sundberg \& Wahlström, 2012). The overall purpose of this chapter is to conceptually investigate and empirically exemplify the concept of curriculum coherence, its potential explanatory values and its potential pitfalls and shortcomings. The guiding two-part question is as follows: how can curriculum coherence be understood, and how does it relate to the locally enacted curriculum in schools and classrooms in different socioeconomic and performative contexts?

\section{Aligning with Transnational Standards in Curriculum-Making}

In the past two decades, a global convergence around curricular reform talk, formal policy discourse and scripts can be observed (Anderson-Levitt, 2008). In this respect, researchers have witnessed standards-based curricula and the summative assessment of students' knowledge achievements acquiring the status of 'global education policies' that travel across nations throughout the world (Chisholm \& Leyendecker, 2008). Standards-based educational reform has advanced educational policy based on the premise that a uniform curriculum, enforced by high-stakes testing and accountability policies, is necessary to improve teaching and learning and reduce inequalities in 'educational outcomes' (Sundberg, 2019). Although proponents of standardisation claim that curriculum standards make clear what students should know across educational contexts and that standardised tests provide an objective way of measuring student learning, many educators decry standardisation, arguing that it makes very little clear, other than the fact that epistemic conformity is mandatory and that test failure will be met with negative consequences (Altinyelken, 2011). Au (2007) concludes that 'standardised test results are validated based on the assumption that they can be cross-culturally applied to different populations, thus enabling the fair and objective comparison of individuals across different contexts' (p. 39). 


\section{Daniel Sundberg}

Despite some researchers' claims to the contrary, the findings of Au's (2007) research review suggest that high-stakes tests encourage curricular alignment to the tests themselves. This alignment tends to take the form of a curricular content-narrowing to tested subjects to the detriment or exclusion of nontested subjects. The findings of the study further suggest that the structure of the knowledge itself is also changed to meet the test-based norms: content is increasingly taught in isolated pieces and is often only learned within the context of the tests themselves. Finally, in tandem with both content contraction and the fragmentation of knowledge, pedagogy is also implicated, as teachers increasingly turn to teacher-centred instruction to cover the breadth of test-required information and procedures. Au (2007) identifies three different, yet interrelated, types of curricular control associated with high-stakes testing: content, formal and pedagogic control. The formal control over knowledge content and the form the knowledge takes are also related to and associated with the control of pedagogy.

These conclusions are backed up by world society theorists, who argue that the global diffusion of common curriculum models is largely a spontaneous aspect of the development of what they describe as a 'modern world culture.' In other words, similar education policies are being adopted around the globe due to external and internal legitimation reasons - for example, complying with educational reform imperatives in the global competition on qualified workforces and investments (Meyer \& Rowan, 2006). Nevertheless, some others, such as the Globally Structured Agenda for Education, point out that the ideology of the global capitalist economy is the driving force behind globalisation, and that it has a significant structuring influence over what educational and curricular ideas spread around the world (Dale, 2005). Furthermore, Steiner-Khamsi (2014) underlines the importance of the 'politics' and 'economics' of educational borrowing and lending. Another important dimension of the debate on globalisation and the curriculum has focused on whether convergence around discourses and national curricular policies has resulted in the convergence of educational practices around the world (Anderson-Levitt, 2021; Nordin \& Sundberg, 2021). As will be further argued in the following sections, curricular ideas imported from the West (e.g. a learner-centred pedagogy) have been recontextualised and adapted in local contexts, resulting in a diverse range of understandings, interpretations and practices. Hence, convergence has often remained at a superficial level around new rituals and practices (Altinyelken, 2011; Balarin \& Benavides, 2010). Transnational curriculum convergence on the formal and intended curriculum raises questions of curriculum coherence more substantially than when considering the national and locally enacted curriculum by school leaders and teachers in schools and classrooms.

\section{What Is Curriculum Coherence?}

It is hard to argue against the self-evident fact that educational policies need to be aligned. If a new education policy (e.g. new prescribed performance 
standards) contradicts another newly introduced policy or an existing policy, then the implementation of the new policy will encounter serious setbacks. Moreover, if new policy programmes lack internal coherence, their implementation and enactment will most surely produce divergent outcomes. Therefore, the alignment of new policies with existing policies, as well as with internal elements, needs to be carefully examined, and possible conflicts and contradictions should be addressed. Additionally, in providing sufficient resources for reform implementation, curriculum reforms, beyond punctual and isolated interventions, need to have the necessary conditions (e.g. learning materials, teacher preparation, monitoring and supervision) and the enabling environments guaranteed by the state and made available for teachers and schools. This is general common sense in terms of curriculum policy alignment and the sought-after coherence in the intended and enacted curriculum.

Usually, curriculum coherence refers to the alignment of knowledge or learning standards from transnational and national expectations to local and classroom arenas in terms of the goals, content and assessment of learning practices. Most definitions concern the internal alignment between what the intended academic expectations are and what is actually taught, learned and assessed in teaching practices. However, it also includes the many elements that are present in education and teaching, such as assessment, standardised tests, textbooks, assignments, lesson plans, instructional methods and teachers' in-service programmes (Biggs, 1999). It has generally been assumed that strong curriculum coherence indicates a high pedagogical quality, where different parts of the activities (such as governance, management, organisation, competence development, systematic quality work and assessment) are linked to the curriculum and its standards.

However, there are several aspects to consider in exploring the concept of curriculum coherence, as research has shown. Previous research on the topic ranges from examining coherence at the local and district levels (Cohen, 1987) and at the institutional (Cowan et al., 2004), programme (Newmann et al., 2001) and national policy levels (Spillane \& Jennings, 1997). Furthermore, Anderson (2002) describes curriculum alignment as having a strong link between objectives and assessments, between objectives and instructional activities and materials, and between assessments and instructional activities and materials. In other words, content validity, content coverage, and the opportunity to learn are all included within the more general concept of 'curriculum alignment.'

Generally, previous research on curriculum coherence has been based on a definition that views coherence as an achievable, objective outcome - that is, the internal alignment of standards, curricula and assessment (see, for example, Biggs, 1999). This dominating perspective, what is here referred to as a coordinative approach, tends to foster the assumption that the more coordination, the better, and this calls for a strong top-down mandate. However, this framing does not cover the vertical dimension of policy intentions and enactment. Despite a range of levels and topics, the enacted curriculum 
addressing the so-called policy-practice gap or the 'implementation gap' is less researched. Some researchers have suggested that the lack of a central theory about the nature of learning and knowing in a given domain of knowledge and expertise makes it difficult to coordinate the curriculum, instruction and assessment (Pellegrino, 2006). As will be shown in this chapter, this has led to some crucial aspects of the enacted curriculum being neglected in different educational settings, including its institutional context.

Often, the attention and energy of policy-makers focus on the 'what' of a desired change, and they tend to neglect the 'how' (Rogan, 2007). Indeed, misjudging the ease of implementation is one of the most frequent mistakes in educational policy-making (Rogan, 2007). When the implementation stage has not been well planned and structured, it may result in unexpected outcomes and strong resistance to policies (Dyer, 1999). The coordinative and system-related approach to implementing curriculum reforms focuses on clear and efficient communication with the actors involved in the implementation at the regional and local levels to avoid insecurities, confusion and irregularities among local implementation actors. This can be simply called the policy-practice gap, which is based on a quite technical definition of curriculum coherence. However, if epistemic and content-related dimensions are taken into consideration, the espoused theory of alignment needs to be related to the theory in use that refers to the world view and values reflected in the behaviours that actually drive the dynamic process of the enactment and translation of curriculum frameworks into practice. An integrative approach to curriculum coherence, as explored in this chapter, raises other types of questions for the local enactment of the curriculum that involve epistemic dimensions and institutionalised background assumptions among the actors set to implement curriculum standards at various levels.

\section{Critical Aspects of Curriculum Coherence}

There is considerable research evidence which demonstrates that pedagogical practices are resilient to change, partly because pedagogy is complex and multidimensional (Buchmann \& Floden, 1992; Nordin \& Sundberg, 2021; Spillane, 1999). Various studies have also pointed to a range of issues that make the implementation of achievement standards highly difficult and challenging in diverse contexts. These issues include a range of complex cultural and systemic factors, including mismatches with lived local realities (such as understandings, teacher and learner backgrounds, identities and motivations), a lack of policy alignment between various curricular aspects, inadequate teacher preparation and supervision, backwash effects of highstakes examinations leading to 'teaching to test,' and unfavourable material conditions in schools (Schweisfurth, 2013). Furthermore, curriculum standards seem to be inaccessible to ordinary teachers and lack operational clarity; hence, they are subject to a variety of interpretations. The effectiveness of such programmes with children from disadvantaged socioeconomic 
backgrounds, as well as their appropriateness for teaching lower-order cognitive skills (especially basic literacy and numeracy skills), has been particularly questioned (Schweisfurth, 2013). The policy response to these obstacles has, to a large extent, been one of a coordinative approach to strengthen the alignment of the elements of the curriculum programme.

However, there are obvious lessons from previous research that suggest that the epistemic and normative dimensions need to be considered. Teachers' resistance to reforms and their principled resistance when they express negative feelings and reluctance to act in line with a reform are based on either a personal or a professional principle - that is, a genuine commitment to a particular normative idea and/or epistemic assumptions. This personal or professional principle may be informed by a variety of aspects, such as organisational, social-professional or cultural-ideological interests, as well as self-understanding or pedagogical knowledge. The suggestion is that reforms force teachers to rethink their professional self-understanding. This may negatively affect their task perception and job motivation. In a more positive sense, it may make them reflect on the possibility of providing good teaching. The implementation of reforms is, therefore, suggested to strongly depend on the congruency of the normative ideas in the teacher's personal interpretative framework, on the one hand, and those in the rationale underpinning the reform, on the other. This concerns curriculum coherence in an epistemic and content-related manner.

This research suggests that, often, reform failures are not due to technicalities, limited funding or implementation problems. Rather, such failures reflect the fundamental enactment contradictions that arise when (policy) solutions are borrowed from educational systems where the problem contexts are entirely different (Steiner-Khamsi, 2014). When the context is not adequately considered in education policy transfer, coordination and alignment may be accomplished at a superficial policy level, yet at the epistemic and cultural levels, contradictions prevail. Indeed, policies prescribed by the same paradigm might produce different practices when applied in different contexts. Sometimes, such differences might be so large that it would be difficult to imagine they were the result of the same global policy. Ignoring such contextual capacities might lead to unintended and unexpected consequences, and reforms aimed at improving educational quality might unintentionally undermine that quality or intensify socioeconomic inequalities (Carnoy \& Rhoten, 2002).

My argument is, therefore, that adequate attention being paid to the context and the recontextualisation of transnational curriculum standards beyond coordinative and system dimensions is crucial. To strengthen curriculum coherence in a more integrative and substantial respect, during curriculum development and implementation, the involvement of teachers and their specific school contexts is crucial. Teachers and other local actors need to be involved in the entire policy process - from formulation to evaluation, not only via formal participation but also as curriculum actors and mediators. Although teachers are widely recognised as the real driving force 


\section{Daniel Sundberg}

behind educational reforms, change agencies, be it ministry departments or development organisations, hardly act accordingly. In many cases, teachers are not or are only vaguely involved in the initiation. However, participation may not be enough since it only concerns the coordinative dimension. It is essential to acknowledge the epistemic dimension in the preparation, design, development and recontextualisation of any new curriculum proposal (Spillane, 1999; Wahlström \& Sundberg, 2018).

\section{Curriculum Coherence in the Enacted Curriculum: Two Empirical Examples}

Although global policy trends have informed reform processes in many countries, including Sweden, research on policy implementation in diverse contexts reveals that divergence at the country level persists (Wahlström \& Sundberg, 2018). The Swedish standards-based curriculum reform of 2011 was based on a strong assumption of curriculum alignment and coherence (i.e. its internal programme features). Previous research, however, has shown that the reform has been recontextualised and adapted to local contexts as different versions of the intended curriculum (Nordin \& Sundberg, 2021). Moreover, the curriculum reform, introducing specified and prescribed knowledge requirements and performance standards, has gone through a metamorphosis as a result of different understandings, interpretations and practices of the actors involved at the implementation phase, such as teachers and students. Such recontextualisation and deviations from national intentions and expectations most likely vary between schools in different achievement and socioeconomic settings. Classroom studies in Swedish schools indicate that the enacted curriculum displays different patterns in high- and low-performing classroom contexts, which makes it possible to discuss knowledge segregation between schools in terms of what knowledge is offered. The following examples were chosen from individual interviews with principals and teachers and group interviews with students over a school year in order to capture a longer series of lessons. ${ }^{1}$ The main unit of analysis consisted of various themes (cf. 'curriculum tasks'), which represent a longer sequence of lessons combined with the same content theme (e.g. sustainable development). Two schools were selected to provide contrasting examples of how curriculum coherence played out in different settings, in high- and low-performing contexts. The two examples represent different socioeconomic settings, as well as different internal pedagogical profiles, in the Swedish education system.

\section{Pine Tree School}

Pine Tree School is a lower secondary school. The school's results were within the 75th percentile, which is considered the average merit value over five years. The school is a public school with an outspoken progressive pedagogy and an aesthetic profile and is located in the centre of a medium-sized 
city. The school has about 240 students ranging from 6-16 years old (years 0-9). The school has a common pedagogical platform that they describe as enhancing aesthetic learning processes that include the intellectual, as well as emotional, aspects of learning - that is, the theory and practice of student-oriented learning. The platform emphasises that aesthetic learning processes mean that man himself creates his knowledge in social and cultural contexts. The local curriculum emphasises common thematic tasks that are cross-disciplinary and involve most subjects, covers longer periods of time and is anchored in the local community. The schoolwork is goal-oriented and not teaching-material-driven; therefore, the students have no homework.

The natural sciences teacher, Anna, interpreted state standards and benchmarks to include different objectives to be learned, which included different forms of knowledge as facts, widened understandings, ethical considerations and emotions that relate to climate change over a series of lessons, topics, tests and examinations. The theme of climate change was part of a horizontal collaboration not only between the subject teacher group but also across the social and natural sciences, as well as the practical/aesthetical subjects. The planning of the theme included the selection of different textbooks and learning materials (films, websites, documentaries, etc.) and a variety of assessment forms based on the goals, core content and relevant knowledge requirements.

The local enactment of the national knowledge standards was aligned in tests, materials, and instructional activities and assessment forms not only in a coordinative way but also in epistemic and pedagogical respects. Even in Pine Tree School, with its explicit and high-profile pedagogical platform, such active curriculum work was underway to implement the curriculum intentions based on different local conditions and where the management emphasised the importance of the curriculum also becoming part of the management and teachers' basic pedagogical view. Here, however, control was not as prominent. At Pine Tree School, it was more about achieving a kind of substantial curriculum coherence by weighing up different views on the curriculum, knowledge, teaching and learning and gradually developing a consensus so that they were interconnected:

The abilities and the central content are not a problem, but the knowledge requirements are completely catastrophic ... In language, certain things are impossible to assess.... There are a lot of conflicts in the curriculum that we must find a way to handle simply.

(Cecilia, Swedish language teacher, Pine Tree School)

This work was given priority by both the principal and the school management, according to Cecilia. Many school conferences were devoted to the school's special profile and its curriculum interpretations so that teachers interpreted the requirements in a similar way. The corresponding curriculum patterns were not found in the other case study schools, where the management of curriculum work was much more sporadic between the principal 


\section{Daniel Sundberg}

and the school. The curriculum patterns that can be identified at Pine Tree School also include horizontal curriculum coherence involving connections and relationships between and across subject boundaries that are perceived in different ways and linked to a common curriculum assignment at the school. The different subject traditions were thus not seen as completely separate but were linked to the school's curriculum system, as formulated by the principal in the following way:

It clashes with the timetable if you are to work in an interdisciplinary manner ... you have to make a fake schedule to show that they have received their subject hours, but our actual schedule is subject-integrated.... it is a system that clashes.

(Principal, Pine Tree School)

Anna also gave examples of how the school had created a subject, Life Studies (Swedish: Livskunskap), to work with curriculum goals that cut across several different subjects - for example, around the theme of sex and relations, which was coplanned by different subject teachers:

No, we also have life skills here at school, so it comes up in many different subjects ... all the time.

(Anna, science teacher, Pine Tree School)

Pine Tree School represents an example of the enacted curriculum as a goal- and process-driven curriculum - which was coordinated with national knowledge requirements or even integrated, as has been discussed, and enacted in the local pedagogical approach, as well as in teaching practices. The epistemic assumptions and dimensions in the intended curriculum were also explicated and accounted for among the professionals in local deliberations in order to develop an integrative and substantial approach to curriculum coherence.

\section{Birch Tree School}

The school's results were within the 25th percentile of the average merit value $(198 / 340)$ for five years, based on the grades in year 9. The class had 25 students, most of whom had Swedish as their mother tongue. The school is located in a sparsely populated area with farmlands and small- and medium-sized industries, as well as a large utility industry. Historically, it was a central school, and for a long time, it was the only high school in the municipality. The school has no special pedagogical profile according to themselves and is a typical traditional organisation with separate subjects and subject-based teacher teams. Less than half of the students had a foreign background (SIRIS, the national database for grades, the 2018/2019 school year). Just over two out of five students had parents with a postsecondary education (SIRIS, the 2018/2019 school year). The proportion of students 
who had achieved all the knowledge requirements for year 9 was below the national average. The principal explained that external factors, to a large degree, dictated the teaching conditions at the school:

I: Does the curriculum affect which areas you, as the principal, attach importance to in your governance of the school?

- Study days and things like that. So you get those pieces in place. National tests control, actually control, the year, and involve a lot of planning. How can we create the time for a certain part to be able to perform well in the national tests?

(Principal, Birch Tree School)

The principal, in the quote just cited, believed that external imperatives (such as national tests), rather than the internal curriculum work, govern teachers' teaching. This indicates that performance management, more than goal management, was at play. For example, in aligning with tests, the school developed some 'control stations' to screen which students/student groups needed special support outside the classroom. A two-teacher system with semi-groups was established at Birch Tree School, and the principle of physical inclusion in the same class was established. The teaching observations show that the large variety of prior knowledge among the students led to a lot of self-work, with individual help from teachers regarding relatively isolated skill training (Swedish). Sarah, the science teacher at the school, declared that the national tests involved strong control in terms of content taught in the classroom:

I try to mix things up a little. I get some inspiration from the National Agency for Education's material sometimes, from the National Agency for Education's national test, since much of that is in the call with formative assessment.

(Sarah, science teacher, Birch Tree School)

The framing of the taught curriculum was also linked to the pace of teaching - governed by keeping up with as much of the central content as possible to reach the knowledge requirements, Sarah explained. The performative pressures to meet the knowledge requirements for as many pupils as possible contributed to narrowing the curriculum content and separating the content into units that could be assessed according to the available assessment devices, most notably national tests and pretests. Cross-disciplinary thematic curriculum tasks as sustainable development goals tend to, Sarah explains, be downplayed, as they are formulated as general objectives and because there is only one knowledge requirement in physics that explicitly relates to this teaching content.

In conclusion, the local enactment of the curriculum was, to a large degree, characterised by an assessment and activity-driven curriculum, rather than the 


\section{Daniel Sundberg}

goal- and process-driven version at Pine Tree School. The example of Birch Tree School highlights a different curriculum pattern that is loosely coordinative rather than integrative or substantial in terms of how the national curriculum standards were adopted and translated into classroom instruction. This is an example of how curriculum coherence played out differently due to external conditions, such as socioeconomic and cultural factors of the school, and internal factors - such as the local curriculum-making in enacting and translating curriculum policy and standards into, for example, teachers' curriculum deliberations and common curriculum tasks, as well as teaching activities and assessment procedures in the classrooms.

\section{Conclusion}

In this chapter, I have tried to show that curriculum coherence in the implemented and taught curriculum can be an important aspect to study in order to understand differences in goal attainment in schools and achievements between schools and classes (Newmann et al., 2001; Oates, 2011; Sullanmaa et al., 2019). However, I have also identified critical aspects of current dominant framings, understandings and definitions of curriculum coherence. For curriculum alignment $t \mathrm{o}$ be substantial and not merely technical and coordinative, the conditions for an integrative approach need to be considered. The two contrasting empirical examples from two very different schools Pine Tree School and Birch Tree School - highlight how the conditions for achieving curriculum coherence for teaching and learning in schools are highly diverse. Local enactment by teachers and students is structured by not only internal working conditions and organisational concerns but also external pressures and expectations on improved performances.

The analyses indicate that three different analytical levels appear to be central in exploring integrative curriculum coherence to be more than a superficial top-down mandate for compliance. First-order curriculum coherence is about teaching in the classroom. It means that the teaching connects classroom activities to the students' lives, that teaching and evaluation correspond to the goals in an understandable way for teachers and students, and that there is a real connection between the intended curriculum, overall goals, content, and assessment and the teaching that students encounter. The example of Pine Tree School shows that first-order curriculum coherence requires that core assumptions and understandings of knowledge, teaching and learning need to be addressed. It also requires involving teachers as active curriculum makers in enacting standards and translating them into meaningful teaching practices.

Second-order curriculum coherence concerns the consistency between the local school's goals and pedagogy and what happens in the classroom. Research has demonstrated the importance of local enactment and understanding among professionals in translating intended curricula into practical pedagogy and teaching practices (Tikkanen et al., 2019). Curriculum coherence here means that the school's pedagogical ideas (local curriculum) 
and classroom activities are connected in a deliberate way - that is, not only coordinated but also interpreted, discussed and implemented collectively and collegially. This implies that the school should be able to identify and trace the central ideas in various lesson plans, course plans, themes, tests and examinations, and so forth so that the school's collective work with the curriculum has a real impact on teachers and their teaching.

Finally, third-order curriculum coberence means that there is coherence in the intended, communicated and enacted curriculum, from the practical teaching classroom context to the school and principal levels, as well as to the district and national levels. If this alignment is to be more than superficial and technical, the local enactment of the curriculum that involves epistemic dimensions and institutionalised background assumptions, knowledge views and pedagogical philosophies among the actors set to implement curriculum standards at various levels needs to be addressed. This challenges common ideas about the implementation of curriculum standards.

In conclusion, the results of this analysis suggest that there needs to be a redefinition of curriculum coherence that takes recontextualisation and local enactment in all its complexity into account. To meet the challenges of the elusive teaching gap and the increasing knowledge segregation in policy-making and teaching practices, this chapter suggests that this is still a major task ahead.

\section{Note}

1 The selection of schools was based on variation in terms of high- and lowperforming schools (five-year criteria based on the average of the merit values applied). The selection of case schools also included some variation regarding urban and rural areas, with differences in socioeconomic and ethnic backgrounds in the student composition (Wahlström, 2019).

\section{References}

Altinyelken, H. K. (2011). Teachers as curriculum mediators: A study on the implementation of social studies curriculum in Turkey. In R. V. Nata (Ed.), Progress in education (Vol. 22, pp. 83-100). Nova.

Anderson, L. (2002). Curricular alignment: A re-examination. Theory into Practice, 41(4), 55-64. doi:10.1207/s15430421tip4104_9

Anderson-Levitt, K. M. (2008). Globalization and curriculum. In F. M. Connelly, M. F. He, \& J. Phillion (Eds.), The SAGE handbook of curriculum and instruction (pp. 349-368). SAGE. doi:10.4135/9781412976572.n17

Anderson-Levitt, K. M. (2021). 21 st century skills in the United States: A late, partial and silent reform. Comparative Education, 57(1), 99-114. doi:10.1080/030500 68.2020 .1845059

Au, W. (2007). High-stakes testing and curricular control: A qualitative metasynthesis. Educational Researcher, 36(5), 258-267. doi:10.3102/0013189X07306523

Balarin, M., \& Benavides, M. (2010). Curriculum reform and the displacement of knowledge in Peruvian rural secondary schools: Exploring the unintended local 
consequences of global education policies. Compare: A Journal of Comparative and International Education, 40(3), 311-325. doi:10.1080/03057920903374440

Bernstein, B. (2000). Pedagogy, symbolic control and identity: Theory, research, critique (Rev. ed.). Rowman \& Littlefield. doi:10.2307/591755

Biggs, J. (1999). What the student does: Teaching for enhanced learning. Higher Education Research \& Development, 18(1), 57-75. doi:10.1080/0729436990180105

Buchmann, M., \& Floden, R. E. (1992). Coherence, the rebel angel. Educational Researcher, 21(9), 6-9. doi:10.3102/0013189X021009004

Carnoy, M., \& Rhoten, D. (2002). What does globalization mean for educational change? A comparative approach. Comparative Education Review, 46(1), 1-9. https://www.journals.uchicago.edu/doi/10.1086/324053

Chisholm, L., \& Leyendecker, R. (2008). Curriculum reform in post-1990 sub-Saharan Africa. International Journal of Educational Development, 28, 195-205. doi:10.1016/j.ijedudev.2007.04.003

Cohen, S.A. (1987). Instructional alignment: Searching for a magic bullet. Educational Researcher, 16, 16-37. https://www.jstor.org/stable/1175370?seq=1

Cowan, J., George, J. W., \& Pinheiro-Torres, A. (2004). Alignment of developments in higher education. Higher Education, 48, 439-459. doi:10.1023/ B:HIGH.0000046722.64326.doc

Dale, R. (2005). Globalisation, knowledge economy and comparative education. Comparative Education, 41(2), 117-149. doi:10.1080/03050060500150906

Desimone, L. (2013). Teacher and administrator responses to standards-based reform. Teachers College Record, 115, 1-53. https://eric.ed.gov/?id=EJ1020168

Dyer, C. (1999). Researching the implementation of educational policy: A backward mapping approach. Comparative Education, 35(1), 45-61. doi:10.1080/ 03050069928062

Honig, M. I., \& Hatch, T. C. (2004). Crafting coherence: How schools strategically manage multiple, external demands. Educational Researcher, 33(8), 16-30. doi:10.3102/0013189X033008016

Karseth, B., \& Sivesind, K. (2010). Conceptualising curriculum knowledge within and beyond the national context. European Journal of Education, 45, 103-120. doi:10.1111/j.1465-3435.2009.01418.x

Meyer, H., \& Rowan, B. (Eds.). (2006). The new institutionalism in education. State University of New York Press.

Newmann, F. M., Smith, B., Allensworth, E., \& Bryk, A. S. (2001). Instructional program coherence: What it is and why it should guide school improvement policy. Educational Evaluation and Policy Analysis, 23(4), 297-321. doi:10.3102/01623737023004297

Nordin, A., \& Sundberg, D. (2021) Transnational competence frameworks and national curriculum-making: The case of Sweden. Comparative Education, 57(1), 19-34. doi:10.1080/03050068.2020.1845065

Oates, T. (2011). Could do better: Using international comparisons to refine the national curriculum in England. The Curriculum Journal, 22(2), 121-150. doi:10 $.1080 / 09585176.2011 .578908$

Pellegrino, J. W. (2006). Rethinking and redesigning curriculum, instruction and assessment: What contemporary research and theory suggests. National Center on Education and the Economy. https://ncee.org/wp-content/uploads/2017/03/ Rethinking-and-Redesigning.pdf

Rogan, J. M. (2007). How much curriculum change is appropriate? Defining a zone of feasible innovation. Science Education Policy, 91(3), 439-460. doi:10.1002/ sce. 20192 
Schweisfurth, M. (2013). Learner-centred education in international perspective: Whose pedagogy for whose development? Routledge.

Spillane, J. P. (1999). External reform initiatives and teachers' efforts to reconstruct their practice: The mediating role of teachers' zones of enactment. Journal of Curriculum Studies, 31(2), 143-175. doi:10.1080/002202799183205

Spillane, J. P., \& Jennings, N. E. (1997). Aligned instructional policy and ambitious pedagogy: Exploring instructional reform from the classroom perspective. Teachers College Record, 98(3), 449-469. https://eric.ed.gov/?id=EJ549957

Steiner-Khamsi, G. (2014). Cross-national policy borrowing: Understanding reception and translation. Asia Pacific Journal of Education, 34(2), 153-167. doi:10.10 80/02188791.2013.875649

Sullanmaa, J., Pyhältö, K., Pietarinen, J., \& Soini, T. (2019). Curriculum coherence as perceived by district-level stakeholders in large-scale national curriculum reform in Finland. The Curriculum Journal, 30(3), 244-263. doi:10.1080/09585176.2 019.1607512

Sundberg, D. (2019). Three waves of education standardisation: How the curriculum changed from a matter of concern to a matter of fact. In C. E. Mølstad, \& D. Pettersson (Eds.), New practices of comparison, quantification and expertise in education: Conducting empirically based research (pp. 50-65). Routledge.

Sundberg, D., \& Wahlström, N. (2012). Standards-based curricula in a denationalised conception of education: The case of Sweden. European Educational Research Journal, 11(3), 342-356. doi:10.2304/eerj.2012.11.3.342

Tikkanen, L., Pyhältö, K., Pietarinen, J., \& Soini, T. (2019). Lessons learnt from a large-scale curriculum reform: The strategies to enhance development work and reduce reform-related stress. Journal of Educational Change, 51 (21), 543-567. doi:10.1007/s10833-019-09363-1

Wahlström, N. (Ed.). (2019). Classroom research: Methodology, categories and coding. Linneaus University Press. diva2:1361576

Wahlström, N., \& Sundberg, D. (Eds.). (2018). Transnational curriculum standards and classroom practices: The new meaning of teaching. Taylor \& Francis. 


\section{Principal Agency \\ Educational Leadership at the Intersection Between Past Experiences and Present Environments}

\section{Katarina Ståblkrantz}

Today, the issue of equality in education is one of the most pressing concerns, since increased socio-economic inequality and migration present major challenges for school leaders (Møller, 2017). From the Programme for International Student Assessment (PISA) results (NAE, 2016, 2019), we know that in Sweden, differences in performance between schools have been exacerbated and that there is a correlation between socio-economic factors and academic performance. The PISA results further indicate that students in schools with a less favourable student composition are at risk of receiving poorer education. Principals in these schools struggle to a greater extent with problems related to teacher recruitment and teachers' skills and qualifications. A messy classroom climate, truancy and late arrivals also seem to be a greater problem in these schools. Previous research (Wahlström \& Sundberg, 2018) also indicates that there is a difference in students' access to 'powerful knowledge' (Young, 2013) between low- and high-performance classrooms.

The Organisation for Economic Co-operation and Development (OECD) and the European Union (EU) have increasingly been setting the agenda for education, as well as school leadership, in policymaking (Rizvi \& Lingard, 2010; Sundberg \& Wahlström, 2012). Recent policy initiatives in the EU have led to streamlined curricula based on performance and standards (Sundberg \& Wahlström, 2012; Wahlström \& Sundberg, 2015) and to more standardisation in each country's approach to school leadership (Møller, 2009). For example, frameworks and ideas about introductory programmes and leadership development recommended by the OECD (see, e.g., Pont et al., 2008) have been integrated into national school leadership policies in Sweden, among other countries.

Successful leadership and the discourse of equity are mainly based on data from international student assessments, such as PISA and the Trends in International Mathematics and Science Study (TIMSS) (Møller, 2017), which further define the type of knowledge that is prioritised as 'powerful' (Young, 2013). Møller (2017) further argues that over the last 20 years, large-scale international research on school leadership, as well as such research cited in OECD reports, has tended to lead to decontextualised lists of best practices, what works and what school leaders should do to be considered successful 
(see, e.g., Leithwood et al., 2008; Pont et al., 2008; Robinson et al., 2009). This has influenced educational policy discussions about school leadership in Scandinavia as well, with measurements, standards and accountability being central issues, with the important aim of reducing inequality in student outcomes across social groups. School principals struggle with these 'tensions of managerial demands from the outside and their own standards for acting as professional educational leaders' (Møller, 2009, p. 176). Through the lens of principal agency, the aim of this study is to challenge the discourse in which the current policy agenda for successful school leadership and equity is embedded beyond the agenda of what works (Møller, 2017). Building on the foundational educational question posed by Biesta (2017), 'Educational leadership for what?,' the study is guided by educational questions concerning what values, knowledge and skills school leaders should lead towards. Drawing on transactional realism and an analytical framework of agency as temporal, principal agency is explored as context-dependent. The following section presents transactional realism as a theoretical framework and outlines the theme of principal agency. It then presents the analytical and methodological framework and the analytical process of the study. The next section presents the results. The chapter ends with a concluding discussion.

\section{Transactional Realism}

The transactional perspective of realism, which guided this study, is based on the theory of pragmatism. Pragmatism refers to action, and therefore to a practical engagement with the world, and allows an understanding of human interaction and communication in thoroughly practical terms (Biesta \& Burbules, 2003). According to the transactional realism approach within pragmatism, there is no gap between human beings and the world (Biesta, 2014). As humans, we are participants in an unfinished, constantly evolving universe (Garrison, 1994). From a transactional perspective, "the world" always appears as a function of what we do' (Biesta, 2014, p. 43), and as humans, we always act as part of both the physical and the social world. John Dewey's transactional realism cuts across the dichotomy of objectivism and subjectivism. For Dewey, the constitution of subject/object distinctions is treated as an act, not as a given (Rosiek, 2013). As humans, we are always 'a part of the reality we investigate and our inquiries are transactions across boundaries that have no set definition' (Rosiek, 2013, p. 695). In Dewey's view, we constantly engage with reality in our environment through incessantly ongoing transactions. Referred to as a pragmatist relational perspective, transactional realism implies that human activities can never be fully understood in isolation (Raffo \& Roth, 2020). Actions involve a movement back and forth between the actor and the environment, whereby the actor both influences and is influenced by it.

Bergh and Wahlström (2018) argue that the later works of Mead and Dewey within pragmatism, with a philosophy of action as a philosophy of time and nature, have changed our understanding of intentionality. For a 


\section{2}

pragmatist, action is not the outcome of predetermined ends, as theories of rational action hold. Setting goals for action 'can only be done in an actual context and as a result of reflection on the emerging constraints in the practical world that always precede action' (Bergh \& Wahlström, 2018, p. 137). Dewey's transactional realism can further be described as an experimental transaction, as 'a continuous reconstruction carried out to solve our problems' (Garrison, 1994, p. 8). The pragmatist theory of action analyses 'conditions of possibility' (Joas, 1993, p. 250) 'for the evaluative, experimental, and constructive dimensions of perception and action, within the contexts of social experience' (Emirbayer \& Mische, 1998, p. 968). The choice of action from many possibilities is then what gives an action its creativity.

Because human actions are not bound by predetermined ends, they are radically open, but they are also responsible (Säfström, 2012). Drawing on Joas (1993), Bergh and Wahlström (2018) emphasise that for both Dewey and Mead, action is not about making intelligence practical but about making praxis intelligent. According to Dewey (1993), intelligence is 'a method of adjustment of capacities and conditions within specific situations' (p. 73) and another name for the exercise of equality and justice. Intelligence is not a faculty or property of which we have more or less in our minds but inherently bound to public responsibility and directly connected 'with equality and justice as it is exercised in actual social contexts, which, in turn, has consequences for the democratic society and for real men and women in a social environment' (Säfström, 2012, p. 419). Every action of intelligence is thus grounded in the capacity to read the future in present ongoings, prospective and creative in its core, with an emphasis on what projects are good for (Emirbayer \& Mische, 1998).

\section{Principal Agency through the Lens of Transactional Realism}

From the perspective of transactional realism, agency is not something that people have; it is something that people do (Biesta \& Tedder, 2007). A transactional notion of the individual -for instance, a school leader - as part of a dynamic environment means that the individual's actions are not static or given and, hence, are always open to creative possibilities for transacted moments that point to change and transformation. Educational moments can be regarded here as aspects of events 'in which relational transactions jointly create the possibilities of joint new experience' (Raffo \& Roth, 2020, p. 457). In the context of school leadership, every leadership moment is a unique event characterised by the school leader and the environment. From a transactional perspective, school leaders are simultaneously affected by and affect every leadership act. From this perspective, they 'are not self-authoring per se and as agents are affected not only by external conditions but also by their own actions while these are unfolding' (Raffo \& Roth, 2020, p. 458). The transactions are further not predetermined, 'as the unpredictability of the unfolding event of schooling as a social field of transactions is a product of its interconnectedness to other social fields and transactions that 
individuals experience and bring with them' (Raffo \& Roth, 2020, p. 458). Principal agency may thus result in similar transactions (but not the same, as transactions can never be identical to previous ones).

School leaders are always socially and historically situated in contexts in which 'every present experience has a forward direction, toward the future, at the same time that it is permeated by past experiences' (Bergh \& Wahlström, 2018, p. 137). Distinguishing between different dimensions of agency, like temporal aspects of past, present and future experiences, as proposed by Emirbayer and Mische (1998), makes it possible to 'account for variability and change in actors' capacities for imaginative and critical intervention in the diverse contexts within which they act' (p. 970). Thus, drawing on temporality in transactional realism offers a broader and deeper understanding of the factors and phenomena that shape the conditions for and influence school leadership actions (Sundström Sjödin \& Wahlström, 2017).

\section{Temporal Dimensions of Principal Agency}

Dewey argued 'that reality itself should be understood in temporal terms' (Biesta \& Burbules, 2003, p. 52). To understand agency in different contexts and times, we can capture agency in its full complexity only within the flow of time (Biesta \& Tedder, 2006; Ecclestone, 2007; Emirbayer \& Mische, 1998). Emirbayer and Mische (1998) conceptualise agency in both an empirical and an analytical sense 'as a temporally constructed engagement, based on the habits, imagination and judgements of what seems best to do at the present with respect to what has been and what one wants to achieve' (Alvunger et al., 2017, p. 2). According to Emirbayer and Mische (1998), principal agency can be regarded as 'a historically variable phenomenon, embedded in changing theoretical and practical conceptions of time and action' (pp. 972-973). They locate agency primarily in the actors' orientations, suggesting that the way in which we understand our relationships with the past, future and present makes a difference to our actions. Likewise, the ways in which school leaders understand their own relationships with the past, future and present make a difference to their actions. This, in turn, means that their 'sense of agency, and possibly the way in which they (are able to) talk about their orientations towards the past, future and present - the narration of their orientations' (Biesta \& Tedder, 2006, p. 12) is an important factor in their actual agency as well.

Emirbayer and Mische (1998) argue that agency should be regarded as an analytical category in its own right, 'with distinctive theoretical dimensions and temporally variable social manifestations' (p. 963). In line with pragmatist transactional realism, they theoretically developed the concept of agency as analytically situated within the flow of time, considering it a temporally embedded process of social engagement, and made an analytical distinction between three constitutive elements: iteration, projectivity and practical evaluation. Since these aspects correspond to the different 
temporal orientations of agency, they make it possible to examine different kinds of actions and to determine whether they are more oriented towards the past, the future or the present. The iterational element of agency 'is manifested in the actors' ability to recall, select and apply more or less tacit and taken-for-granted schemas of action that they have developed through past interactions' (Biesta \& Tedder, 2006, p. 13). This dimension further refers to "the selective reactivation by actors of past patterns of thought and action, as routinely incorporated in practical activity, thereby giving stability and order to social universes and helping to sustain identities, interactions, and institutions over time' (Emirbayer \& Mische, 1998, p. 971). The practical-evaluative dimension of agency can be understood 'as the way in which actors bring their past experiences and future orientations to bear on the present situation' (Biesta \& Tedder, 2006, p. 15). In this dimension of agency, the contextualisation of social experience is in focus. As a concept, practical evaluation can be associated with different forms of activity and 'entails further the capacity of actors to make practical and normative judgments among alternative possible trajectories of action, in response to the emerging demands, dilemmas, and ambiguities of presently evolving situations' (Emirbayer \& Mische, 1998, p. 971). As a central aspect of the practical-evaluative dimension, judgement is related not only to strategic decision-making (i.e. finding the most effective and efficient means to achieve specific, predetermined ends) but also to decisions about the desirability of likely ends (Biesta \& Tedder, 2006). Finally, the projective element of agency 'encompasses the imaginative generation by actors of possible future trajectories of action, in which received structures of thought and action may be creatively reconfigured in relation to actors' hopes, fears, and desires for the future' (Emirbayer \& Mische, 1998, p. 971). Located at the critical mediating juncture between the iterational and practical-evaluative aspects of agency, the projective aspect of agency focuses on the hypothesising of experience, 'generating alternative possible responses to the problematic situations' (p. 984). Emirbayer and Mische (1998) stress that the temporal aspects of agency, in varying degrees, can always be found 'within any concrete empirical instance of action' as 'a chordal triad of agency' (p. 972). Although it is possible to make an analytical distinction between the three dimensions of agency, they are still intertwined and dependent on each other. In the iteral dimension, for example, the future and present emerge as secondary tones in the chordal triad of agency - the future through expectation and the present through manoeuvre. Emirbayer and Mische (1998) further argue that

while the temporal-relational contexts of action influence and shape agency and are (re)shaped by it in turn, the former is never so deeply intertwined with every aspect of the latter that these different analytical elements cannot be examined independently of one another. 
Table 7.1 Schools and principals

\begin{tabular}{ll}
\hline School & Principals \\
\hline Birch Tree School & Eli and Elliot \\
Larch Tree School & Nico \\
Oak Tree School & Wallis \\
Pine Tree School & Sam \\
\hline
\end{tabular}

\section{Data and Method}

This study was based on an analysis of empirical data collected through interviews. Five principals from four schools in Sweden representing lowand high-performance schools were interviewed. A semi-structured interview guide consisting of questions about teaching policies at the respective schools was used. The interviews were recorded and then transcribed. The schools and principals have been given fictitious names (Table 7.1).

The data analysis was interpretative. First, the transcribed interviews were read several times to find commonalities, variations and themes. To understand differences between individuals in similar contexts (e.g. principals in Swedish comprehensive schools), it was important to include both the contextual and temporal dimensions in the analysis. Therefore, the analytical framework of principal agency as 'a chordal triad' (Emirbayer \& Mische, 1998) was used as an analytical tool in the subsequent in-depth and structured text analysis. The analysis model was based on the transactional realist understanding of agency outlined above, and in the manifestations of the iterational, practical-evaluative and projective dimensions in the principals' narratives of school leadership and curriculum.

\section{Principal Agency and the Standards-Based Curriculum}

This section presents the principals' narratives about school leadership and curriculum. First, focus is on the iterational dimension of the three temporal phases, as the principals reflect on past personal and professional experiences. Second, focusing on the present, the principals describe their experiences of dealing with problems, dilemmas and challenges in present situations. Finally, focusing on the projective dimension of principal agency, the principals' future goals and visions are outlined.

\section{Referring to the Past: Iterational Experiences}

The principals describe different past experiences of school leadership. Working as principals at high-performing schools, Nico and Sam refer to experiences of stability in terms of both staff and students, which in turn seems to facilitate and create good conditions for curriculum alignment and student outcomes. Teachers who have worked at the same school for a long 
time know each other well and cooperate better. Since Pine Tree School was established more than twenty years ago, it has had a special pedagogic profile focusing on aesthetic learning processes and working across subjects. As a result, the teachers have worked together on the curriculum extremely intensively throughout the school's history, according to Sam. Larch Tree School and Pine Tree School have been high-performing schools for several years. According to both Nico and Sam, student stability creates good conditions and produces good results, as it offers the possibility of shaping the students from Grades 1 to 9.

At the two low-performing schools, the principals refer to past experiences of struggling to recruit qualified teachers and low expectations on the students. Although Wallis claims that the school has succeeded in recruitment and in improving teacher competence over time, there are still some teachers who are not qualified. Eli and Elliot mention that many staff members were replaced a while ago. Nevertheless, the teachers have recently started to get to know each other, collaborate more and work more across subjects and have created a more open atmosphere. At Oak Tree School, the success rate of qualification for upper secondary school in Grade 9 increased to $52 \%$, from $31 \%$ the previous year. Thus, 'we have come a long way,' says Wallis, who also claims to have stubbornly held on to the belief that everything in school should be done to benefit students' learning progress:

I've basically been doing this since I started. For a year, my mantra was to ask in every single meeting in every forum, "Does this benefit students' learning and knowledge development?" It takes a lot to hold on, even if you sometimes feel that you can no longer do it. I have to be strong and hold on.

(Wallis)

Both Elliot and Wallis refer to past experiences with a lack of trust among students' parents in their schools, and how over the years the number of school inspection reports has increased. Elliot feels that the school no longer seems to play a particularly important role:

From a broader perspective, I think I see a big difference in the importance of the school - it can certainly depend on its location, but education is not perceived as the most important thing here, even though it is located in a place with an entrepreneurial spirit.

To summarise, when reflecting on the past, the principals report quite different experiences. While Nico and Sam refer to staff and student stability that creates favourable conditions for their schools' high performance, the Birch Tree School and Oak Tree School principals experience considerable difficulty in recruiting qualified teachers and struggle with a lack of trust in the school and low expectations on the students. 


\section{Dealing with the Present: Practical-Evaluative Experiences}

This section focuses on the principals' leadership activities in present situations. Reflecting on the curriculum, the principals place slightly different emphasis on the various parts of their daily work as school leaders. According to Nico, the overall values and objectives form the basis for the entire school's work. These are used in the school's policies and action plans, 'so everything is woven together through "the school's wallpaper." For Wallis at Oak Tree School, the syllabus must always come first 'because there is a risk that if you only think about creating security, you lose the learning perspective.' Wallis feels that this may happen especially in schools with difficulties such as those that Oak Tree School faces. At Birch Tree School, the principals see the various parts of the curriculum as intertwined. 'The overall values and objectives are the basis for the school - and my mission,' says Elliot, 'and these values and goals should reflect the interaction with the students; they are the glue, the moral compass.' The syllabus is more of something that you look at and 'check off to ensure that you have included everything in planning different teaching areas,' Elliot continues. At Pine Tree School, the curriculum as a whole forms the basis for the school's 'pedagogical platform' - that is, a shared idea about what teaching should be about.

The curriculum affects the areas and activities that the principals prioritise in their daily school leadership work in different ways. An example is new legislation to be implemented, such as digitalisation. Other examples are school inspection reports and national tests. A great deal of time is spent on national tests, 'actually controlling the year and a lot of planning,' according to Eli. Sam argues that the curriculum and the school law are so comprehensive that it is impossible to focus on all those things at once and further refers to having a strategy to sort everything into three basic things to work on: quality work, equal treatment and student health. However, Sam notes that there are other things to do as well, above all as a municipal official. This part tends to swell, according to Sam, 'because I have to do it, because someone says I have to.' No one controls the work on student health, equal treatment and quality work as much as the leadership assignments from the municipality, according to Sam. Wallis notes that principals need to have courage when prioritising what to focus on in their daily work:

I know the laws, and I know where to look if I have forgotten something or if I am unsure about something. But I feel safe in it. And I know that, yes, now I know I missed this thing, but it was because I did this and this, and it was much more important to do right now.

Nico believes that it is hard to tell in what way the curriculum affects what is prioritised in the management of the school. By delegating responsibility for teaching and grading mainly to the subject teachers, Nico mainly focuses on the curriculum's overall goals and values. Achieving the right character and attitude is of utmost importance. 
The principals further reflect on different ways to approach and manage the curriculum as school leaders. At Pine Tree School, there is a course template that functions as 'a simplified checklist for all parts of the curriculum,' which the teachers can use when working across subjects to ensure that they include all parts of the curriculum. 'We created it ourselves because it is beneficial for us, not because someone says you need to document,' says Sam. This way of working places high demands on teachers and their cooperation. At Larch Tree School, a specific 'value concept' is used, including - among other things - teaching materials, posters and songs. It is 'like a copy of the curriculum,' says Nico, 'ensuring that the overall values and objectives are fulfilled.' Nico further describes rules, follow-ups and routines that ensure that the concept is worked on in the entire school. When it comes to the syllabus, there are specially appointed subject teachers who are responsible for it. The teachers are organised in academic teams, in which they share the same planning, work materials, books, tests and assignments. The subject teachers are coordinated by an academic coordinator. In the end, it is the principal who controls the academic coordinator. 'So, we usually joke about having a system where the checkers check but a checker checks the checkers,' says Nico. Thus, there are several layers of control that ensure that everybody is doing what they are expected to do, and 'in this way we have all parts of the curriculum covered,' Nico continues.

Wallis, Eli and Elliot advocate trust in the professionals:

We have to listen to the profession. It's so important. I have to assume that my teachers know what they are doing. And that they are professionals. And that they carry out their assignments in the best way for our students to achieve the goals.

(Wallis)

Even though some teachers are not qualified, the Birch Tree School and Oak Tree School principals still believe that they do an excellent job. Eli and Elliot express their happiness at having 'such good teaching staff in a place as small as this.' In the subject teams, the Oak Tree School teachers are expected to engage in a constant dialogue about how they can develop teaching according to the students' prerequisites and results. Trying to take in the outside world so that the school does not become an isolated phenomenon is also important, according to Wallis. For Wallis, the most important message as a pedagogical leader of the teachers is that everyone can have and always has high expectations of the students:

For me, it is very important. Everyone can. But there are different ways to get there. We should always offer new chances. We will work to really try different ways $[\ldots]$ All students want to succeed. 
In a similar manner, Eli and Elliot assert that their message as pedagogical leaders is that nothing is impossible. Moreover, they stress the importance of engaging the students. Eli believes that the reason for poor student results is that students find school and teaching boring. The principals want the teachers 'to think outside the box,' work across disciplines and do unexpected things. Eli and Elliot further argue that teachers need to incorporate the outside world and current events into their teaching.

The practical-evaluative dimensions of principal agency presented in this section illustrate the differences in the emphasis that the principals place on the various parts of the curriculum. Nico manages the curriculum through a refined control system, while Sam manages it by a coordination of shared values. The principals at the two low-performing schools do not describe a clear strategy for managing the curriculum. They rather advocate trust in the professionals, which to them means trusting that the teachers provide the best teaching to the students.

\section{Envisioning the Future: Projective Experiences}

This section presents the principals' visions for the future. Using the metaphor 'Mind the gap,' Nico's message to the teachers is to always prepare the students for the next step of their education. Nico is convinced that the Larch Tree School staff can always do a little better every year and go one step further by refining routines and working proactively to prepare the students for the future. Of all the things that the students will take with them when they leave Larch Tree School, the most important are high grades and good knowledge of different subjects because these are 'keys that can open doors later in life.' However, they are temporary keys, according to Nico. They open the door to upper secondary school 'and you need it as a basis for further studies, because you still have to move on.' Sam envisions students being proud not only of the knowledge they have gained upon finishing school but also of the knowledge that is available to them in the future so that they 'can choose which door they want.' Whereas Nico's and Sam's goal is to prepare the students, 'making sure that they go as far as possible,' for Wallis, the most important thing is that the Oak Tree School students can enter upper secondary school 'because we know that if the students enter upper secondary school, the probability that they succeed and secure a place in our society is much higher. We know that this is a success factor.' Therefore, Wallis emphasises the importance of always having high expectations of the students.

All principals emphasise that more than knowledge and grades are important for the future. They envision their students becoming useful members of society from both a socio-economic and a democratic perspective. Wallis, for example, wants to prepare the students for the future because it is them 'who in ten years' time will be the ones who vote and have influence.' An important thing that Nico wants to convey to the students is that hard work 
will prepare them for the next step, both academically and socially, and that a good character and attitude opens 'doors to life.'

Because you leave school with completely useless grades but find a job if you have a good character, believe in yourself, know how to take someone by the hand and have eye contact and create dialogue, keep a promise, arrive on time, be happy. If you have a good character and a good attitude towards yourself and others, you can succeed at anything, even if you do not have the grades.

(Nico)

In the future, students should be able to contribute to society. 'We should prepare them for that so that they understand its meaning - understand how they should handle their responsibilities as citizens later in life,' Nico argues. Both Elliot and Nico emphasise the importance of investing time and energy in school to get where you want. According to Eli, social skills are important for the future. However, students must also be prepared for further studies. To the question of what the Birch Tree School principals think the students should take with them when they finish school, Eli answers:

Knowledge of being a good citizen, knowledge of being able to take out a loan for your first home, but basic knowledge as well. These are also about upbringing to some extent. Knowing how to write a CV and read documents. Of course, also how to relate to others, to behave to others, rights and obligations, what is right and wrong, what is expected of you. Knowing your boundaries but also feeling freedom and self-confidence.

Elliot further emphasises the importance of critical thinking and of not being swayed by the massive flow of information. Elliot's vision is one of strong adults - of each student becoming 'an individual who stands by their opinion, who can express themselves in words, who can argue, who can use the language.' As a pedagogical leader, Sam has a vision of every student being proud of themselves, as well as their relationships with others.

In summary, using the key metaphor, the principals of the two high-performing schools express visions of offering students the keys that will open any door they want. Nico emphasises the importance of having the right character and attitude to become a good future citizen, especially in socio-economic terms. Sam highlights the importance not only of having good relationships but also of being proud of oneself, in the same way as Wallis, the Oak Tree School principal. For Wallis, however, the primary goal is to prepare students for admission to upper secondary school as a prerequisite for future life opportunities. The Birch Tree School principals convey visions of equipping students with social and practical skills for their future lives as adults, as well as for becoming critically thinking individuals. At the intersection between the iterational and practical-evaluative aspects of principal agency -namely, the projective dimension - the findings of this study indicate 
differences in the principals' visions for the future. The answer to the question of 'educational leadership for what?' - that is, what values, knowledge and skills principals should lead towards - is thus different for each principal.

\section{Concluding Discussion}

Addressing Biesta's (2017) question, 'Educational leadership for what?,' this study explored principals' temporal experiences of the Swedish curriculum based on a pragmatic transactional realism framework. Incorporating notions of temporality, this perspective of school leadership as context-dependent contributes to a broader and deeper understanding of principal agency. By analysing how experiences of the past and the present influence the principals' visions for the future, it became clear that principal agency in relation to the standards-based curriculum is different for each principal. This is in line with Emirbayer and Mische (1998), who consider the formation of future projects 'an interactive, culturally embedded process by which social actors negotiate their paths toward the future, receiving their driving impetus from the conflicts and challenges of social life' (p. 984).

When implementing the curriculum, principals make different choices, which must be viewed in the context of wider normative and ideological questions about what it is that shapes the outcomes of education (Hammersley-Fletcher \& Strain, 2011; Levin, 2008). The type of knowledge prioritised today as 'powerful' draws on a normative policy discourse based on data from international student assessments, such as PISA and TIMSS, and the question of what school leadership's direction should be is often answered in the 'language of targets, outcomes, and Key Performance Indicators' (Biesta, 2017, p. 15). The Larch Tree School principal emphasises the importance of a standardised pedagogical structure and control systems that ensure equal teaching for all students in terms of both what and how to teach. These structures also aim to provide effective teaching to prepare students to achieve good academic results, as well as 'the right' character and attitude. The Larch Tree School principal's agency indicates neoliberal assumptions about and experiences of education based on the idea that it is possible for all students to choose their own individual futures. These visions of students' futures are further based on assumptions about their future contributions to society, primarily in socio-economic terms.

Principals' priorities and actions in their daily work are heavily influenced by wider political agendas. While principals may feel authorised to make decisions according to their own visions, desires and needs, 'their agency is in reality constrained by the less visible structures and rules constructed within wider agendas which, in their turn, influence the cultural norms and practices of society and the institutions within which they operate' (Hammersley-Fletcher \& Strain, 2011, p. 876). The principals of both Larch Tree School and Pine Tree School emphasise the importance of equipping their students with the values, knowledge and skills that will enable them to go as far as possible as individuals. However, the Pine Tree School principal 
emphasises a holistic view and a democratic way of implementing the curriculum. While the curriculum is managed top-down by the Larch Tree School principal, the Pine Tree School leadership is characterised more by a coordination of the curriculum based on shared pedagogical values from a bottom-up perspective. The principal, however, describes how expectations to document and school inspection reports - among other things - constitute external pressure affecting principal agency. Academic skills are important for the Pine Tree School principal, but equally important is a sense of pride of one's relationships. The Pine Tree School principal's agency indicates visions of socially educating students to become citizens in a democratic society. Unlike Larch Tree School and Pine Tree School, the two low-performing schools lack a clear strategy for implementing the curriculum. Curriculum implementation is not part of the respective principals' agency. The principals at these schools emphasise the importance of trust in the teachers and confidence that they know what they are doing and always fulfil their duties in the best way for the students.

In terms of equity, successful school leadership draws on ideals of a standards-based curriculum that reduces variations and improves performance and outcomes. However, the findings of this study suggest that, on the contrary, principals' agency contributes to reinforcing inequalities between schools in students' access to 'powerful knowledge' (Young, 2013). Furthermore, there is a risk that standards-based political agendas, with their emphasis on outputs and a performance-oriented culture, neglect 'the development of the child as a whole human being' (Forrester, 2005, p. 284). For principals, therefore, tensions can emerge between external demands for improved performance and the daily needs of the students, as well as social and democratic endeavours.

Through principal agency, school leaders have the capacity to promote reflection on potential changes and alternative opportunities and guide their future visions of what values, knowledge and skills to lead towards, based on the intention to create a future that is different from the present and the past. Returning to intelligent action as an expression of principal agency, the framework of agency proposed by Emirbayer and Mische (1998) further delineates an 'analytical space within which reflective and morally responsible action might be said to unfold' (p. 1012). This opens up opportunities for alternative considerations of what versions of curriculum and 'powerful knowledge' students should be offered - beyond the language of performance, outcomes and standards.

\section{References}

Alvunger, D., Sundberg, D., \& Wahlström, N. (2017). Teachers matter - but how? Journal of Curriculum Studies, 49(1), 1-6. doi:10.1080/00220272.2016. 1205140

Bergh, A., \& Wahlström, N. (2018). Conflicting goals of educational action: A study of teacher agency from a transactional realism perspective. The Curriculum Journal, 29(1), 134-149. doi:10.1080/09585176.2017.1400449 
Biesta, G. (2014). Pragmatising the curriculum: Bringing knowledge back into the curriculum conversation, but via pragmatism. The Curriculum Journal, 25(1), 29-49. doi:10.1080/09585176.2013.874954

Biesta, G. (2017). Educational leadership for what? An educational examination. In D. Waite, \& I. Bogitch (Eds.), The Wiley international handbook of educational leadership (pp. 15-27). John Wiley \& Sons.

Biesta, G., \& Burbules, N. (2003). Pragmatism and educational research (Philosophy, theory, and educational research). Rowman \& Littlefield.

Biesta, G., \& Tedder, M. (2006). How is agency possible? Towards an ecological understanding of agency-as-achievement (Working paper 5). The Learning Lives Research Project.

Biesta, G., \& Tedder, M. (2007). Agency and learning in the lifecourse: Towards an ecological perspective. Studies in the Education of Adults, 39(2), 132-149. doi:10. 1080/02660830.2007.11661545

Dewey, J. (1993). Intelligence and morals. In D. Morris, \& I. Shapiro (Eds.), The political writings (pp. 66-76). Hacket Publishing.

Ecclestone, K. (2007). An identity crisis? Using concepts of 'identity', 'agency' and 'structure' in the education of adults. Studies in Education of Adults, 39(2), 121131. doi:10.1080/02660830.2007.11661544

Emirbayer, M., \& Mische, A. (1998). What is agency? The American Journal of Sociology, 103(4), 962-1023.

Forrester, G. (2005). All in a day's work: Primary teachers 'performing' and 'caring'. Gender and Education, 17(3), 271-287. doi:10.1080/09540250500145114

Garrison, J. (1994). Realism, Deweyan pragmatism, and educational research. Educational Researcher, 23(1), 5-14.

Hammersley-Fletcher, L., \& Strain, M. (2011). Power, agency and middle leadership in English primary schools. British Educational Research Journal, 37(5), 871-884.

Joas, H. (1993). Pragmatism and social theory. The University of Chicago Press.

Leithwood, K., Harris, A., \& Hopkins, D. (2008). Seven strong claims about successful school leadership. School Leadership and Management, 28(1), 27-42. doi:10.1080/13632430701800060

Levin, B. (2008). Curriculum policy and the politics of what should be learned in schools. In F. Connelly, H. Michael, F. Ming, \& J. Phillion (Eds.), The SAGE handbook of curriculum and instruction (pp. 7-24). SAGE Publications.

Møller,J.(2009).ApproachestoschoolleadershipinScandinavia. JournalofEducational Administration and History, 41(2), 165-177. doi:10.1080/00220620902808244

Møller, J. (2017). Leading education beyond what works. European Educational Research Journal, 16(4), 375-385. doi:10.1177/1474904117705487

NAE. (2016). PISA 2015. 15-åringars kunskaper $i$ naturvetenskap, läsförståelse och matematik. [PISA 2015. 15-year-olds' knowledge of science, reading and mathematics]. Skolverket [Swedish National Agency for Education]. https://www. skolverket.se $/$ getFile? file $=3725$

NAE. (2019). PISA 2018. 15-åringars kunskaper i läsförståelse, matematik och naturvetenskap. [PISA 2018. 15-year-olds' knowledge of reading, mathematics and science]. Skolverket [Swedish National Agency for Education]. https://www. skolverket.se $/$ getFile? file $=5347$

Pont, B., Nusche, D., \& Moorman, H. (2008). Improving school leadership: Vol. 1. Policy and practice. OECD Publishing.

Raffo, C., \& Roth, W.-M. (2020). Learner agency in urban schools? A pragmatic transactional approach. British Journal of Sociology of Education, 41(4), 447-461. doi:10.1080/01425692.2020.1748571 


\section{Katarina Ståhlkrantz}

Rizvi, F., \& Lingard, B. (2010). Globalizing education policy. Routledge.

Robinson, V., Hohepa, M., \& Lloyd, C. (2009). School leadership and student outcomes: Identifying what works and why: Best evidence synthesis iteration (BES). New Zealand Ministry of Education. https://www.educationcounts.govt.nz/_data/ assets/pdf_file/0015/60180/BES-Leadership-Web-updated-foreword-2015.pdf

Rosiek, J. L. (2013). Pragmatism and post-qualitative futures. International Journal of Qualitative Studies in Education, 26(6), 692-705. doi:10.1080/09518398.20 13.788758

Säfström, C. A. (2012). Intelligence for more than one: Reading Dewey as radical democrat. Philosophy of Education Archive, 2012, 418-426.

Sundberg, D., \& Wahlström, N. (2012). Standards-based curricula in a denationalised conception of education: The case of Sweden. European Educational Research Journal, 11(3), 342-356. doi:10.2304/eerj.2012.11.3.342

Sundström Sjödin, E., \& Wahlström, N. (2017). Enacted realities in teachers' experiences. Journal of Curriculum Studies, 49(1), 96-110. doi:10.1080/00220272. 2016.1205139

Wahlström, N., \& Sundberg, D. (2015). Theory-based evaluation of the curriculum Lgr 11 (Working paper 2015:11). Institute for Evaluation and Labour Market and Education Policy (IFAU).

Wahlström, N., \& Sundberg, D. (2018). Transnational curriculum standards and classroom practices: The new meaning of teaching. Routledge.

Young, M. (2013). Overcoming the crisis in curriculum theory: A knowledge-based approach. Journal of Curriculum Studies, 45(2), 101-118. doi:10.1080/002202 72.2013 .764505 


\section{Teaching Repertoires and Student Perceptions of Knowledge in High- and Low-Performance Classrooms}

\section{Daniel Alvunger}

As with many other countries, the Swedish education system is founded on principles of social equity and equal distribution of education. As the new millennium has progressed, national and international evaluations have reported declining student results, 'marketisation' and competition leading to higher differentiations between schools and students from different socio-economic backgrounds, followed by growing social inequity. Apart from reforms and resource allocation, the government has attempted to meet these challenges in 2011 by introducing new standards-based curricula that emphasises subject-disciplinary knowledge and abilities and prescribed teaching and assessment targets in the form of 'knowledge requirements' (Adolfsson \& Alvunger, 2018). Contemporary education debates on equity and social inclusion are, therefore, not only focused on macro-economic questions but are highly attentive to what happens in schools and classrooms, as well.

Classrooms may appear to be messy places yet they constitute 'a transformative space in which knowledge is created' (Hopmann, 2007, p. 120). A genuine curriculum question is what kind of knowledge is produced and formed in classrooms, but of course, this cannot be separated from other imperative questions, such as why, how, when, by whom and for whom (Deng, 2020 )? When considered from another angle, there are several aspects that influence the different ways students are granted access to knowledge that can determine their future career choices, democratic and civic participation and social inclusion. Moreover, teaching repertoires - that is, modes of communication and interactions (Alexander, 2001) - and knowledge concepts that shape classroom contexts also raise questions about teaching factors that can explain knowledge segregation and democracy and even move beyond socioeconomic factors; these questions are explored in other chapters of this book.

In this chapter, teaching repertoires and 14- to 15-year-old students' perceptions of knowledge and teaching in high- classroom and a low-performance classrooms will be analysed. To theoretically address social and discursive practices in classrooms regarding knowledge conceptions and teaching repertoires, Doyle's (1992) perspective on the involvement of teachers and students in the constitution of 'curriculum events' in the classroom is used. According to this approach, curriculum content enacted in teaching is regarded as 'text' 
authored by the teacher for a designated aim and co-authored by the students in response to their involvement and interaction; meanings are then shaped and established in a co-constructive process between students, teachers, teaching materials and the contextual setting of the classroom (Doyle, 1992; cf. Priestley et al., 2021). Teaching is the enactment of a specific pedagogic discourse with the classification of knowledge boundary classifications and the framing of teacher-student interactions as interrelated modes in what Bernstein (2000) called pedagogic recontextualisation; when describing this concept, Bernstein referred to the underlying principles and rules that comprise pedagogic practice and regulate pedagogic communication. Recontextualisation primarily concerns the translation and justification of societal values, power relations, the transmission of knowledge - in other words, the how of teaching - and the knowledge and skills that are selected, produced and re-produced - or the what and the content of teaching; it is a process of 'meaning-making' and recasting concepts to generate new meanings in pedagogic practice by repositioning and relocating discourse.

The question as to what knowledge is considered to be the most valuable is closely related to democracy and life choices. During recent decades, social-realist scholars like Young and Muller (2015) have been influential voices in debates on what constitutes and distinguishes 'powerful knowledge' from other forms of knowledge - for example, social and everyday knowledge - and claim that access to such knowledge is a matter of social inclusion (Muller \& Young, 2019). Furthermore, social realists argue that specialised disciplinary knowledge is 'powerful' when it is generalisable and 'provides reliable explanations or new ways of thinking about the world' (p. 110).

In an attempt to move 'beyond social realism,' Deng (2020) has discussed powerful knowledge by integrating Schwab's ideas related to 'practical curriculum,' liberal education and the northern European tradition Bildung-centred didactics - the focus of which is on the triad of learner, teacher and content (Klette, 2007). A topical question is the manner in which students should develop knowledge and self-formation; through critical reflection, students can transform content into many different meanings (Hopmann, 2007). Deng (2020) emphasises the importance of disciplinary knowledge as a means, not as an end in itself; as it relates to the creation of agentic and educated individuals, educators should ask themselves: 'What are the intellectual, moral, social, civic, aesthetic, technological and (even) physical powers such an educated person needs to possess' (p. 93)?

By drawing from the perspective of the co-construction of curriculum events and the concept of recontextualisation, this chapter explores teaching repertoires and students' perceptions of knowledge based on empirical data retrieved from students and teachers in natural sciences and Swedish classes in high- and low-performance secondary school classrooms. Rather than taking a stand and defining what form of knowledge should be regarded as powerful, an exploratory approach will be utilised and this query will be treated as an empirical, open question, the answers for which will be based on the students' conceptions of knowledge. 
In the first section of the chapter, which rests on analyses from classroom observations and interviews with teachers, a contextual description of the different classrooms and teaching repertoires will be presented, guided by the following questions: What are dominating teaching repertoires in the classrooms? How are the classes described by their teachers? The second section focuses on student perceptions of knowledge, specifically, conceptions of knowledge that emerge from the student discussions about teaching. In the final section of the chapter, implications of the dominating teaching repertoires will be evaluated and discussed in terms of the students' access to knowledge, according to the general observations and conclusions of the study.

\section{Knowledge Standards on the Agenda: 2011 Swedish Curriculum for Compulsory Schooling}

In 2011, Sweden introduced compulsory-school curriculum with standardised aims and goals, specified criteria related to prescribed content and abilities (i.e. competences) and 'knowledge requirements' for assessments in each school subject; this necessitated a shift from a learner-centred, competence-based, highly autonomous curriculum with over-arching aims and goals dating back to 1994 (Nordin \& Sundberg, 2016). While many European countries introduced competence-based curricula, Sweden followed a path towards subject-based curricula and explicit standards (Alvunger et al., 2021 ); in doing so, the country displayed a 'combination of a neo-conservative curriculum tradition (the subject tradition) and a technical-instrumental curriculum ideology' (Sundberg \& Wahlström, 2012, p. 352). Despite the emphasis on disciplinary boundaries between subjects, there is an interdisciplinary dimension wherein teachers combine and 'patch' content together between curriculum areas to deal with content crowding and time pressure (Adolfsson \& Alvunger, 2018); this move towards interdisciplinary knowledge areas and collaboration in teaching can be seen as a way for teachers to achieve agency (Alvunger, 2018).

The 2011 curriculum included overall objectives and syllabi for the school subjects that included the aims, core content and knowledge requirements. The core content was divided into topical areas of study, and combined with abilities, which can be equated with competences students must acquire. Core content consists of facts (i.e. events, processes and names) and concepts (i.e. ideologies, historical periods, subject-specific terms, physical laws, axioms and procedural terms). Abilities can be categorised as analytical, meta-cognitive, communicative, procedural and conceptual; their principal structure is verbs - for example, name, describe, comprehend, apply, analyse, compare and discuss content - and descriptive attributes in a taxonomic structure - such as basic, nuanced, elaborated and advanced - to describe progress and increasing complexity. Grading is performed on a scale ranging from A (i.e. the highest grade) to E, which are awarded to a student who has passed, while an $\mathrm{F}$ grade indicates the student failed (National Agency for Education, 2011). 


\section{Empirical Material and Methodological Considerations}

This study draws from empirical data of one high-performing class and one low-performing class and offers a close qualitative description and analysis of each of the classes as significant cases. To protect the identities of teachers and students, the classes will be referred to as the Birch tree class (BTC) and the Larch tree class (LTC); the different contexts and characteristics of each class are presented in Table 8.1:

The methodological design of this study is based on a mixed-methods approach (Cresswell, 2010) in which quantitative and qualitative data were collected and sampled to obtain different-but-complementary types of data for the same phenomenon. Each class was studied throughout a full school year, thereby yielding 16 video-recorded lessons with participatory observation and field notes in the Swedish (i.e. eight lessons) and the natural sciences (i.e. eight lessons) classes; Table 8.2 delineates the curriculum areas included in these lessons.

The video-recorded lessons $(n=32)$ were categorised according to a coding scheme to identify teaching repertoires and the sub-categories thereof. Each teaching repertoire was time-logged; the coding scheme distinguished between main elements of the lesson divided into sub-categories, which facilitated a detailed analysis within each teaching repertoire (Wahlström et al., 2019). Table 8.3 specifies and describes the dominant teaching repertoires, which were the focus of this study.

Table 8.1 Description of classes and contextual information about schools

\begin{tabular}{|c|c|}
\hline The Birch tree class & The Larch tree class \\
\hline $\begin{array}{l}\text { Context: Secondary school located in } \\
\text { a small-sized municipality in a rural } \\
\text { area; relatively small public sector; } \\
\text { main employment industry, small- and } \\
\text { medium-sized enterprises. }\end{array}$ & $\begin{array}{l}\text { Context: Secondary school with an } \\
\text { international profile located in an } \\
\text { urban area outside a large-sized } \\
\text { municipality; substantial public sector; } \\
\text { large industries and commerce and } \\
\text { trade companies. }\end{array}$ \\
\hline Size: 25 students & Size: 29 students \\
\hline $\begin{array}{l}\text { Cultural background: Less than half of } \\
\text { the students have a background other } \\
\text { than Swedish. }\end{array}$ & $\begin{array}{l}\text { Cultural background: More than half of } \\
\text { the students have a background other } \\
\text { than Swedish; half of these students } \\
\text { study Swedish as a second language. }\end{array}$ \\
\hline $\begin{array}{l}\text { Parents' education: Approximately two } \\
\text { out of five students have parents with } \\
\text { a tertiary education. }\end{array}$ & $\begin{array}{l}\text { Parents' education: More than half } \\
\text { of the students have parents with a } \\
\text { tertiary education. }\end{array}$ \\
\hline $\begin{array}{l}\text { Student achievement over past five years: } \\
\text { Results based on grades in Year } 9 \text { are } \\
\text { within the } 25 \text { th percentile. }\end{array}$ & $\begin{array}{l}\text { Student achievement over past five years: } \\
\text { Results based on grades in Year } 9 \text { are } \\
\text { within the } 75 \text { th percentile. }\end{array}$ \\
\hline $\begin{array}{l}\text { Attainment of all knowledge } \\
\text { requirements in Year 9: Proportion of } \\
\text { student attainment below the national } \\
\text { average. }\end{array}$ & $\begin{array}{l}\text { Attainment of knowledge requirements } \\
\text { in Year 9: Proportion of student } \\
\text { attainment above the national average }\end{array}$ \\
\hline
\end{tabular}


Table 8.2 Curriculum areas included in study

\begin{tabular}{|c|c|}
\hline Natural sciences & Swedish \\
\hline $\begin{array}{ll}\text { - } & \text { Electromagnetism } \\
\text { - } & \text { Pressure and power } \\
\text { - } & \text { Optics and light } \\
\text { - } & \text { Human biology, body and health } \\
\text { Sound and waves }\end{array}$ & $\begin{array}{l}\text { - History of literature: the Renaissance, } \\
\text { Enlightenment and Romantic } \\
\text { movements } \\
\text { - Poetry and literature analysis } \\
\text { - Source criticism and references } \\
\text { Text genres: news coverage, editorials } \\
\text { and chronicles }\end{array}$ \\
\hline
\end{tabular}

Table 8.3 Coding scheme for elements of lesson elements and teaching repertoires in classroom discourse

\begin{tabular}{|c|c|}
\hline Main element & Teaching repertoire \\
\hline $\begin{array}{l}\text { Elements in which } \\
\text { the teacher is the } \\
\text { central actor }\end{array}$ & $\begin{array}{l}\text { Monologue: lecture, narration, showing a movie, reading } \\
\text { aloud } \\
\text { Recitation: question-answer sequences as part of } \\
\text { monologue, systematic use of questions to explore } \\
\text { students' knowledge and/or gain new knowledge } \\
\text { Dialogue: whole-class conversation in which the teacher } \\
\text { aims to develop and use the students' knowledge for } \\
\text { educational purposes } \\
\text { Discussion: entire class engages in sequence of open } \\
\text { questions; students participate with comments } \\
\text { Rote: question-answer sequence, asking questions from } \\
\text { example homework, focus on getting specific facts from } \\
\text { teacher } \\
\text { Instruction: on tasks, projects, grouping; instructions } \\
\text { on board/whiteboard for how students should write; } \\
\text { commenting behaviour; general information from the } \\
\text { teacher } \\
\text { Lesson gaps: as an example, someone coming to class to } \\
\text { provide general information, waiting for students to sit } \\
\text { down, for the class to be quiet or for students to leave }\end{array}$ \\
\hline $\begin{array}{l}\text { Element in which } \\
\text { the students are } \\
\text { central actors }\end{array}$ & $\begin{array}{l}\text { Pair/group work: discussion as a free exchange of ideas } \\
\text { based on given theme, tasks presented to class, task- } \\
\text { controlled work, project-oriented group work with } \\
\text { relatively freely formulated content }\end{array}$ \\
\hline $\begin{array}{l}\text { Individual work as } \\
\text { a clear element of } \\
\text { teaching }\end{array}$ & $\begin{array}{l}\text { Individual work: individually conducted writing, reading } \\
\text { or searching for information tasks; or individual } \\
\text { work organised as working in pairs in which tasks are } \\
\text { individually reported }\end{array}$ \\
\hline
\end{tabular}

Adapted from Wahlström et al. (2019, pp. 41-42)

On different occasions during the school year, interviews $(n=16)$ were conducted with teachers of the aforementioned subjects, and additional information was collected to clarify how the different classes were described by their respective teachers. These interviews also provided information as to how teachers viewed the structure of and student activity during their lessons. 
Data used to analyse knowledge conceptions from the students' discussion about teaching were collected through semi-structured focus group interviews $(n=16)$ of $3-4$ students related to the lesson, knowledge in the curriculum and teaching; this process provided ample opportunities to capture the students' views on the subject matter. Interviews were conducted with an interview guide that included questions on lesson content, the connection thereof to knowledge in the curriculum, organisation of the teaching, assessment practices, interactions and activities during class; follow-up questions were asked during the interviews that allowed further investigation into what the students regarded as worthwhile knowledge.

\section{Data Analysis}

Based on the coded lesson transcripts and time logs, the time spent on each teaching repertoire was calculated and divided with the total time for teaching; the results were formatted into a diagram to illustrate the percentage proportion of teaching repertoires in classroom discourse. When combined with the teachers' descriptions, this quantitative data provided information to analyse dominant teaching repertoires and accurately present the contextual conditions in the classrooms.

The initial step of the analysis of the student interview material was to develop an overview of characteristic themes for the students' expressed views on the teaching and their different conceptions of knowledge. In line with the exploratory approach, the reading was inspired by the open, thematic coding delineated by Braun and Clarke (2006), who stressed the importance of not becoming limited to the early observed categories but rather being flexible and sensitive to reorganise and retest the original categories against the empirical material. Throughout this iterative process, specific themes related to how the students conceived and valued subject matter content emerged, and a direct focus was given to these motifs.

While the question of what knowledge the students regarded as worthwhile and 'powerful' remained open and empirical, it was still necessary to relate the identified topics to an analytical framework. In the next step, the key themes were analysed from three knowledge conceptions to understand the curriculum content developed by Deng and Luke (2008; cf. Deng, 2020):

- A theoretical/disciplinary knowledge conception: This conception rests upon formal and propositional knowledge about the world that is distinctly framed within the academic and intellectual community, 'conceived as a corpus of facts, concepts and ideas that have been formulated and verified through the logical and discursive procedures of discourse communities' (Deng, 2020, p. 15). There is the notion of a knowledge hierarchy - from specific and detailed to more advanced, abstract and generalised levels - which determines the structure and composition of the curriculum. 
- A practical conception of knowledge: According to Deng and Luke (2008), this conception embraces actions and practices to solve practical and societal problems and encourages the ability to make sound social and ethical judgments, to make choices and take actions, to deliberate on decisions and to develop meta-cognitive strategies. In this context, 'practical' refers to everyday tasks (i.e. riding a bike), procedural skills and mastery of a specific technique or complex actions, such as reading. Furthermore, this conception includes students' ability to handle contingencies and contextual conditions and make wise choices and decisions.

- An experiential conception of knowledge: At the heart of this conception is the understanding that knowledge cannot be separated from human experience; as such, 'knowledge and ideas emerge only from situations in which the learners have to draw them out of experiences that have meaning and importance to them' (Deng, 2020, p. 15). Knowledge is therefore social and is created in the transaction between the subject and the outer world; it is about meaning-making and how the actor experiences phenomena and their relations to other actors. (Deng \& Luke, 2008).

Drawing from these three conceptions of knowledge will not only provide a frame to analyse the students' perceptions of knowledge but also facilitate a discussion of the implications thereof as they relate to the students' access to knowledge.

\section{Meet the Larch Tree and Birch Tree Classes}

The BTC and LTC classrooms are described in this section based on an analysis of the dominant teaching repertoires and views expressed by the teachers in each context. The percental proportion of each teaching repertoire in each classroom are presented in Figures 8.1 and 8.2; the dark grey columns represent elements with the teacher as the central actor, the black columns indicate elements with students as the central actors, and the light grey columns illustrate the lesson gaps.

At first glance, the proportion of 'recitation,' 'rote' and 'instruction' between the classes is similar. In the LTC, however, 'monologue' stands out, because it represents one-quarter of the lesson time; this suggests that the teachers generally valued and were confident enough to present content in the form of lectures, which is supported by observing the recorded lessons. The classroom could be characterised as focused and disciplined; the teachers were not interrupted, and there was no disturbing behaviour. In the interviews, the teachers described their students as motivated and stated that the structured organisation of their teaching was due to their awareness of different students' needs:

A-kids [high-performance students] will pull out the knowledge. [...] They will pull it out in a test. The kids who retain knowledge like this, 


\section{Daniel Alvunger}

that's good for them. [...] The low-ability kids need the reassurance I give them $[\ldots]$ kids on the autism spectrum need this structure.

(Interview 1, LTC natural sciences teacher)

Regardless of the students' challenges and special needs, the LTC teachers reportedly focused on content and performance. This can be contrasted to how the BTC teachers described their students; in this classroom, the struggle lies in motivating students and ensuring that basic teaching preconditions are in place:

The most important thing to understand with this student group is that when they participate in the lessons, and they bring [everything they need], they can achieve the knowledge requirements. I understand many students here identify themselves with an F [failing grade] and, you know, I'm not sure if they think it's cool. Sometimes, students just abandon the lesson before it's finished, but if they behave, they will at least have an E-grade.

(Interview 1, BTC natural sciences teacher)

The BTC teachers must contend with problematic attitudes among students and a collective sense of being low achievers. In one of the interviews, the BTC natural sciences teacher remembered a group of girls who acted as if they did not know how to multiply, even though the teacher knew they could; a similar example was given by the teacher in Swedish regarding some of the boys in class, who said they were unable to read a brief instructional text.

In relation to the teachers of the LTC, the BTC teachers spent more time trying to maintain the students' focus; this might explain the slightly higher percentage of the use of 'recitation' as a teaching repertoire, wherein the teacher uses question-and-answer sequences to interact with the class, and in this respect, maintains order by initiating question and offering feedback on student responses. Even though 'dialogue/discussion' was only utilised for $2 \%$ of the time, this is a whole-class activity, which was not recorded at all in the LTC, as shown in Figure 8.1.

The difference between activity organisation in the classrooms becomes evident when attention is turned to the black columns in Figures 8.1 and 8.2 , which depict the respective proportions of 'group work' and 'individual work' in each classroom. Group work was significantly more common in the BTC (22\%) than in the LTC (9\%); even though the LTC surpassed the BTC in their proportion of individual work (33\%), the BTC used this teaching repertoire $25 \%$ of the total lesson time. The combined amount of group and individual work for the BTC (47\%) would seem to refute the previous assertion that these teachers expended significant effort to maintain discipline in the class; the following quote from the BTC teacher in Swedish reveals that group and individual work also helps students to focus and that working together with peers helps to motivate students, or to at least keep them calm: 


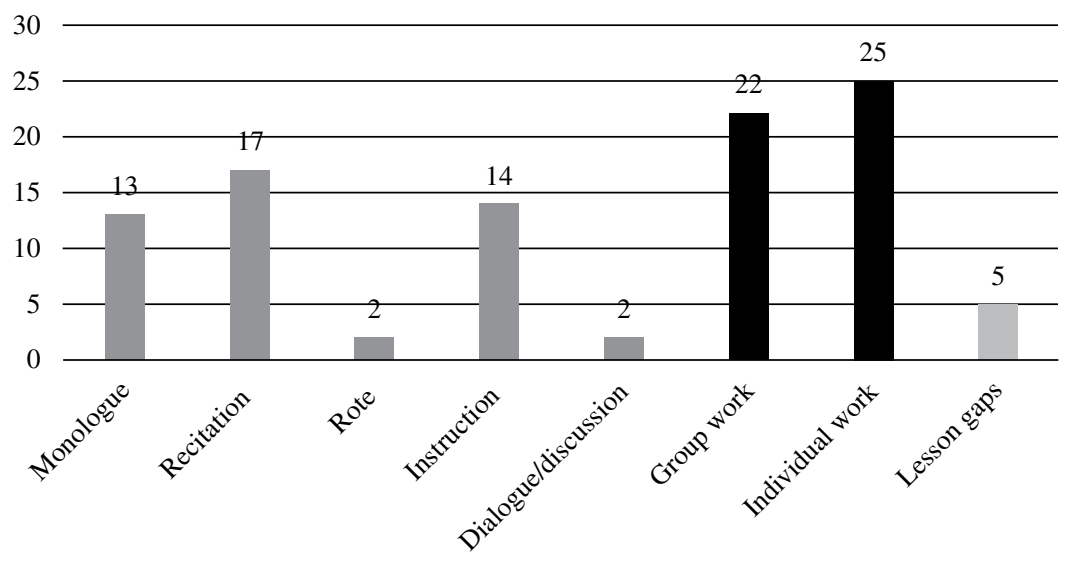

Figure 8.1 Birch tree class: Teaching repertoires (\%)

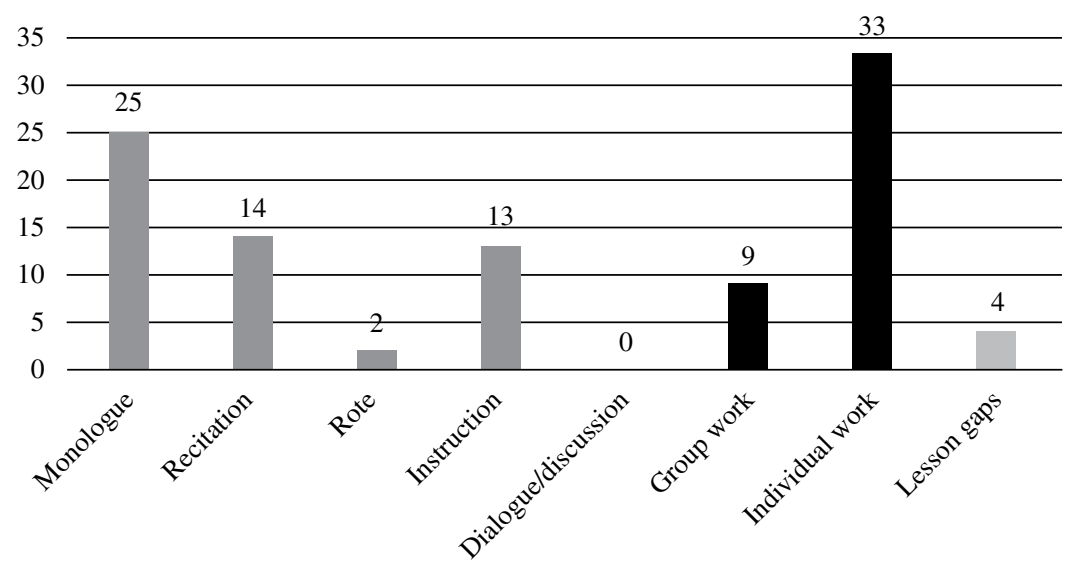

Figure 8.2 Larch tree class: Teaching repertoires (\%)

We have noticed that [students] become calmer when we divide the class in two, [so] during individual work, we split them up. They are many [students who] need help and support; in the full class, there are a lot of noises and disturbances, [and] many [students] move around. There is somewhat of an anti-study culture, so it works to create smaller groups.

(Interview 1, BTC teacher in Swedish)

Interestingly, the teachers in both classes referred to a special 'culture' or mood in their classrooms. While the BTC teachers struggled to engage their students and to help them to understand the importance of learning, 


\section{Daniel Alvunger}

the LTC teachers faced a different challenge behind the façade of motivation and discipline: a competitive and results-oriented attitude among their students:

[There is a stronger] focus on grades instead of knowledge and learning [...] It's in the walls, somehow-the culture of the school - the students are very focussed on their grades. I know that in this class in particular, they compare themselves with each other a lot.

(Interview 7, LTC teacher in Swedish)

While there is not a connection between 'individual work' as a dominant teaching repertoire and the individualist 'mindset' and atmosphere of competition reported by the LTC teachers, this is still an interesting aspect of this classroom context, and the observed characteristic features of the BTC and the LTC are important to consider as this text now turns to the students' thoughts and ideas related to knowledge.

\section{Hievarchy of Knowledge: Moving Up and Down the 'Progression Steps'}

A recurring theme when students discussed knowledge was the notion of knowledge as being theoretical, abstract and hierarchically structured. An emphasis on the importance of school-subject-specific content (i.e. facts and concepts) and competencies (i.e. abilities) was discerned, and these were significantly framed within the context of knowledge requirements. As such, the curriculum standards seemed to have a clear influence on the students' conceptions of what they regarded as legitimate and important knowledge.

The students exemplified content knowledge by utilising disciplinary vocabulary, or 'science words': 'You are supposed to know these words. Instead of "air", you say "oxygen", [and] when you refer to "water", you say " $\mathrm{H}_{2} \mathrm{O}$ " instead. So, you make sure to use those in the test' (Interview 7, LTC natural sciences students). The reference to the 'test' was illustrative of how students perceived knowledge and assessment standards as being closely related; a similar view was expressed in one of the interviews with the BTC students. In this context, using concepts from a disciplinary discourse was equated to applying 'smart' phrasings, explaining and developing the meanings of concepts and reasoning about them:

WILSON: Explain so others can understand: You use smart words, like 'cylinder'. I don't know any other way to explain it.

JUDITH: Subject-related concepts and such. WILSON: That's what I meant.

ALEX: And at the same time develop and show what it means and stuff. SANDRA: You explain more. 
JUDITH: You explain, like, in a detailed way.

SANDRA: Like, someone who does not know this should be able to understand.

ALEX: You describe pros and cons.

(Interview 4, BTC natural sciences students)

The BTC students presented several examples of how facts and concepts combined with the students' abilities - which is a 'practical' conception of knowledge - is part of a hierarchical knowledge structure. An interesting observation was the students' tendency to conflate the theoretical and hierarchical conceptions of disciplinary knowledge content with a results- and assessment-oriented discourse. To a great extent, this relationship is in the knowledge requirements, but the manner in which it has made its way into the making of curricula in classrooms is worth noting. The LTC students, for example, discussed 'the progression steps' and referred to knowledge requirements and grades; every step represents what is considered to be a higher and more complex knowledge structure, which is in turn associated with a specific grade. In one of the interviews, the students explained how the progression steps work:

MARY: [The teacher] usually says for a $\mathrm{C}$, you need a two-step answer, and for an A, [you need] a three-step answer. In a two-step answer, you mention two facts, then explain [them] in another sentence, $[\ldots]$ while three-step answers are generally facts-you explain the facts and then [state] what they lead to.

GEORGE: Consequences.

INTERVIEWER: Aha! Consequences as well?

GEORGE: Mmm.

SOPHIE: Yeah, and for an E, [you only need] to give an example.

(Interview 4, BTC natural sciences students)

In the preceding section, one of the LTC teachers described the competitive culture in the class and the focus on grades, rather than on 'knowledge and learning.' The excerpt cited earlier suggests that this 'obsession' with grades cannot solely be ascribed to the students but is actually a result of the joint authoring of curriculum events; the teachers and students co-constructed the assessment discourse. This is exemplified in the following excerpt, wherein two LTC students appraised the teacher for helping the students understand the progression steps:

ROGER: I like when she shows student examples-other students who did this assignment last year. And then you are, like, supposed to say what grade they got, so you just about know the criteria for how to write.

INTERVIEWER: Are there different examples for different grades? 


\section{Daniel Alvunger}

BENSON: Yes, and we used to read what [the previous students] had written, and we marked them with different grades. This way, we could, you know, figure it out before we got to know the actual grade.

ROGER: That way, you can also learn what to write and how to write to earn a certain grade. That is pretty good, 'cause then you can kinda think about how you should write.

(Interview 8, LTC Swedish, students)

The notion of knowledge as high-order theoretical and abstract concepts and the connection thereof to assessment criteria is also related to procedural aspects, such as performing certain tasks and solving practical problems, and high-order abilities like critical and creative thinking, cooperation and learning how to learn; these abilities constitute a hierarchical knowledge structure that includes the students' transversal and integrative characters as components of the knowledge requirements, which, in brief, results in the potential for certain capabilities that transcend subject-disciplinary contexts.

When explaining these skills, the BTC students showed that they were well aware of how their competency in Swedish would assist their work in other academic subjects. Interestingly, the BTC students referred to different signs posted on the classroom walls with questions like 'What?,' 'Who?,' 'When?' 'Why?' 'For what?' and advice on abilities, which were intended to provide guidance as to how the students should think when they read and analyse texts (i.e. information evaluation) and to remind them to ask questions and think critically. As components of a hierarchical knowledge structure, these skills promote students' ability to think both within a subject and across different subjects; the following quote is an example of this:

You must explain causes and effects [and] arguments. You must be able to reason, stick to the golden thread, see contexts. In Swedish [class], you learn what to do in other subjects and how to explain what, when and how. What we learn in Swedish [class] can be used to explain things in the natural sciences and the social sciences, [because] we learn how to talk and argue.

(Interview 2, BTC, Swedish, students)

In this way, the procedural knowledge and competences students experience and perceive as being important can serve as a kind of 'tool kit' for disciplinary boundary-crossing and epistemic transactions to explore new meanings in school-subject knowledge.

\section{Learning for Life and Future Studies}

Even though the curriculum standards seemed to have a significant influence on the manner in which students expressed what they considered to be important knowledge, there were other emergent themes concerning the societal, civic and democratic aspects of knowledge. In this respect, 
the students valued knowledge because of the way it helped them to create meaning out of their own experiences, enabled them to handle societal or everyday issues, encouraged them to take part in society as active citizens and allowed them to pursue future goals.

In the interviews, both the BTC and the LTC students provided examples of knowledge they characterised as being 'good to know' in life; this educational knowledge facilitated their personal development and increased their empathy. In an interview conducted after a natural sciences lesson that focused on the human biology, body and health curriculum area, the LTC students agreed that knowing about the endocrine system's functions was very helpful when they wanted to better understand what happens in moments of stress and fear, such as when they made presentations in front of other people: According to the students, talking about hormones - and especially what adrenaline does to your body - was important because, 'we need to learn more about why we react the way we do' (Interview 3, LTC natural sciences students). The students also claimed that this knowledge helped them to better understand the importance of being supportive towards one another in such situations.

Similar arguments related to knowledge the BTC students considered to be useful to properly understand phenomena in the world were raised in their interviews. They felt it was very important to learn about the ecosystem and photosynthesis to fully understand the manner in which humans can care for the environment and work towards sustainable development.

One of the few examples of students expressing an experiential knowledge conception occurred when the BTC students were discussing a natural sciences laboratory exercise in the 'optics and light' curriculum area: During this lesson, the students worked with laser lights and concave and convex lenses to document how the light is reflected and/or refracted. Many of the students were interested in cars and vehicles, and they appreciated learning how different kinds of rear- and side-view mirrors work, in addition to learning how cameras work; the content became tangible to them when the teacher appealed to their experiences and their specific social and cultural contexts. Another example of these students relating to an experiential knowledge conception as part of a curriculum event transpired when they described how the teacher in Swedish typically commenced a new curriculum area. The students created a mind map to give their teacher an idea of what they already knew, and from this mind map, the teacher was able to identify potential gaps and adequately expand upon the subject.

In the previous section, the students debated the value of practical knowledge, both in terms of procedural skills and high-order abilities, that is needed for different school subjects. Many of the students believed they needed to acquire specific competences for their future studies or abilities that would be required of them, both as citizens and when they were adults. They also expressed an understanding of learning knowledge for its own sake and for unexpected situations: 
I think it is important to know a little about everything, because I don't think we'll use everything [in our everyday life] when we get older. [Even] if we do not want to become, like, an expert in mathematics or a maths teacher [...] it is still good to know [this information, because] there might come a time when we will need to know it.

(Interview 6 LTC natural sciences students)

An interesting observation was that the students tended to emphasise the societal and relational aspects of knowledge as being closely related to what they regarded as worthwhile and important in life. The teachers' commitment to their chosen subject and their willingness to engage in the wellbeing, success and future prospects of their students proved to be a key feature:

[The 'good' teachers] are more interested in the subject [they teach]. They tell us we must know this for our future education, so we will be able to study at the upper-secondary-school [level] and to get a job; in some subjects, [however,] they do not mention this at all. The [good teachers] want us to get high grades, and they help us develop our answers and ability to reason. They want us to improve our critical thinking, so we can understand information evaluation.

(Interview 8, BTC, Swedish, students)

Based on the quote just cited, students appreciated when the subject knowledge and associated abilities were related to their future plans. It was also obvious that they understood the importance of learning certain abilities that went beyond the scope of school and the importance of grades. In addition to information evaluation and critical thinking, the students stated that being able to read and write different types of text was important for them to be able to participate in conversations related to various societal matters. In the following excerpt, the LTC students explained why it was important to know about news coverage as a text genre:

VERA: I imagine it's valuable to be able to recognise different types of text, so we can recognise news coverage in the future. That's, you know, $[\ldots]$ what they want with a news coverage-why they do it.

BETTY: We're surrounded by the media all the time, [which is why] it's important to know whether it's news coverage or an article, and why they wrote it that way.

CINDY: We will encounter lots of news coverages ahead.

(Interview 6, LTC, Swedish, students)

The students considered being media-literate as a significant aspect of being a member of society. In the interviews, the students often emphasised practical uses for the abilities they learned in Swedish class; in this context, curriculum events concerning meta-cognitive and analytical skills were associated with future democratic and civic participation. Teaching critical literacy was 
considered meaningful when it was directed at society and the students' experiences; in this way, knowledge became a means for the students to change their respective situations: 'If you become discontent with something and want to write to the authorities or a newspaper or such, you need to know how to write to make your point' (Interview 3, LTC, Swedish, students).

There were also students who displayed negative or 'rebellious' attitudes towards school and critically questioned the importance of certain knowledge areas. This challenging attitude surfaced more often in interviews with the BTC students and bolstered the teachers' impressions that there was an 'anti-study culture' in this classroom. In the following excerpt, some students were discussing a natural sciences lesson in the 'electromagnetism' curriculum area (i.e. physics). This sequence was interesting because it offered a view of the complex dimensions involved in classroom teaching, which span from social and relational to epistemological aspects. The students eventually argued about the importance of knowing the 'right-hand rule,' which is a helpful guideline when attempting to remember the direction of an electrical current relative to a magnetic field:

INTERVIEWER: Why do you think it's necessary to know the right-hand rule? LUKE: For the future, I guess.

AISHA [NODS]: The future!

MARY [SARCASTICALLY]: Hey, what are you actually supposed to use it for? 'Now, when I plug in this cord, [should I] wonder if it's [following] the right-hand rule?' There is absolutely no use for it!

AISHA [TURNS TO MARY]: It's for your future job. You know...[because] you wanna become a firefighter? [Turns to the interviewer]. You do this [makes a hand gesture to illustrate the rule], and then you know the direction of the current.

LUKE [IN AN IRONIC TONE]: Yeah, really? If there is a house on fire? Is there electricity in this house? The right-hand rule-that's it!

MARY: The only thing you do when you become an adult is go to work, then go home and buy pizza, then go to sleep and rise up in the morning, go to work, buy pizza and go to sleep.

MARK: Yes, and you receive a bill in the middle of it all.

MARY: Yes, but you don't need to know the right-hand rule. It's completely unnecessary

(Interview 6, BTC natural sciences, students)

A number of points can be drawn from the manner in which this brief conversation evolved. First, a societal and relational shift occurs when Mary questions Luke's and Aisha's statements about the future importance of knowing the right-hand rule; even though their claim was vague, Luke was influenced by Mary, and his attitude became somewhat sarcastic as a result. Aisha attempted to convince Mary based on her future plans to become a firefighter and what the teacher has discussed during the lesson; she was ignored, however, and Luke, Mark and Mary made an epistemological 
move away from the theoretical/conceptual knowledge content and into everyday experiential and societal knowledge by describing a particularly boring and repetitive daily routine they might experience when they became an adult.

\section{Concluding Comments}

This chapter explored different teaching repertoires and student perceptions of knowledge in high- and low-performance classrooms in Sweden. In this conclusive section, the main study results are presented and considered from the perspective of potential implications for student access to knowledge.

An analysis of the dominant teaching repertoires and contextual factors revealed similar time distributions related to repertoires wherein the teacher was main actor, such as recitation, rote and instruction; compared to the BTC, however, the LTC was characterised by a higher proportion of lecturing (i.e. a monologue) in whole-class teaching. Differences in teaching repertoires can be explained by contextual factors with an emphasis on societal, cultural and relational dimensions related to teacher-student interactions. To a large extent, the BTC was characterised by unrest and students who lacked motivation; there was a widespread sense among the students of being low achievers and an 'anti-study culture' in the classroom, and the teachers were often occupied with maintaining order. Conversely, the LTC appeared to be disciplined, and teaching was not disturbed by individual students or by disobedient behaviour; these teachers described their students as being ambitious and highly competitive, which creates the challenge of trying to divert the students' attention away from high grades and towards an understanding of the significance of learning and knowledge. When viewed as a whole, there were significantly different contextual conditions in terms of interactions between the teachers and the students and the teaching content (Doyle, 1992).

Moreover, the different contextual features of the two classrooms influenced the students' conceptions of knowledge and the manner in which knowledge was recontextualised. It was possible to discern a relationship between the societal and epistemic factors associated with the students' conceptualisation of what they considered to be worthwhile and valuable knowledge. These differences should not be exaggerated, however.

A notable conclusion that can be drawn is that knowledge requirements of the curriculum shaped the students' understanding of knowledge. The students described knowledge as being theoretical, abstract and hierarchically structured and including content facts and concepts, and viewed knowledge as being practical and procedural and encouraging competences and abilities related to creativity and problem-solving, critical thinking, communication skills and cooperation. The analysis revealed examples of an experiential conception of knowledge, but students seemed to appreciate when knowledge was linked to everyday and societal situations and experiences and thus appealed to their future plans for their adult and professional 
life; in this way, perceptions of subject-disciplinary and experience-based knowledge from the students' world could be simultaneously played out in complex ways.

A pivotal question to consider is the extent to which teaching repertoires enable or limit students' access to different forms of knowledge and thereby provide space for meaning-making and transactions between the students' subjective worlds of experience and forms of knowledge in classroom teaching; by extension, this is a question of how different teaching repertoires can potentially encourage systematic exploration and knowledge formation that can help students critically reflect on themselves as subjects and actors in society (Deng, 2020; cf. Hopmann, 2007). It could, therefore, be asserted that the dominant repertoires of the LTC, which were 'monologue' and 'individual work,' actually allowed limited space for the students to interact with one another - and hypothetically, the dominance of these repertoires would seem to suit the results- and competition-oriented classroom culture described by the teachers. The teachers attempted to combine the 'monologue, 'recitation,' 'individual work' and 'group work' teaching repertoires, however, to balance social and epistemic factors and provide access to valuable and worthwhile knowledge to their students.

In the BTC, 'group work' was a dominant teaching repertoire, which led to a greater potential for student interactions, knowledge exchange, critical enquiries, discussions and collaborations with joint meaning-making. While this repertoire seemed to be used as an attempt to maintain order in the class, it could be argued that the teachers' choice of group work and their organisation of 'individual work' into smaller groups provided access to 'powerful' knowledge, compared to whole-class teaching. Different dynamics and contingencies created by situational, contextual, societal and cultural factors influenced the manner in which the students were able to develop empowering and worthwhile knowledge.

\section{References}

Adolfsson, C.-H., \& Alvunger, D. (2018). The selection of content and knowledge conceptions in the teaching of curriculum standards in compulsory schooling. In N. Wahlström, \& D. Sundberg (Eds.), Transnational curriculum and classroom practices: The new meaning of teaching (pp. 98-115). Routledge.

Alexander, R. (2001). Culture and pedagogy: International comparisons in primary education. Blackwell Publishing.

Alvunger, D. (2018). Teachers' curriculum agency in teaching a standards-based curriculum. The Curriculum Journal, 29(4), 479-498. doi:10.1080/09585176.201 8.1486721

Alvunger, D., Soini, T., Philippou, S., \& Priestley, M. (2021). Conclusion: Patterns and trends in curriculum making in Europe. In M. Priestley, D. Alvunger, \& S. Philippou (Eds.), Curriculum making in Europe: Policy and practice within and across diverse contexts (pp. 273-293). Emerald Publishing.

Bernstein, B. (2000). Pedagogy, symbolic control and identity: Theory, research, critique. Rowman \& Littlefield Publishers, Inc. 


\section{Daniel Alvunger}

Braun, V., \& Clarke, V. (2006). Using thematic analysis in psychology. Qualitative Research in Psychology, 3(2), 77-101. doi:10.1191/1478088706qp063oa

Cresswell, J. W. (2010). Mapping the developing landscape of mixed methods research. In A. Tashakkori, \& C. Teddlie (Eds.), SAGE handbook of mixed methods in social and behavioral research (2nd ed., pp. 45-68). Sage Publications, Inc.

Deng, Z. (2020). Knowledge, content, curriculum and Didaktik: Beyond social realism. Routledge.

Deng, Z., \& Luke, A. (2008). Subject matter: Defining and theorizing school subjects. In F. M. Connelly, M. F. He, \& J. A. Phillion (Eds.), SAGE handbook of curriculum and instruction (pp. 66-87). Sage Publications, Inc.

Doyle, W. (1992). Constructing curriculum in the classroom. In F. K. Oser, A. Dick, \& J.-L. Patry (Eds.), Effective and responsible teaching: The new synthesis (pp. 6679). Jossey-Bass, Inc.

Hopmann, S. (2007). Restrained teaching: The common core of Didaktik. European Educational Research Journal, 6(2), 109-124. doi:10.2304/eerj.2007.6.2.109

Klette, K. (2007). Trends in research on teaching and learning in schools: Didactics meets classroom studies. European Educational Research Journal, 6(2), 147-160. doi:10.2304/eerj.2007.6.2.147

Muller, J., \& Young, M. (2019). Knowledge, power and powerful knowledge re-visited. The Curriculum Journal, 30(2), 196-214. doi:10.1080/09585176.2019.1 570292

National Agency for Education. (2011). Läroplan för grundskola, förskola och fritidshemmet [Curriculum for the compulsory school, preschool class and the leisure-time centre] Lgr 11. The Swedish National Agency for Education.

Nordin, A., \& Sundberg, D. (2016). Travelling concepts in national curriculum policy-making: The example of competencies. European Educational Research Journal, 15(3), 314-328. doi:10.1177/1474904116641697

Priestley, M., Alvunger, D., Philippou, S., \& Soini, T. (Eds.). (2021). Curriculum making in Europe: Policy and practice within and across diverse contexts. Emerald Publishing.

Sundberg, D., \& Wahlström, N. (2012). Standards-based curricula in a denationalised conception of education: The case of Sweden. European Educational Research Journal, 11(3), 342-356. doi:10.2304/eerj.2012.11.3.342

Wahlström, N., Alvunger, D., Schmidt, C., Sundberg, D., \& Vogt, B. (2019). Coding scheme for analysing classroom classroom discourse and conceptualisations of knowledge. In N. Wahlström (Ed.), Classroom research: Methodology, categories and coding (pp. 39-43). Linnæus University Press.

Young, M., \& Muller, J. (2015). Curriculum and the specialization of knowledge: Studies in the sociology of education. Routledge. 


\section{Pedagogical Segregation from Students' Perspectives}

\section{Catarina Schmidt}

The divide between low- and high-performing schools, as well as the school segregation this creates, now evidently characterises the Swedish educational landscape. Low-performing schools' merit points are clearly below the national average, and many students in these schools have difficulties reaching the minimal standards for entering upper secondary school, while high-performing schools make up for the totally opposite situation. This pedagogical segregation has been reinforced by factors of a high socio-economic index and by the free school choice (Brandén \& Bygren, 2018; NAE, 2012, 2020). Many students in low-performing schools live within urban or rural areas, characterised by a high socio-economic index and low possible school choices. Reports from NAE $(2018,2019 \mathrm{a})$ and the Governments' Office (SOU 2020, p. 46) show that since the end of the 20th century, students' socio-economic backgrounds have become increasingly significant for students' school success regarding complete marks and qualification for upper secondary school.

Also, we know that among the heterogeneous group of multilingual students, that is, $28 \%$ of the students with another first language than the majority language, general academic results are below those achieved by students with monolingual backgrounds (NAE, 2019b) - a situation that links strongly to socio-economic conditions. Unfavourable socio-economic conditions in urban and multicultural areas in Sweden have increased, inducing residential segregation (Aldén \& Hammarstedt, 2016; Bunar et al., 2021; Johansson \& Hammarén, 2011; SOU 2020, p. 46). Residential segregation has reinforced school segregation, which, in turn, has been reinforced by the segregating forces produced by free school choices, thereby making students become increasingly divided among schools, considerably based on their socio-economic backgrounds. At the actual school reported in this chapter, the circumstances of high socio-economic index, segregation and diverse language backgrounds are intertwined.

This chapter examines pedagogical segregation from students' perspectives within a school, here named Oak School, which, according to statistics from the National Agency of Education, is low-performing. Students' voices coming forward in this chapter are affected by socio-economic and residential segregation, since they live and school in an urban area characterised by such inequalities. Asking questions like 'what kinds of classroom pedagogies do these students experience within this specific low-performing school context and how do these students perceive these pedagogies?' is 


\section{Catarina Schmidt}

crucial to reflect on. This chapter will specifically focus on how the actual teaching that the students are involved in is organised and performed in Swedish subjects and the Natural Sciences, including the students' experiences and thoughts on this.

Previous studies, which this chapter adds to, highlight the risk of misery descriptions of underprivileged settings in which concepts like diversity or multiculturalism tends to equate with school areas with a larger proportion of migrated inhabitants with a weaker social position (Bunar, 2011; Wedin, 2015). For individual students, this includes the risk of developing a low self-image, a feeling of not belonging, or being discounted as a legitimate citizen (Cummins, 2001; Runfors, 2003). In order not to reinforce a deficit discourse, the importance of providing intellectually challenging education for second-language learners, combined with high support and explicit language teaching, has long been emphasised (Cummins \& Early, 2011; Gibbons, 2008). Also, previous research regarding second-language learners' opportunities for learning and developing knowledge highlights the importance of contextualisation, structure, high expectations and exploration-based activities, including opportunities for students' active participation and active language use (Cummins, 2001; Schleppegrell, 2004; Schmidt \& Skoog, 2017, 2018).

\section{Aims and Research Questions}

Drawing on the analysis of 16 video-recorded lessons and seven student focus group interviews, this chapter aims to examine the created classroom discourse, including the impact of teaching factors, and the student's perspectives on this. This aim will be addressed by elaborating on the following research questions:

1. What characterises the classroom pedagogies, that is, the organisation, the chosen content for teaching and learning, the possible interaction and communication, and what versions of knowledge emerge?

2. What students' perspectives regarding these classroom pedagogies emerge, and how can these perspectives be understood?

\section{Theoretical Standpoints}

Transmitting knowledge from one generation to another is simply the task of education. The role of knowledge within education is not an easily targeted concept. Educational knowledge includes generic subjects' content, that is, what is regarded as correct and just subject knowledge. Furthermore, according to the basic social values within the curriculum, educational knowledge should be combined with opportunities for students' influence and participation. The ways in which knowledge is drawn upon, situated and handled in classrooms enable students to access several knowledge versions with various opportunities for their learning and knowledge 
development. For example, a conception of knowledge as meaning-making might facilitate a multifaceted and dialogic approach with connections to other subjects, their own experiences and to the surrounding society, while an essentialistic view implies knowledge as unambiguous with frequent references to the actual subject (Wahlström, 2019). Another possible version of knowledge is knowledge as result-oriented, referring to when content and abilities are strongly linked to the content and knowledge requirements of the actual syllabus.

Powerful knowledge is, according to Young (2013), specialised regarding how it is produced and on what educational level, but it is also differentiated regarding the experiences that students bring to classrooms. In this way, powerful knowledge emerges as being, in Young's words, 'an epistemological issue that defines what constitutes the entitlement for students at different stages and in different specialist fields, and a social justice issue about the entitlement to knowledge of all students' (emphasis in original, p. 109). Since students' identities and backgrounds are multifaceted, they bring various experiences and prerequisites to classrooms. Within classrooms, students continuously define and redefine social situations, mirroring themselves regarding these through the classroom pedagogies they encounter. Students' identity making is 'part and parcel of the routines of everyday life, induced in the fine detail of everyday interaction' (Antaki \& Widdicombe, 1998, p. 1). The Swedish Education Act prescribes that education should be equal regardless of students' backgrounds (SFS 2010:800). A foundational educational and democratic question relates to how various classroom discourses, including the impact of differing knowledge versions, might have on teaching and learning in classrooms. Henceforth, this educational question will be illuminated regarding classroom pedagogies, which include the role of teaching factors, the curriculum content and the central actors of a classroom - the teachers and the students.

\section{Classroom Pedagogies}

Classroom pedagogies are, in this chapter, equivalent to the interplay between teaching factors, the curriculum and the classroom actors. Pedagogies in classrooms concern the ways in which the curriculum and the chosen content are translated and designed into teaching, and the role that the chosen teaching factors play in student's learning and knowledge development. Here, teaching factors refer to the organisation of classroom teaching and the possible interaction and communication within the classroom, occurring through the teacher's teaching talk and the student's learning talk (Alexander, 2008). These teaching factors are interdependent with curricula and vice versa (Doyle, 1992; Wahlström, 2018).

Teachers interpret the curriculum according to teaching content, aims and assessment criteria. Simultaneously, they make daily considerations regarding how to organise and conduct classroom teaching, including the choices of teaching talk regarding rote, recitation, instruction or dialogue, 


\section{Catarina Schmidt}

and discussion. Here, using rote is understood as the drilling of facts by repeating certain content or key concepts, while instructions inform the students on what to do and how to further (Wahlström, 2019). Drawing on Alexander's (2008) international discourse data, recitation was identified as the overall dominant category of teaching talk. The recitation category comprises closed-ended questions and brief recall answers, with a minimum of teacher feedback. Less frequently, and regarding deeper possibilities for meaningful feedback, were discussions and dialogues. Here, discussions are understood as exchanges of ideas and shared information between students, while dialogues achieve 'common understanding through structured cumulative questioning' to 'guide and prompt, reduce choices, minimise risk and error, and expedite the 'handover' of concepts and principles' (Alexander, 2008, p. 110). Teachers' teaching talks have, in turn, different meanings for the students' opportunities of learning talk, that is, their opportunities to listen to others, ask questions, act upon different kinds of answers, solve problems and the like (Alexander, 2008). The teaching factors of an organisation, teaching talk and learning talk are illustrated in Table 9.1.

Here, teaching factors are viewed as being situated within classroom practices. Students' opportunities for learning and achievement are viewed as being both a matter of knowledge development and the democratic purpose of education. Altogether, teaching factors mean the coordination of the three repertoires of organisation, teachers' teaching talk, and students' learning talk.

As we know, curricula are not only about aims, content and knowledge requirements regarding various subjects but are also shaped by basic social values, such as democratic aspects on influence and outspoken strives on equality. In translating any curriculum and its formation within a classroom, teachers and students are actors. Since students encounter classrooms from various positions, they are in different ways in a dependency state towards their teacher and the kinds of pedagogies they are offered. As actors in classroom pedagogies, teachers can, in various ways, create opportunities for their students to learn and develop knowledge and to become actors in their own learning. Classroom pedagogies, therefore, elucidate the pedagogical questions of what content to teach, why, and how. As Figure 9.1 illustrates, classroom pedagogies concern the ways in which the curriculum is translated and designed into teaching and the role that

Table 9.1 Teaching factors

\begin{tabular}{lll}
\hline Organisation & Teaching talk & Learning talk \\
\hline Whole-class teaching & Rote & Listening to others \\
Pair/group work & Recitation & Asking questions \\
Individual work & Instruction & Acting upon answers \\
& Monologue & Negotiating \\
& Dialogue/discussion & Reasoning \\
& & Solving problems
\end{tabular}




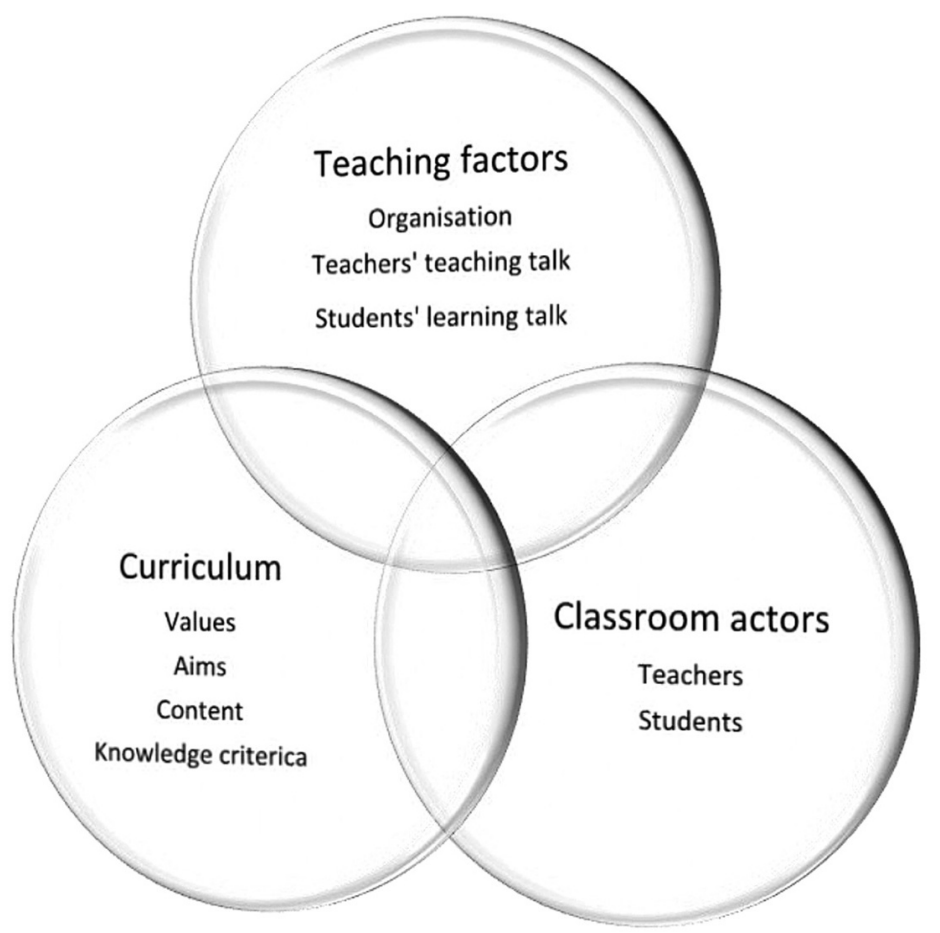

Figure 9.1 Classroom pedagogies

the teacher's chosen teaching factors play in the student's learning and knowledge development.

The transformation from the chosen curriculum's text content to the actual teaching content is understood by Doyle (1992) as constituting of curriculum events. Wahlström (2018) observed that the latter can be understood as if the teacher is authoring a basic text following the curriculum, determining what content to choose, how to introduce it and the perspectives to present it. The teacher's authored and communicated classroom text has, in turn, to be interpreted and acted upon by the students. It also means that the teacher, in one way or another and with higher or less awareness, decides on what knowledge version the students will access (Wahlström, 2018). Underlying knowledge assumptions, which affect lessons and the student's learning, can, as have been previously highlighted, focus on knowledge to meaning-making, as essentialistic or as result-oriented. When authoring a discursive text in the classroom, curriculum events are constituted where teaching factors are critical. Commonly, teachers design ongoing themes that persist over a sequence of lessons linked by their content, often when two or more subjects are integrated. Also, this speaks of an understanding of the curriculum as a coherent set of contexts and activities sequenced over days or weeks to build students' competencies towards desired goals. 


\section{Oak School - Contextualisation}

The setting of Oak School is diverse in terms of its residents' linguistic and cultural backgrounds. Drawing on 2019 statistics from NAE, 39\% of the students qualified for upper secondary school in Grade 9, compared with the national average of $73 \%$ for the same year. The study was conducted over one school year, 2018-2019, in Swedish subjects and the Natural Sciences, that is, in two classrooms, and in one Grade 8 class of 18 students.

Each student had access to an individual laptop but accessed this digital resource only at the beginning of Grade 8, despite the emphasis on the clarification of digital competence, such as confident and critical usage of digital technologies (Government Offices, 2017). Many students spoke a language other than Swedish in their homes, and one was a newly arrived student. While the school had no authorised teacher for Swedish as a Second Language ${ }^{1}$, most teachers were authorised in other subjects. Accordingly, the students in this school did not learn regarding the syllabus 'Swedish' as a second language, where differences regarding second-language learners are integrated, but instead from the Swedish syllabus directed towards learners having Swedish as their first language. For Oak School, the lack of authorised teachers in Swedish subjects as a second language, the delayed access to individual student laptops and a higher share of students affected by socio-economic inequalities are examples of underprivileged conditions.

\section{Methodology}

The case study of this specific school draws on ethnographic reflexive approaches, where I, as a researcher, observed and described actions regarding the articulated aim (Hammersley and Atkinson, 1989). Over one school year, 2018-2019, six lessons were video- and audio-recorded. One stationed-video camera was placed at the back of the classroom, and one extra microphone was placed at the front. The content and the structure of each specific lesson were the focus of these video recordings, together with the repertoires of teaching factors. Using video recordings enabled systematic documentation, capturing, and understanding of different ways in which the curriculum was organised and communicated in concrete classroom situations (Schmidt, 2019). Also, focus group interviews with the students were conducted, which enabled capturing a broader scale of thoughts and ideas (Xerri, 2018). A semi-structured interview guide was followed. Concurrently, my ambition was to listen carefully and follow the conversation and to ask follow-up questions or, if necessary, to return the conversation to the study's aim (Brinkmann, 2014). Seven interviews with 13 students were conducted during the school year (Table 9.2; the names are anonymised). 
Table 9.2 Focus group interviews, 15 students

\begin{tabular}{ll}
\hline $\begin{array}{l}\text { Interview one } \\
\text { October 2018 }\end{array}$ & Jenica, Benny, Admir, Mesude \\
$\begin{array}{l}\text { Interview two } \\
\text { October 2018 } \\
\text { Interview three } \\
\text { November 2018 }\end{array}$ & $\begin{array}{l}\text { Wahib, Abdul, Moukib } \\
\text { Anterview four }\end{array}$ \\
$\begin{array}{l}\text { Amale } \\
\text { November 2018 }\end{array}$ & Boris, Josef \\
$\begin{array}{l}\text { Interview five } \\
\text { March 2019 }\end{array}$ & Sara, Benny, Isra \\
Interview six & Boris, Josef \\
April 2019 & Jenica, Sara, Mesude \\
Interview seven & \\
April 2019 &
\end{tabular}

\section{Analysis of Classroom Discourse}

First, drawing on the designed curriculum tasks within the two subjects, teaching factors were analysed regarding organisation (regarding whole-class teaching, pair/group or individual work) and elements of the teachers' teaching talk (regarding rote, recitation, instruction, or monologue) (Wahlström, 2019). In this analysis, the discussion and dialogue categories were coded as one category. Also, lesson gaps (those gaps where the teacher waited for the class to be quiet and/or commented on students' behaviours) were added as a category in the analysis. Here, the category of lesson gaps is equal to disturbed classroom peace. Coming so far in the analysis, conclusions regarding the students' opportunities of learning talk, that is, their opportunities to listen to others, asking questions, acting upon different kinds of answers, solving problems, and so forth (Alexander, 2008), could be drawn. In this part of the analysis, a compilation regarding subject content and the selection of textual resources was also conducted.

Second, the analysis focused on the transcribed student interviews. Here, a content analysis (Hsieh \& Shannon, 2005) was conducted regarding the student's perspectives on the classroom pedagogies, that is, the organisation, the chosen content for teaching and learning, and their possibilities of interaction and communication. Here, the analysis aimed to investigate what classroom discourse emerged through the students' talk regarding various aspects of classroom pedagogies and also to investigate what kind of knowledge characterised the classroom discourse. The underlying assumptions for this were that discourses are created within social contexts, such as classroom practices, and that they form prevailing notions, or certain fixed ways of discussing and understanding what the words 'teaching and learning' (Foucault, 1993) are and should be about 
in this case. As these discourses influence and determine the borders for what is socially and culturally accepted, they identify what is seen as worth striving for.

\section{Results}

The presented results explore the classroom pedagogies regarding the chosen curriculum content, the teaching factors and the students as classroom actors. The curriculum content clarifies the chosen content, including the various resources presenting this content, while the teaching factors elucidate the used classroom repertoires of an organisation, the communication and the interaction. While presenting the classroom pedagogies in the following, the student's perspectives on this will be added together with my analytical reflections.

\section{Curriculum Content}

In Swedish subjects, the curriculum tasks of reading comprehension, debate articles, fact and fiction, poetry, and news articles frame classroom teaching, while the curriculum tasks in the Natural Sciences subject are electricity, heat, chemical elements, ecosystems and movement (Table 9.3).

The tasks listed in Table 9.3 and their contents were presented from various resources, such as textbooks, fictional texts, and digital resources. The textual resources in Swedish subjects included printed resources, such as textbooks, newspapers, and fiction literature, together with educational video clips and motion pictures. The chosen textual resources in the Natural Sciences comprised, during the first semester, a printed textbook combined with educational videos. In the second semester, the textbook was replaced by a digitised educational textual resource, covering all subjects in the Natural Sciences, including visual and written information and shorter videos, but still, other educational videos were used. Concrete materials for conducting scientific laboratory exercises were not drawn upon or used. In both classrooms, the students used their laptops and the digital resource Google Classrooms.

Table 9.3 Curriculum tasks

\begin{tabular}{ll}
\hline Swedish & Natural sciences \\
\hline Task one. Reading comprehension & Task six. Electricity \\
Task two. Debate articles & Task seven. Heat \\
Task three. Fact and fiction & Task eight. Chemical elements \\
Task four. Poetry & Task nine. Ecosystems \\
Task five. News articles & Task ten. Movement \\
\hline
\end{tabular}




\section{Students' Perspectives - Curriculum Content}

All the students agreed that the teacher decides on what content to teach about, and most of them mention the curriculum as a reason for the teacher's choice of content. The students, Jenica, Benny, Admir, and Mesude, stated collectively that the teacher in Swedish occasionally refers to the curriculum and that the teacher in the Natural Sciences does not.

Many students expressed the idea that the teacher in Swedish also chooses teaching content regarding the student's everyday lives. In task one, the students collectively read the youth novel Onsdag kväll, strax före sju [Wednesday Evening, Just Before Seven] (Berggren, 2016). In this novel and in the movie Màste gitt [Have to Walk Away] (Zubak, 2017), being part of task two, a suburban context with elements of violence is portrayed. Referring to the novel, Wahib observes, 'This book is precisely about us.' While some of the students, like Wahib, consider the novel as realistic, other students claim that the novel's description of a 'suburb' does not correspond with their experiences.

All the students were aware that they should develop certain abilities using various teaching content in Swedish subjects, and they gave several examples of this. Also, referring to the novel, Wahib states, 'Well, you read it, then you summarise it, and by that, you develop reading comprehension.' Referring to task two, Benny says, 'Everyone has different opinions, so you have to bring them forward.' Jenica adds, 'You have to be able to express your opinions.' Admir listens and takes slightly another direction than Benny and Jenica when observing, 'It is about correctness of the Swedish language, like reading with fluency and writing with correct grammar.' Following this last utterance, Josef says on another occasion, 'You cannot use suburban language or slang; you have to know how to start and end a sentence, that is important.' By this utterance, Josef highlights that, as students, they should develop their ability to use what he refers to as 'correct Swedish.'

Referring to the Natural Sciences and what they are to learn in these subjects, the students highlighted the importance of knowing about, for example, how electricity works. The students, Wahib, Abdul, and Moukib, mentioned Ohm's law, and Moukib continues, 'Through electricity, we as humans have accomplished great change.' The students, Perjsa, Moukib, Wahib, Diana, and Amale, described how they are to learn about the ecosystem in task nine, and started laughing suddenly. These students explained that they found the situation a bit absurd since they, according to themselves, are having difficulties with explaining what they are actually learning and why. Also, Boris and Josef found it hard to explain the content they are learning about, referring to the same task. Boris says, 'It is like bacteria and bugs in nature.'

Several students expressed dissatisfaction with the digitised educational resource Digilär, which considerably represents the content of the Natural Sciences during the second semester. Sara and Isra expressed that 'they do not 


\section{2}

understand anything.' The reason for this, according to these last students, is due to 'many difficult words and concepts.' These students described that they do not take notes any longer; rather, they take photos on the screen with their mobile phones. Also, Admir criticised the digital resource, saying, 'Give me a book, I go astray at the Internet.' Admir explains further:

They say to me, prepare yourself before the test. I go in on the Internet. Then, for example, if you forget the password, you have to provide many codes and stuffs. Well, then if you do not get the code, you cannot study. So, the test goes to the * with it. So, I say, give me a book, then I know what pages to study and so on.

Another student, Moukib, says, 'The teacher says one thing, and Digilär another thing, so we do not know who is right.' Benny, however, expresses that 'Digilär is kind of factual book in many subjects,' continuing, 'it works fine for me,' while Jenica nods in agreement. Sara accounts that the increased use of internet-based recourses also means that messages pop up steady. She explains, 'For example, we have a group on Facebook at school, where the teachers write information about tests and so on, or it could be a student adding a video.'

\section{Analytical Reflections - Curriculum Content}

The student's perspectives reveal that they do not think it is possible for them to have some influence on what content to learn from. Instead, the students expressed that the teachers should conduct the content selection on curriculum basis. Concurrently, some of the students express a mistrust regarding this professional selection in the subjects of the Natural Sciences. The content from which the students are going to learn in the Natural Sciences focuses, according to the student's expressed experiences, on subject-specific concepts. The content from which the students are going to learn in Swedish subject focuses, according to the student's expressed experiences, on fiction with two alternatives of retold suburban contexts with elements of violence, and other textual resources, aiming at developing communicative abilities. Several students expressed dissatisfaction and confusion regarding the digitised resource Digilär, and because of this and the classroom pedagogies, as will later be shown, several students do not seem to make sense of or reach an understanding of the curriculum content presented by this resource. The classroom discourse that emerges regarding the curriculum content is shaped by a narrowed content in the Natural Sciences (i.e. concepts and words). In this way, the curriculum content from which the students are going to learn in these last-mentioned subjects seems not to always be available for the students. Regarding the Swedish subject and its curriculum content, a classroom discourse emerges that takes somewhat for granted what suburban contexts can be or not, and what the students' experiences of their own living area are. 


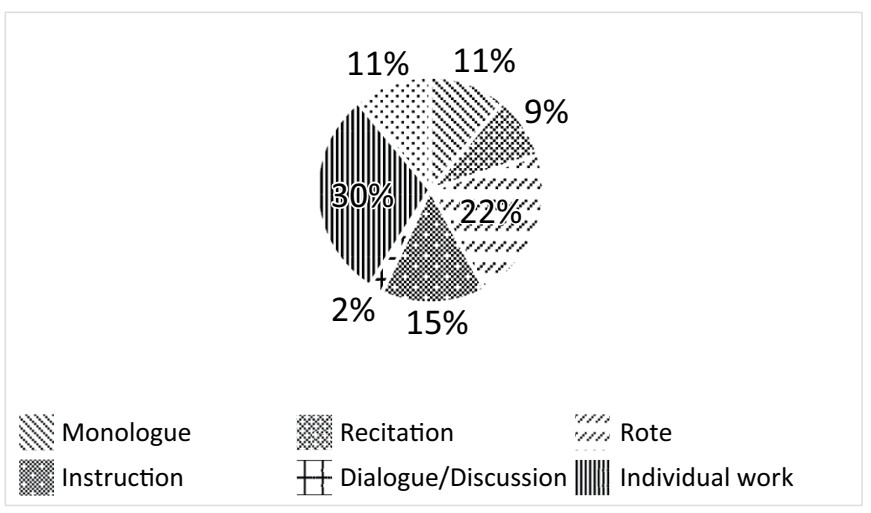

Figure 9.2 Organisation and teaching talk (\%)

\section{Teaching Factors}

The analysis of teaching factors, situated within the ten curriculum tasks, reveals that classroom practice is organised considerably through whole-class teaching $(70 \%)$ and individual work (30\%) (Figure 9.2). During whole-class teaching, the teacher functions or is supposed to function as the main actor using the following elements of teaching talk: rote $(22 \%)$, instruction $(15 \%)$, monologue (11\%), recitation (9\%) and dialogue/discussion (2\%). Students' individual work occurs after whole-class teaching. Although classroom practice is not organised through group/pair work, the students occasionally interact during individual work. Dialogue and/or discussion are hardly present. The lesson gaps category (11\%) affects some of the lessons.

\section{Students' Perspectives - Teaching Factors}

During whole-class teaching in Swedish, the teacher, according to the students and following the analysed teaching factors, usually goes through the lesson content and then instructs the students on how to proceed and on which individual work follows. Perjsa says, 'It is usually about texts; one has to read and write texts.' The student, Sara, expresses that she likes the lessons in Swedish and explains, 'I feel like I understand more and more.' Benny agrees with this and says, 'I actually feel the same thing.'

Some of the students are satisfied with the structure of teaching factors during the lessons in Swedish, while others find the tempo a bit tedious combined with too low expectations. Perjsa says, 'Well, the teacher could have explained this in a minute [referring to how to find counterargument in an argumentative text]; instead, the teacher extends and you stop listening.' Amale agrees with this and says, 'The teacher could have explained a bit faster.' Persja concludes, 'The teacher should just say, 'Take up your laptops and start writing.' In contrast to the last-mentioned students, Wahib finds the teacher's recitation during whole-class teaching to be a good thing: 


\section{Catarina Schmidt}

'Well, they explain until you get it.' In line with Wahib, the students, Boris and Josef, argue that a good teacher 'shall go through so that everyone would be carried along.'

During whole-class teaching in the Natural Sciences, the teacher, according to the students and following the analysed teaching factors, usually recites in front of the class what they should know, on which individual work follows. Regarding teaching in the Natural Sciences, Benny states, 'It is like the University, you sit and note what the teacher says and writes on the white board.' According to Jenica, it is 'hard to understand the teacher's explanations.' Benny and Mesude agree on this, and Mesude continues, 'You sit throughout the whole lesson and stare at the whiteboard, writing down words that you do not understand.' Also, Moukib and Wahib stress that the teacher cannot explain properly. The students, Perjsa, Diana, and Amale, collectively express that they find the lessons 'rather troublesome.' Benny suggests that 'it would be better to do experiments in front of the whole class' and continues, 'Then you can see with your eyes and understand better.' Benny's solution for the classroom situation is to sit and 'just take in as much as I can,' whereupon Jenica nods and agrees. In line with the other students, Boris and Josef also bring forward that they find it difficult to learn during the lessons in the Natural Sciences.

\section{Analytical Reflections - Teaching Factors}

Since whole-class teaching dominates classroom practices, to be followed by individual work, this means that the students are offered rather nondialogical classroom pedagogies with few possibilities of their own learning talk (Alexander, 2008). Also, this gives evidence that this group of students, where the majority are second-language learners, lack access to opportunities for exploration-based activities, including opportunities for active language use (Cummins, 2001; Schleppegrell, 2004; Schmidt \& Skoog, 2017, 2018). While some of the students find the tempo a bit tedious in Swedish subjects, combined with very low expectations, others are satisfied with the structure of teaching factors in this subject. This provides evidence that some of the students are not met with enough expectations. Regarding the subjects of the Natural Sciences, the students express in unified ways that they find it hard to learn during these lessons. The students seem, as I interpret their utterances, to be aware that the classroom pedagogies in these last-mentioned subjects do not function well and that they are withheld from far better alternatives regarding learning and developing knowledge in these subjects. The classroom discourse that emerges is characterised by narrowed repertoires of teaching factors, that is, organisation, teachers' teaching talk, and students' learning talk, with few opportunities for the students to actively participate, with very low expectations for many of them. 


\section{Classroom Actors}

The ways the teaching is organised, including the repertoires for interaction and communication, impact the student's opportunities regarding their participation and acting on an individual level and on their opportunities of interacting with other peers and the teacher. Since the classroom practice is organised through whole-class teaching $(70 \%)$ and individual work (30\%), this means that the students considerably listen, watch, or note when the teacher, through recitation, monologue and rote, is teaching. Also, the analysed teaching factors reveal that dialogues or discussions are seldom conducted, meaning that the teacher most often is the central actor of the classroom, while the students take on a more passive role. The analysed teaching factors reveal simultaneously that the category of lesson gaps (11\%) affects some of the lessons in Swedish and the Natural Sciences. This means that, quite often, there is a struggle as to who functions as the dominant actor in the classroom.

\section{Students' Perspectives - Classroom Actors}

Most of the students interpret student participation as being equal with being active during lessons. Jenica explains student participation in the following way, 'Well, the students actively participate, answer questions, and discuss, that is not sleeping or using the mobile phone.' All the students state that they take their responsibility of being attentive during lessons. Concurrently, many of them accentuate that it is difficult to always live up to this. Diana says, 'Well, it easily gets a little boring and repetitive, and then, you do not cope.' The repetitiveness occurs because, according to Jenica, 'some are on higher levels than others,' and she proposes that 'those students could be opportune to try on somewhat higher levels.' Mesude agrees, 'Yes, I feel restless to be at the same level always,' and Wahib adds, 'If you want to develop, you must get some more difficult stuffs.' All the students insist that they generally lack influence on the teaching and state that the teacher actually decides.

Most of the students criticise the teaching in the Natural Sciences. At the end of the school year, and with the summer holiday approaching, many students express anxiety regarding their learning in these subjects and their grades. Sara says, 'In the beginning of the semester, I was worried about my grades, but well, now I have lost my hope.' Sara explains further: 'We have discussed with one of our mentors and the principal, but no one does anything.' Jenicia, Sara, and Maria say that they want the classroom situation in the Natural Sciences to change. Sara says, 'If we were allowed to discuss, ask each other questions, and argue, then I think the information would stick much better.'

Also, most of the students panic regarding the recurring tests. Perjsa says, 'We have a test on Wednesday about heat, and as such, I am much afraid over that because I do not understand everything.' Perjsa develops her thoughts 


\section{6}

on this assessment, saying, 'this teacher just goes through things and then gives us a paper.' The students, Moukib, Wahib, Diana, and Amale, who have listened, nod their heads in agreement on this utterance. Sara observes, 'If I do not learn in grade eight, where will I turn in the upper secondary?' She continues, 'This is what I am disappointed at.'

Most of the students claim the classroom practices in both classrooms as 'messy,' in the sense that the teaching is interrupted, mainly due to disciplinary reasons. This condition greatly impacts the lessons and mostly during whole-class teaching. According to the students, there are certain students who disturb the classroom peace, but the situation affects, however, all the students. The students explain that because of this situation, they sometimes miss a great deal of the lesson, that it is harder to concentrate, and that one has to be one's own teacher. Concurrently, the students admit that they contribute to the disturbance in the classroom, like laughing, turning around, tapping on the phone, and so forth. Sara explains the classroom situation in the following way, 'We do not focus on one another, we are in the same classroom, but it is as if we are also on different places, it is as if someone is going on one train and another is watching Star Wars.'

\section{Analytical Reflections - Classroom Actors}

The student's perspectives show that they are aware of what student participation can be, and should be about, explained by one of them as actively participating, answering questions and discussing. Such student participation is, however, delimited due to the dominating teaching factors of whole-class and individual works, and also by the classroom disturbance, conducted by a few of the students. Therefore, the students cannot participate as central actors of the classroom, collaboratively with one another and with the teacher, with the consequence that the students cannot use language and texts actively and collaboratively, drawing on various curriculum content (Cummins, 2001; Schleppegrell, 2004; Schmidt \& Skoog, 2017, 2018). Furthermore, the student's perspectives elucidate what I describe as 'hopelessness' regarding the pedagogical situation in the subjects of Natural Sciences. Some of the students have tried to make their voices heard, aiming at changing the classroom situation, and several students have wisely and fruitfully suggested how to improve this classroom practice. The latter attempts are, however, not met, and hence unconsidered; instead, an option is left regarding being a central actor of the classroom (i.e. classroom disturbance). Regarding the student's opportunities of acting in the classroom, the classroom discourse is characterised by few opportunities for the students to engage with one another when learning and developing knowledge of subject-specific content in Swedish subjects and the Natural Sciences. In this way, the classroom discourse is also characterised by a distance towards the content that the students are going to learn about through active participation and interaction. 


\section{Concluding Thoughts}

The created classroom discourse comprises whole-class teaching, followed by individual work, mainly recitation or rote. The teaching in Swedish subject is characterised by dialogic recitation, aiming at meaning-making and developing abilities of reading comprehension and written communication. The teaching in the subject of Natural Sciences is characterised by the drilling of subject-specific concepts following an essentialistic approach of knowledge development, and conducted teaching in this direction. What we also see within this created classroom discourse is that these students are not encountering pedagogies that support them to develop sound relationships with one another. As Sara describes it, they are instead 'on different places concurrently; it is as if someone is going on one train and another is watching Star Wars.'

The student perspectives expressed in this chapter elucidate appreciation when exemplifying what they have learnt regarding various communicative abilities in Swedish subject. Concurrently, the student perspectives account that it would be possible to speed up the tempo to learn more and enhance the level of possible knowledge development. The student perspectives elucidate that they want more from the classroom pedagogies, which they are encountering. Simply put, they want to learn. Importantly, the student perspectives show an awareness of when they are learning or not and when the teaching they encounter is conducted in repetitious and non-dialogic ways, accompanied by low expectations and messy classroom situations.

Exploring Young's (2013) study, there is an urgent need to critically examine how different classroom discourses affect what counts as knowledge and to scrutinise how certain groups are excluded from accessing powerful knowledge. This narrative accounts for pedagogical segregation since most of these students within this school contexts are excluded from accessing knowledge, which they need in preparing for upper secondary school. Consequently, most of these students face circumstances that deny them of equal opportunities of both accessing upper secondary school and preparation for citizenship. The questions that arise from these conclusions are worrying: if these students are experiencing pedagogical segregation, what will it induce? If other students, just like these students, are also excluded instead of included in the current educational system, what will the consequences be? For individual students, this includes the risk of developing a low self-image, a feeling of not belonging, or being discounted as a legitimate citizen (Cummins, 2001; Runfors, 2003). For groups of students, living in multicultural areas with high socio-economic index, a sense of rightful disappointment risk to influence the whole groups of adolescents with a feeling of, again, not belonging and not counting as a legitimate citizen. For the individual student, for student groups within low-performing contexts, and for the society generally, this makes up for a dreadful failure. In the near future, and 
hence not in the long run, the conclusions just discussed risk altogether to threaten the very fundament of democracy. The obvious remark on this is that we can do better.

\section{Note}

1 The syllabus for the subject of Swedish as a second language is directed towards multilingual students, as a way to efficiently support their learning of Swedish. A student must study either Swedish or Swedish as a second language, and the time plan is equal.

\section{References}

Aldén, L., \& Hammarstedt, M. (2016). Boende med konsekvens - En ESO-rapport om etnisk bostadssegregation och arbetsmarknad. [Consequences of residential living An ESO-report about ethnical residential segregation and labour market]. Retrieved 10 June, 2021 from https://eso.expertgrupp.se/wp-content/uploads/2016/02/ Hela-2016_1-till-webben.pdf

Alexander, R. (2008). Essays on pedagogy. Routledge.

Antaki, C., \& Widdicombe, S. (1998). Identity as an achievement and as a tool. In C. Antaki, \& S. Widdicombe (Eds.), Identities in Talk (pp. 1-14). Sage Publications.

Berggren, M. (2016). Onsdag kväll strax före sju [Wednesday evening just before seven]. Opal Pocket.

Brandén, M., \& Bygren, M. (2018). School Choice and School Segregation: Lessons from Sweden's School Voucher System. The IAS Working Paper Series 2018 (1). Retrieved 10 June, 2021 from http://www.diva-portal.org/smash/get/diva2:1218847/ FULLTEXT02.pdf

Brinkmann, S. (2014). InterViews: Learning the craft of qualitative research. SAGE Publications.

Bunar, N. (2011). Multicultural urban schools in Sweden and their communities: Social predicaments, the power of stigma, and relational dilemmas. Urban Education, 46(2), 141-164.

Bunar, N., Hagström, M., \& Rojas, C. (2021). Barn och ungdomar $i$ stadens olikheter [Children and adolescens in the differences of the city]. Natur \& Kultur.

Cummins, J. (2001). Negotiating identities: Education for empowerment in a diverse society. California Association for Bilingual Education.

Cummins, J., \& Early, M. (Eds.). (2011). Identity texts: The collaborative creation of power in multilingual schools. Trentham Books.

Doyle, W. (1992). Curriculum and pedagogy. In P. W. Jackson (Ed.), Handbook of research on curriculum (pp. 486-516). Macmillan.

Foucault, M. (1993). Diskursens ordning. Brutus Östlings bokförlag.

Gibbons. (2008). 'It was taught good and I learned a lot': Intellectual practices and ESL learners in the middle years. Australian Journal of Language and Literacy, $31(2), 155-173$.

Government Offices. (2017). Stärkt digital kompetens [Reinforced digital competence]. Retrieved 13 June, 2021 from https://www.regeringen.se/pressmeddelanden/2017/03/starkt-digital-kompetens-i-laroplaner-och-kursplaner/

Hammersley, M., \& Atkinson, P. (1989). Ethnography. Principles in practice. Routledge. 
Hsieh, H-F., \& Shannon, S. E. (2005). Three approaches to qualitative content analysis. Qualitative Health Research, 15(9), 1277-1288.

Johansson, T., \& Hammarén, N. (2011). The art of choosing the right tram: Schooling, segregation and youth culture. Acta Sociologica, 54(1), 45-59.

National Agency of Education. (2012). Likvärdig utbildning $i$ svensk grundskola? [Equal education in Swedish compulsory education?]. Retrieved 10 June, 2021 from https://www.skolverket.se/publikationsserier/rapporter/2012/likvardig-utbildning-i-svensk-grundskola-en-kvantitativ-analys-av-likvardighet-overtid.?id=2816

National Agency of Education. (2018). Analyser av familjebakgrundens betydelse för skolresultaten och skillnader mellan skolor. En kvantitativ studie av utvecklingen över tid $i$ slutet av grundskolan [Analysis of the impact of family background on school results and differences between schools. A quantiatative study of the development over time in the end of the compulsory school years]. Retrieved 30 March, 2020 from https: / / www.skolverket.se / getFile?file $=3927$

National Agency of Education. (2019a). PISA 2018. 15-åringars kunskaper $i$ läsförståelse, matematik och naturvetenskap [PISA 2018. 15-year olds knowledges in reading comprehension, mathematics and natural sciences]. Retrieved 30 March, 2020 from https://www.skolverket.se /getFile?file $=5347$

National Agency of Education. (2019b). Statistics. Retrieved 30 March, 2020 from https://www.skolverket.se/skolutveckling/statistik/sok-statistik-om-forskola-skola-och-vuxenutbildning? sok=SokC\&omrade $=$ Skolor $\% 20$ och $\% 20$ elever\&lasar $=2019 / 20 \&$ run $=1$

National Agency of Education. (2020). Skolverkets lägesbedömning [National Agency of Education: Situation Assessment]. Retrieved 11 June, 2021 from https://www.skolverket.se/publikationsserier/rapporter/2020/skolverketslagesbedomning-2020

Runfors, A. (2003). Mångfald, motsägelser och marginaliseringar: en studie av hur invandrarskap formas $i$ skolan [Diversity, contradictions and marginalisations: a study of how migrationship is shaped in school]. Prisma.

Schleppegrell, M. (2004). The language of schooling: A functional linguistics perspective. Lawrence Erlbaum Associates.

Schmidt, C. (2019). Classroom observations through video recordings Methodological approaches and ethical considerations. In N. Wahlström (Ed.), Classroom research: Methodology, categories and coding (pp. 16-21). Linneaus University Press.

Schmidt, C., \& Skoog, M. (2017). Classroom interaction and its potential for literacy learning. Nordic Journal of Literacy Research, 13, 45-60.

Schmidt, C., \& Skoog, M. (2018). The question of teaching talk: Targeting diversity and participation. In N. Wahlström, \& D. Sundberg (Eds.), Transnational curriculum standards and classroom practices. The new meaning of teaching (pp. 83-97). Routledge.

SFS. 2010:800. The Education Act. Stockholm: Utbildningsdepartementet.

SOU. 2020:46. En gemensam angelägenhet [A shared concern]. Retrieved $30 \mathrm{March}$, 2020 from https://www.regeringen.se/rattsliga-dokument/statens-offentligautredningar/2020/08/sou-202046/

Wahlström, N. (2018). When transnational curriculum policy reaches classrooms teaching as directed exploration. Journal of Curriculum Studies, 50(5), 654-668. doi:10.1080/00220272.2018.1502811 


\section{Catarina Schmidt}

Wahlström, N. (Ed.). (2019). Classroom research: Methodology, categories and coding. Linneaus University Press.

Wedin, Å. (2015). Non-challenging education and tealcher control as factors for marginalization of students in diverse settings. International Electronic Journal of Elementary Education, 7(2), 169-188.

Xerri, D. (2018). The use of interviews and focus groups in teacher research. The Clearing House: A Journal of Educational Strategies, Issues and Ideas, 91, 140-146.

Young, M. F. D. (2013). Overcoming the crisis in curriculum theory: A knowledge-based approach. Journal of Curriculum Studies, 45(2), 101-118.

Zubak, I. (2017). Måste gitt [Have to walk away] [Film]. Film i Väst; Indian Summer Film. 


\title{
10 Knowledge, Curriculum and Teaching on Matters That Concern A Concluding Discussion
}

\author{
Jeff Frank, Catarina Schmidt, Daniel Sundberg, \\ Bettina Vogt and Ninni Wablström
}

Closing the gap between high- and low-performing schools is an aim of countless local, national and international educational policy documents. However, as demonstrated in the introductory chapters, there is often a great deal of undertheorisation, if not outright conceptual confusion, surrounding theories of knowledge and definitions of equity that undergird these policy documents. Given the pressing nature of the problem and the reality that students in low-performing schools are not receiving the educations they deserve, it is tempting to dismiss philosophical and theoretical investigations as irrelevant to addressing a problem that has real and immediate consequences. But this would be a mistake. Even the best-intentioned policy or practice will have unintended negative consequences when key concepts such as equity - are understood differently by key constituencies tasked with implementing the policies. Those most impacted by the policies - students, parents, communities - may also have different understandings of ideals such as equity than the parties implementing or constructing the policies, and this can lead to further unintended negative consequences, such as a widened performance gap and deepened distrust (Schultz, 2019).

This volume has also emphasised how even good policies can lead to constrained agency, which also often has negative consequences. If we want to close the gap between high- and low-performing schools, then teachers and principals in schools labelled low performing must feel like they have a voice and that they can exercise agency. Overzealous policy implementation can silence the insight of experienced school personnel and undercut their agency. This can lead to cycles of distrust and demoralisation that will often only widen the gap between high- and low-performing schools (Santoro, 2018; Schultz, 2019). One way to empower school personnel is to facilitate conversations about the purposes of education so that members of a school community can have a say in how school goals are developed, making it far more likely that these goals will align with their own values and aspirations. Doing this cultivates voice and agency.

Philosophical and theoretical conversations are not sufficient to closing the elusive performance gap, but they are necessary. Given the enormity of the problem, the reality that each child has only one childhood, and many are not receiving an education that will open them to a future of possibility, 


\section{2}

it is understandable that we would want to create policies that promote equity before developing a shared understanding of what equity is through debate, dialogue and study. Nonetheless, the significance of this type of dialogue will only become more important. The Organization for Economic Co-operation and Development's (OECD's) most recent work on the Future of Education and Skills for 2030 aims to close gaps in how students experience well-being. As laudable as this goal is, well-being is often undertheorised, and it has conflicting meanings and ways of being cultivated. As Prilleltensky (2020) noted, the social determinants of well-being are often far more powerful than anything an individual can do to promote their own well-being. Unfortunately, many OECD educational policies seem to emphasise the individual's responsibility for promoting their own well-being, which may further jeopardise the well-being of the most vulnerable students. To avoid this outcome, what is meant by well-being and how it is best cultivated must be clarified and further developed.

We will not make progress in closing the persistent gaps in educational quality until we devote sustained attention to the intersecting values, practices and ideals that must be theorised, studied, discussed and thought through if we are to make the types of progress that will empower students, teachers, principals, schools and communities to close those gaps. The following sections of this concluding chapter touch on key elements involved in improving outcomes and closing gaps, illuminating the complexity and the importance of the task.

In this concluding chapter, four themes of knowledge, equity, teaching (types of feedback, assessment and classroom discourses) and curriculum are discussed. In the final section, we argue for the necessity of a conscious choice of concepts of knowledge and equity, as well as an awareness of the implications of different meanings, as a basis for both the formation of curricula and for the enacting of actual teaching.

\section{View of Knowledge, Equity, Teaching and Curriculum}

The empirical evidence for the project underpinning this volume is classroom studies in school year 8 (14-year-olds) focusing on the recontextualisation of curriculum content into teaching practice. In addition, the insights build on corresponding classroom studies in school year 6 (Wahlström \& Sundberg, 2018). These studies, conducted within the Swedish school system, reveal that standards-based curricula for compulsory school require a new kind of attention from both teachers and students, compared to previously goal-oriented or content-based curricula. What is 'new' can be stated with the following two arguments. First, while previous curriculum models primarily have functioned as a framework of goals and teaching content as a concern for the teacher, the current standards-based curricula have moved into the classroom to become a matter for both teachers and students. A curriculum is used by the teachers to motivate both the content of their teaching and the assessment of the students' knowledge development. The 
students are familiar with the curriculum's function as regulation text and parts of its content. Second, a function of accountability has been added to the teachers' professional role, implicating that a teacher is responsible not only for the content and quality of the teaching but also for the quality of the students' learning, in the sense that all students achieve the requirements for knowledge expressed in the syllabi included in the curriculum (Wahlström, 2018a).

\section{Meanings of Knowledge}

Common to all lessons included in the study underpinning the chapters in this book is a teacher authoring a curriculum content (Doyle, 1992) together with the students in varying degrees - and a responsibility for the teacher to relate the teaching content to the knowledge requirements stated in the national curriculum so that the students will achieve a basic level of skills or higher. What differs between classrooms are the ways the content is authored, based both on space and form of participation for the students to co-construct the content and on the foundational meaning of the concept of knowledge permeating the teaching (see Chapter 2 for a discussion on different concepts of knowledge). Moreover, there were differences between the structure of the learning environment in terms of disruptions and the possibility for the students to focus on their tasks, ranging from very good to poor. The most noticeable difference arises between teaching based on knowledge concepts such as transactional realism and Bildung, on the one hand, and a disciplinary view of knowledge in terms of social realism, on the other. While the former knowledge traditions are based on human existence as a whole, characterised by knowledge developed from relationships embedded in context, the latter assumes knowledge as separate objects outside of human beings and independent of context. The challenge built in transactional realism and Bildung is to coordinate the students' attention and interest towards a certain teaching content (Biesta, 2014), while the challenge in social realism is to give the students access to a specific type of knowledge (Young, 2013).

An inference from this study is that it is crucial to make a conceptual distinction between academic disciplines and school subjects. School subjects can be related more or less closely to the disciplines of knowledge, depending on their characteristics and different subject traditions. As Deng (2020) noted, school subjects differ from, but are at the same time related to, academic disciplines because the purpose of schooling is broader than just preparing for academic studies. The teaching content needs to comprise opportunities for students to develop knowledge about the world, to learn to act responsibly in the world and to realise oneself in the world (Wahlström, 2021). Within the framework of teaching content, the students learn to reflect on different viewpoints and consequences, formulate arguments based on knowledge and facts and analyse and compare different texts and the like. These abilities should be developed and assessed in relation to 


\section{Jeff Frank et al.}

specific content, rather than being viewed as general ('generic') skills. You need to argue for something, and the way you argue needs to be assessed in relation to how well the arguments are built on actual knowledge. Thus, the conclusion is that the encounter between the content, the social learning environment and the student is central to a student's opportunity to develop new knowledge, to take civic responsibility and to develop one's own potential (self-realisation). The teacher's democratic stance in the authoring of teaching content makes a difference for what the student gets the opportunity to co-author and learn. From a perspective of curriculum theory, the teaching content is viewed as crucial for, and integrated between, the three levels of societal policy, the actual curriculum and the teaching practice. One missing point in the perspectives included in curriculum theory is a conceptual perspective of justice.

\section{Two Perspectives on Equity}

What the student gets the opportunity to learn can be conceptualised as a matter of equity. In chapter 3 of this book, we suggested that the capability approach, an approach to justice developed by Amartya Sen and Martha Nussbaum for evaluations at an individual level, and the principle of parity of participation, developed by Nancy Fraser for evaluations at an institutional level, are both fruitful for exploring a school system from a perspective of equity, one at a time or in combination. While the capability approach is focused on investigating what society's offer of compulsory education really means for individual students and how well it corresponds with an individual's own needs, the three-dimensional principle of parity of participation - including redistribution, recognition and representation - examines factors of equal quality and inclusion in the compulsory education system. In contrast to national and international knowledge tests, frameworks of the principle of parity of participation (Fraser, 2004) and the capability approach (Nussbaum, 2007; Sen, 1999) contribute with rich insights on how different social groups may experience very different conditions of teaching up to the day when the final assessments are actually carried out.

Within curriculum research, there is an ongoing discussion on the possibility of integrating the capability approach with the concept of knowledge underpinning curriculum. It is proposed that the capability approach can widen the view of curriculum based on social realism with the development of disciplinary-based capabilities adapted to a broader purpose of schooling (for a discussion, see Deng, 2020). There are, however, strong arguments for keeping conceptualisations of knowledge and equity separate. Combining the capability approach with a specific concept of knowledge risks equating capabilities with competencies, which, in turn, is embedded in a policy language where the concept of knowledge becomes subordinate to the utility of the market needs, and the roots of a tradition of justice in the concept of the capability approach disappears. The theorisations of knowledge and justice have emerged from quite different research traditions and with 
different purposes, and they cannot be conflated without risking their underlying ideas being weakened and misinterpreted. Unlike the conceptualisation of knowledge, which constitutes a prerequisite for curriculum construction, theories of justice above all need to be included in the phase of analysis and evaluation of the implications of national school and curriculum reforms.

As has been argued in previous chapters of this book, theories of knowledge are foundational for the forming of curriculum content as text, both in the curriculum documents and in actual teaching practices. The term knowledge-based curriculum (Young, 2013) is primarily focused on the idea that teachers are transmitting the specialised knowledge prescribed in a curriculum to the students. Although, we do not subscribe to that assumption, the foundation of knowledge in curricula is nevertheless important, albeit from a different angle. A national or state curriculum expresses the society's view and expectations of compulsory education. Thus, curricula need to be viewed as a framework from which the teacher selects the teaching content and calibrates assessment standards, rather than as an instruction to be implemented (Luke et al., 2013). In a European tradition of Dida$k t i k$, the teacher is entrusted with the responsibility to make the selection of teaching content and the assessment of the students' knowledge development based on their professional knowledge (Hopmann, 2007; Klafki, 2000 ) - rather than placing these responsibilities on administrative systems through national or regional authorities. The concepts of knowledge in curricula are significant because they constitute a three-dimensional foundational idea of the subject matter, of human possibilities and of society. The curriculum content forms a common frame of reference for teachers as well as for students, which forms an idea of what a school is. Still, the concepts of knowledge that become visible and mixed in with the teaching activities are not duplications of the written curriculum. At best, the concepts of knowledge that can be traced in actual teaching arise as a consequence of a creative relation between the content taught and the students being taught. In less successful cases, they represent a narrow subject language, incapable of reaching out to the students. An argument in this book is that different conceptualisations of knowledge have different potentials to expand or constrain student learning and growth. Student learning and growth contribute to the citizenship education essential for compulsory school and thus are how we conceptualise knowledge matters for how effectively and deeply students are prepared for citizenship.

\section{Life in Classrooms - Classroom Pedagogies in Current Times}

Classroom pedagogies are not easily measured or possible to pinpoint to one issue. Instead, and drawing on the empirical material from this research project, classroom pedagogies are shaped by daily sequences of interaction and communication - sequences of life in classrooms within institutions, which are, as we know, heavily ladened by traditions and norms and, increasingly in the past few decades, demands regarding knowledge outcomes in line 
with global standards (Wahlström, 2018b). Due to reasons found outside of schools and their classrooms, teaching and learning are more complex than what standardised education leaves room for. Inside a classroom, the complexity of teaching and learning becomes obvious. The complexity is represented in the ways interaction and communication are made possible between the central actors of the classroom (e.g. Lampert, 1985; Fenstermacher, 2001), as well as from the selected content the students are expected to communicate and interact about in order to learn and develop certain knowledge and abilities. These issues make up for a counter story with completely different content, compared to the story of standardisation.

The enacting of teaching is a process in which the curriculum is interpreted and tried out in various forms of teaching. Not the least, teaching needs to be carried out in relation to the ones who are going to learn. In one way or another, the requirement of knowledge achievement needs to be met by and integrated with the individual student's capacity as a unique person. One way to approach this long-standing pedagogical question is to consider the characteristics of classroom interaction and communication. For all students, it is important to participate with and communicate actively about the content from which they are going to learn (Alexander, 2008). When the students are encouraged to express themselves in their own words, they develop experiences and confidence that can counteract what Freire (1970) termed a culture of silence among those who otherwise risk feeling excluded or marginalised in the classroom. Drawing on Dewey (2008), the teacher's task is to support the students in participating in the common teaching tasks by shaping a teaching and learning environment that encourages students to engage in learning activities - to take an interest in the joint learning project and to learn through communication with others (teachers, texts, peers and so on). The educational environment should help students coordinate their interests, understandings and dispositions to social factors and objects in the world. Coordinating the students' interests with the teaching content does not mean building content from the students' personal interests but means coordinating their interests to become, in the broadest sense, members of the world (Hansen, 2002). Creating a teaching and learning environment where every voice is listened to and encouraged to contribute to a common conversation is thus an essential educational aim.

One important result from this research project is the importance of varied teaching and learning repertoires during a lesson. A model can, for example, be an introductory teacher monologue that introduces a new learning task, a short structured talk in student pairs with a clear focus on the target of knowledge, followed by a classroom dialogue drawing on the pair of discussions and ending with collaborative work in groups, creating mind-maps of the learning task, which also include the students' own previous knowledge, thoughts and questions. During the following lessons, the students need to be recurringly invited to participate interactively and communicatively around the teaching content; otherwise, too many of them will not be able to develop the actual target of knowledge. Taking the perspectives 
of second-language learners, the importance of contextualisation, structure, high expectations and exploration-based activities will be even more crucial (Cummins, 2001). As illustrated in Chapter 9, teacher-led recitations and instructions, which are solely based on facts and concepts, can result in a superficial understanding of concepts, like voltage and resistance within the subject area of electricity, without any possibility of accessing deeper levels of knowledge of how electricity was invented and how it works, how it is produced today and the role of electricity in modern everyday life. The obvious risk is that the actual knowledge about a subject topic, which the students are to develop, is decontextualised from the students as unique persons and their previous knowledge relations. When this happens, this is to a large extent due to limited spaces for students' interactions and communication around the teaching content, which needs to be based on their starting points for learning. The enactment of teaching, and its counter story emerging from a student perspective, concerns the art of teaching constituted by what selected content, what sequences of interaction and communication and what pace the students are invited to be involved in their own learning. A curriculum is a holistic attempt of holding together several purposes and goals of knowledge. If democratic values are not integrated with the subject-specific content, it will metaphorically be like eating dry bread. The ways that students can participate and represent themselves in relation to the curriculum content are crucial components for equality (Fraser, 1997; Schmidt, 2018).

Moreover, within this research project, the teachers and the students are actors within classrooms that increasingly have become more segregated and that are characterised with an increased complexity, but also uncertainty, regarding basic social institutions such as citizenship and democracy. For these reasons, the enactment of teaching, and the learning it creates, is increasingly important to explore in order to maintain equality in education and to offer equitable opportunities for each student to construct a meaningful pathway through their education.

\section{Teaching for Assessment with a Curriculum Based on Standards}

One of the overall implications that can be drawn from the classroom studies is that the idea of standards-based education that manifests itself at the national level in the form of curricular standards comes along with a plethora of pedagogical and didactical consequences at the classroom level. When teachers and students come together in teaching situations in classrooms, the initiated processes and the actions undertaken are far from being equated with simply putting curriculum standards into practice. Rather, processes of teaching and learning need to be understood in terms of pedagogical and didactical translations that occur in the complex relationships between the content, the teacher and the students. In a German tradition, the triadic relationship between the content, the teacher and the students is known as the Didactic triangle (Westbury et al., 2000). In an American philosophical tradition, this triad is better known in terms of $I$, Thou, and $I t$, pointing 
at "how the "It" enters into the pattern of mutual interest and exchange between the teacher and the child' (Hawkins, 1974, p. 50). The relationship between the content, the teacher and the students is also framed by the conditional matrix of the classroom. However, when a standards-based curriculum with its imperatives of efficiency and an outcome-focused understanding of equity is recontextualised in concrete pedagogical practices, the underlying rationales of the standards-based curriculum strongly influence students' and teachers' perceptions about what education is for, how teaching and learning take shape and, ultimately, what kind of education becomes possible at all in different kinds of classrooms.

Performance standards that are set at a national curriculum level, prescribing uniform knowledge expectations that the students are supposed to achieve, turn out to play a central role in the classroom context. In the Swedish curriculum for compulsory school, these performance standards represent a kind of detailed criteria for assessment (the so-called knowledge requirements), which teachers must use when assigning grades by the end of the semester. In the last curriculum reform in Sweden that took place in 2011, one of the main justifications for the implementation of detailed criteria in terms of 'knowledge requirements' in curricula was that the criteria would help strengthen the equivalence of teachers' grading-relevant assessments and thereby contribute to improved educational equity (Swedish Ministry of Education and Research, 2008). However, what becomes visible in classroom studies is that the criteria, originally intended to support teachers' grading, become a vital part of the everyday teaching and learning in the classroom. Expressed in a more illustrative way, teachers remind students of the assessment criteria linked to a specific task and clarify the specific qualities that need to be reached in the students' accomplishment of the task in order to reach a certain grade level, while the students, in turn, endeavour to deliver in line with the expected criteria to achieve the desired grade, also known as 'teaching to the test.'

This kind of outcome focus in teaching processes seems to be exacerbated when a results-based curriculum such as the Swedish one (Sundberg \& Wahlström, 2012) is recontextualised in a highly performance-oriented classroom environment. Here, teaching and learning can easily tend to be dominated by an emphasis on assessments, grading criteria, achievement levels and results. Formative assessment strategies are, in this context, perceived to provide an effective toolkit for optimising the conditions for a high-level student performance and are seamlessly blended into the classroom's performance orientation (Vogt, 2021). However, such a performance orientation seems to not exclusively apply to high-performing classrooms but is also present in classrooms characterised by a considerably lower achievement level. This means that the same pattern also becomes observable in lower-performing teaching environments, but due to different conditions for teaching and learning, it does so in a somewhat different way. In lower-performance teaching contexts, the aim is not to achieve the highest grade levels but to enable the students at least to pass the next test and to make it possible 
for the students to reach the basic level of the knowledge required for grades offering access to upper secondary education. These strategies of knowledge represent a strong focus on student performance as something that can and must be measured to serve the external demands of selection procedures that society poses to schools. It refers, so to speak, to a performance principle that is merely directed towards externally set standards and excludes more pedagogically justifiable performance principles (Klafki, 2007). A too one-sided emphasis on the kind of students' results that are mostly relevant outside the walls of the classroom, but which dominate teachers' and students' experiences of what education actually is about, inevitably leads to didactical and pedagogical limitations in teaching and learning. When the didactical space in the classroom becomes reduced to the effective achievement of standards and when the knowledge content that is taught does not transcend itself beyond its direct utility, then students in both high- and low-performing classrooms are excluded from learning opportunities with the potential to support young people's broader personal and social growth, as well as the widening of their views of the world.

\section{Structures of Curricula and Their Implications}

Standardisation of curricula can, in international terms, be understood as the displacement from a content-centred focus on the 'input side' of curriculum-making during the 1960s by creating a specified language about education for a common understanding of the school's role for the development of the nation, to a performance-centred focus on the 'output side' of curriculum by putting technical and instrumental vocabularies at the forefront for international comparisons of the delivery of curricula and the measurement of pupils' academic skills during the 2000s (Sundberg, 2019).

Curriculum coherence has been targeted as a key factor for standardisation in education and as a lever for improved student knowledge achievement in terms of international tests such as the Programme for International Student Assessment (PISA) (Honig \& Hatch, 2004). Core assumptions have been that a strengthened link between goals, content, assessment criteria, textbooks and teachers' professional development in accordance with set standards of knowledge and skills in curricula will improve goal attainment and student performance. According to the policy rhetoric, clear, precise and detailed performance standards will promote equality and equity because of a levelling effect on differences in student achievement. Curriculum reforms, therefore, tend to promote a formal standardisation. However, these assumptions ignore the basic sociopolitical conditions for the enactment of the curriculum in different schools and classrooms, as well as some critical factors identified in educational research.

The empirical results in this book suggest that in the interplay between the intended and the locally enacted curriculum, crucial dimensions of curriculum policy enactment are generally underestimated (see Newmann et al., 2001). The dominating discourse of coordinative alignment is primarily 
about linking learning materials, teacher preparation, monitoring and supervision to national curricula, which, in turn, promotes some teaching and learning repertoires while others become subordinated. The Swedish standards-based curriculum reform follows in several aspects the transnational and European policy trend focusing on uniform and specified standards and knowledge requirements in the curriculum to obtain measurable results, performance and performance indicators (i.e. a coordinative discourse of curriculum coherence) (Wahlström \& Sundberg, 2018).

To meet the challenges of the elusive teaching gap and the increasing knowledge segregation in policymaking and teaching practices, an alternative 'integrative approach' to curricula is necessary, relating to how goals, content and knowledge requirements and assessments are consistent across the intended and enacted curricula. To address integrative dimensions of curriculum coherence and to understand differences in goal attainment in schools and achievements between schools and classrooms, three analytical levels are central: a coherence between classroom activities and the students' lives and experiences, a coherence between the pedagogy of the local school and the activity in the individual classroom (Tikkanen et al., 2019) and, third, coherence in the discourse of curriculum-making from teaching practices in the classroom context to the national level of curriculum-making.

\section{From Powerful Knowledge to Meaningful Knowledge: Teaching on Matters of Concern}

The question that the chapters in this book have revolved around is a genuine educational question related to the factors that affect knowledge segregation in school beyond the socio-economic and residential factors. We are interested in how different classroom discourses and concepts of knowledge affect students' encounters with the school's subject knowledge. Within a framework of standards-based curricula, patterns of classroom discourses characterising the teaching offered to students in high-performance and low-performance classrooms and the knowledge considered of most worth in different classroom environments have been explored. In relation to the empirical findings and the ongoing debate on knowledge within the curriculum theory field (Deng, 2020, 2021; Rasmussen et al., 2021; Young \& Muller, 2010), our main argument is that a conceptualisation of the concepts of knowledge and equity is necessary, albeit not sufficient, for the formation of the curriculum for compulsory school. Different concepts of knowledge allow for different approaches to the selection of teaching content and for different approaches to pedagogy. While a starting point in scientific rationalism priorities an essentialist view of curricula and a pedagogical focus on the question of how to teach, a logic of social efficiency instead implies an emphasis on performance-based curricula and a focus on competences as transferable skills. If the public philosophy instead pivots around social reconstructionism, curricula will rather emphasise the connection between democracy and knowledge, focusing on the pedagogical question of why, whereas 
a more individual-based tradition of humanism may lead to a curriculum based on the ideals of Bildung and a focus on the pedagogical question of what (Deng \& Luke, 2008; Wahlström, 2016). Evaluations of existing curricula seem to be a neglected area. Evaluations of curricula through national or international knowledge tests do not answer the important question of the most favourable curriculum to arouse students' interest in learning new knowledge and skills. How does curriculum content speak to the individual student so that he or she feels included in the project of knowing and learning? The empirical results show that grades can be an important motivation for students to learn in high-performing classes but that a focus on grades also implicates a narrow view of learning and has less to offer concerning the 'joy of learning' in itself. In other learning environments, the students' feelings of being excluded from the possibility of getting in touch with the different school subjects have been palpable. These students do not think that they belong to the group that the teaching addresses - those 'who learn.' A conclusion is that the much-debated concept of powerful in connection to knowledge is inadequate as a basis for curricula and teaching. In the context of sociology of knowledge, powerful knowledge implies an opportunity for social mobility for underprivileged social classes by learning to master the language spoken by those with access to power (Rasmussen et al., 2021). From a classroom-level perspective within curriculum theory, the main question instead is: 'In what ways can this content concern the students?' What is missing in the curriculum theory discussion on knowledge is the need for a displacement from matters of fact to matters of concern (Latour, 2004).

As Latour (2004) argued, '[ $\mathrm{t}$ ] he question was never to get away from facts but closer to them, not fighting empiricism but, on the contrary, renewing empiricism' (p. 231). Drawing on the 'stubbornly realist attitude' (p. 231) of William James, Latour (2004) claimed that a thing is never only an object out there; on the contrary, 'the word thing designates matters of fact and matters of concern' (p. 233). An object represents a gathering of different non-human and human aspects that defines the characteristics of the object. A displacement of emphasis from matters of fact to matters of concern recognises the need for exploring the web of perspectives in terms of 'societies' or 'associations' for a deeper understanding of the objects. With a displacement towards matters of concern, knowledge of objects and phenomena as a collective affair are emphasised, implying that knowledge is a 'common concern' that affects all of society. It is a realism that does not view facts as separated from man but as related to man - facts as a concern for man. A shift to matters of concern underlines the need for teaching content to be related to critical reflections on the consequences for society regarding living conditions for different social groups, ranging from the perspective of local communities to a global perspective. A transactional realism - or matters of concern - has the potential to make the teaching content in itself important to students. Thus, an educational assumption is that the term powerful in relation to a knowledge-based curriculum (Deng, 2020; Young, 2013) should be replaced by the concept of meaningful knowledge as the basis of curriculum if we really 


\section{2}

Jeff Frank et al.

want different groups of students to direct their interest towards the teaching content and become involved in their own education on matters of concern. Meaningful can be defined as an authoring of the teaching content in the classroom in a way that clarifies the relationships and consequences between objects of facts and human actions, which at the same time opens up for possibilities of change of current conditions. Meaningful knowledge should not be interpreted in terms of the students' personal interests but in relation to common concerns of citizens in society and a civic responsibility. Or to put it short, '[m]atters of concern have to matter' (Latour, 2008, p. 47). Issues of relevance become paramount. In her work on culturally relevant teaching, Ladson-Billings (2014) claimed three factors to be of specific relevance for successful teaching of all students in the class and not just for those who are already included in the school culture: academic success in terms of students' intellectual growth; cultural competence, including cultural awareness and knowledge of both one's own and others' cultures; and, finally, a sociopolitical consciousness viewing school knowledge as a basis for reflections on real-world problems and dilemmas. The third factor, in particular, critical perspectives on issues concerning students' lives and society, is rarely included in teaching content according to Ladson-Billings (2014).

To illustrate how the concept of knowledge underpinning curricula influences the characteristics of teaching in different ways, the following figure distinguishes between two types of knowledge realism. While the first concept of knowledge realism emphasises the relationships between humans and the knowledge of the world, the second concept instead emphasises knowledge as separate from man (Table 10.1).

Table 10.1 Two different types of concepts of knowledge and their implications for curricula and teaching

\begin{tabular}{|c|c|c|}
\hline Purposes of schooling: & $\begin{array}{l}\text { Transactional realism } \\
\text { opens the door for ... }\end{array}$ & $\begin{array}{l}\text { Social realism opens } \\
\text { the door for ... }\end{array}$ \\
\hline Knowledge & $\begin{array}{l}\text { Matters of concern - } \\
\text { related to human } \\
\text { conditions }\end{array}$ & $\begin{array}{l}\text { Matters of fact - separated } \\
\text { from human conditions }\end{array}$ \\
\hline Learning & $\begin{array}{l}\text { A deepening of the } \\
\text { students' experiences }\end{array}$ & $\begin{array}{l}\text { The students' access to } \\
\text { given knowledge }\end{array}$ \\
\hline Society & $\begin{array}{l}\text { Prerequisite for } \\
\text { knowledge and } \\
\text { change }\end{array}$ & Making use of knowledge \\
\hline Assessment & $\begin{array}{l}\text { Professional } \\
\text { responsibility within } \\
\text { the learning process }\end{array}$ & $\begin{array}{l}\text { Externally administrated } \\
\text { evaluations }\end{array}$ \\
\hline Equity & $\begin{array}{l}\text { Coordinating the } \\
\text { students' interest } \\
\text { towards meaningful } \\
\text { knowledge }\end{array}$ & $\begin{array}{l}\text { Getting access to } \\
\text { powerful knowledge }\end{array}$ \\
\hline
\end{tabular}


The connection between knowledge and justice is linked to evaluation of what a student has the opportunity to learn at school. From the principle of parity of participation (Fraser, 2004), we argue that recognition is a precondition for participation in the common learning processes taking place in the classroom. It is the recognition of the individual student as an included member in society with rights and obligations that becomes central to the insistence for the need and opportunity for each individual student to participate in the development of meaningful knowledge in the classroom environment. For knowledge to be meaningful, it needs to matter to the individual student, as well as to society as a whole. The significance of recognition for equity in curriculum, thus, gives prominence to the importance of pluralism in the selection of the teaching content and that each individual is given the opportunity to participate in meaningful knowledge processes offering different perspectives on matters of concern. As curriculum goals are set at national and international levels, and as these goals are enacted in classrooms, matters of concern need to be at the centre of thinking and conceptualisation, not shouldered out by standardisation and ideals of efficiency. In this way, schools can serve the broader purpose of preparing for citizenship and a life of learning.

\section{References}

Alexander, R. (2008). Essays on pedagogy. Routledge.

Biesta, G. (2014). Pragmatising the curriculum: Bringing knowledge back into the curriculum conversation, but via pragmatism. The Curriculum Journal, 25(1), 29-49. doi:10.1080/09585176.2013.874954

Cummins, J. (2001). Negotiating identities: Education for empowerment in a diverse society. California Association for Bilingual Education.

Deng, Z. (2020). Knowledge, content, curriculum and Didaktik: Beyond social realism. Routledge.

Deng, Z. (2021): Constructing 'powerful' curriculum theory. Journal of Curriculum Studies, 53(2), 179-196. doi:10.1080/00220272.2021.1887361

Deng, Z., \& Luke, A. (2008). Subject matter: Defining and theorizing school subjects. In F. M. Connelly, M. F. He, \& J. A. Phillion (Eds.), The SAGE handbook of curriculum and instruction (pp. 66-87). Sage Publications.

Dewey, J. (2008). Democracy and education. In J. A. Boydston (Ed.), John Dewey: The middle works, 1899-1924 (Vol. 9, pp. 3-370). Southern Illinois University Press. (Original work published 1916)

Doyle, W. (1992). Curriculum and pedagogy. In P. W. Jackson (Ed.), Handbook of research on curriculum (pp. 486-516). Macmillan.

Fenstermacher, G. D. (2001). On the concept of manner and its visibility in teaching practice. Journal of Curriculum Studies, 33(6), 639-653. doi:10.1080/ 00220270110049886

Fraser, N. (1997). Justice interruptus: Critical reflections on the "postsocialist" condition. Routledge.

Fraser, N. (2004). Institutionalizing democratic justice: Redistribution, recognition, and participation. In S. Benhabib \& N. Fraser (Eds.), Pragmatism, critique, judgment: Essays for Richard J. Bernstein (pp. 125-147). MIT Press. 


\section{Jeff Frank et al.}

Freire, P. (1970). Pedagogy of the oppressed. Penguin Books.

Hansen, D. T. (2002). Dewey's conception of an environment for teaching and learning. Curriculum Inquiry, 32(3), 267-280.

Hawkins, D. (1974). I, thou, and it. In D. Hawkins (Ed.), The informed vision: Essays on learning and human nature (pp. 48-62). Agathon Press. (Original work published 1967)

Honig, M. I., \& Hatch, T. C. (2004). Crafting coherence: How schools strategically manage multiple, external demands. Educational Researcher, 33(8), 16-30. doi:10.3102/0013189X033008016

Hopmann, S. (2007). Restrained teaching: The common core of Didaktik. European Educational Research Journal, 6(2), 109-124.

Klafki, W. (2000). The significance of classical theory of Bildung for a contemporary concept of Allgemeinbildung. In I. Westbury, S. Hopmann, \& K. Riquarts (Eds.), Teaching as reflective practice: the German Didaktik tradition (pp. 85-109). Lawrence Erlbaum Associates.

Klafki, W. (2007). Neue Studien zur Bildungstheorie und Didaktik: Zeitgemäße Allgemeinbildung und kritisch-konstruktive Didaktik [New studies on the theory of Bildung and Didaktik: Contemporary general Bildung and critical-constructive Didaktik]. Beltz.

Ladson-Billings, G. (2014). Culturally relevant pedagogy 2.0: a.k.a. the remix. Harvard Educational Review, 84(1), 74-84.

Lampert, M. (1985). How do teachers manage to teach? Perspectives on problems in practice. Harvard Educational Review, 55(2), 178-194.

Latour, B. (2004). Why has critique run out of steam? From matters of fact to matters of concern. Critical Inquiry, 30(2), 225-248.

Latour, B. (2008). What is the style of matters of concern? Van Gorcum.

Luke, A., Woods, A., \& Weir, K. (2013). Curriculum, syllabus design and equity: A primer model. Routledge.

Newmann, F. M., Smith, B., Allensworth, E., \& Bryk, A. S. (2001). Instructional program coherence: What it is and why it should guide school improvement policy. Educational Evaluation and Policy Analysis, 23(4), 297-321, doi:10.3102/ 01623737023004297

Nussbaum, M. C. (2007). Frontiers of justice: Disability, nationality, species membership. Harvard University Press.

Prilleltensky, I. (2020). Mattering at the intersection of psychology, philosophy, and politics. American Journal of Community Psychology, 65(1-2), 16-34.

Rasmussen, J., Rasch-Christensen, A., \& Qvortrup, L. (2021). Knowledge or competencies? A controversial question in contemporary curriculum debates. European Educational Research Journal, 1-14. doi:10.1177/14749041211023338

Santoro, D. (2018). Demoralized: Why teachers leave the profession they love and how they can stay. Harvard Education Press.

Schmidt, C. (2018). Ethnographic research on children's literacy practices: Children's literacy experiences and possibilities for representation. Ethnography and Education, 15(1), 48-63. doi:10.1080/17457823.2018.1512004

Schultz, K. (2019). Distrust and educational change: Overcoming barriers to just and lasting reform. Harvard Education Press.

Sen, A. (1999). Development as freedom. Oxford University Press.

Sundberg, D. (2019). Three waves of education standardisation: How the curriculum changed from a matter of concern to a matter of fact. In C. Elde Mølstad, \& D. Pettersson (Eds.), New practices of comparison, quantification and expertise in education: Conducting empirically based research (pp. 50-65). Routledge. 
Sundberg, D., \& Wahlström, N. (2012). Standards-based curricula in a denationalised conception of education: The case of Sweden. European Education Research Journal, 11(3), 342-356. doi:10.2304/eerj.2012.11.3.342

Swedish Ministry of Education and Research. (2008). Tydligare mål och kunskapskrav - nya läroplaner för skolan [Clearer goals and knowledge requirements - New curricula for school] (Official Report 2008/09:87).

Tikkanen, L., Pyhältö, K., Pietarinen, J., \& Soini, T. (2019). Lessons learnt from a large-scale curriculum reform: The strategies to enhance development work and reduce reform-related stress. Journal of Educational Change, 51(21), 543-567. doi:10.1007/s10833-019-09363f

Vogt, B. (2021). Supportive assessment strategies as curriculum events in a performance-oriented classroom context. European Education Research Journal. Published online. doi:10.1177/14749041211030387

Wahlström, N. (2016). Läroplansteori och didaktik [Curriculum theory and 'Didaktik']. Gleerups.

Wahlström, N. (2018a). When transnational curriculum policy reaches classrooms Teaching as directed exploration. Journal of Curriculum Studies, 50(5), 654-668. doi:10.1080/00220272.2018.1502811

Wahlström, N. (2018b). The travelling reform agenda: The Swedish case through the lens of OECD. In N. Wahlström, \& D. Sundberg (Eds.), Transnational curriculum standards and classroom practices: The new meaning of teaching (pp. 15-30). Routledge.

Wahlström, N. (2021). School and the democratic hope: The school as a space for civic literacy [keynote presentation]. European Education Research Conference 2021, Geneva/virtual.

Wahlström, N., \& Sundberg, D. (Eds.). (2018). Transnational curriculum standards and classroom practices: The new meaning of teaching. Routledge.

Westbury, I., Hopmann, S., \& Riquarts, K. (Eds.) (2000). Teaching as a reflective practice: The German Didaktik tradition. Routledge.

Young, M. (2013). Overcoming the crisis in curriculum theory: A knowledge-based approach. Journal of Curriculum Studies, 45(2), 101-118. doi:10.1080/002202 72.2013 .764505

Young, M., \& Muller, J. (2010). Three educational scenarios for the future: Lessons from the sociology of knowledge. European Journal of Education, 45(1), 11-27. doi:10.1111/j.1465-3435.2009.01413.x 


\section{Index}

Pages in italics refers figures, bold refers tables and pages followed by $\mathrm{n}$ refers notes.

Alexander, R. 7, 63, 126

Alvunger, D. 10

Anderson, L. 79

Anmarkrud, Ø. 7

Arnesen, N. 7

$\mathrm{Au}, \mathrm{W} .78$

Baldwin, James 52

Bauer, W. 23

Bentley, A. F. 19

Bergem, O. K. 7

Berger, R. 57n8

Bergh, A. 91-92

Bernstein, B. 39, 106

Biesta, G. 57nl, 91, 101

Bildung 70, 106, 143, 151; knowledge concept 22-27; orientation and General Didaktik 64-66; and social realism 8

Birch Tree School: class 108, 108, $111,113,113$; principal's agency 95 , 96-98, 100

Brighouse, H. 34-35, 35

classroom: discourses 6-7, 109, 129-130, 137; high and low performing class 105, 108, 108, 120; interactions 7 , 146; practices 60-61 classroom pedagogies 125-127, 126, 127; classroom actors $135-136$; curriculum content 130, 130-132; life in classrooms 145-147; research questions 124; teaching factors 133-134

Cooper, D. E. 49

critical-constructive Didaktik model 64-66 curriculum: alignment $79,82,86$; areas in Swedish and natural sciences 108 , 109; elements 10; equitable 40; standardisation 60-61, 149

curriculum based on standards 147-149

curriculum coherence 10; concept of 79; coordinative approach 76,79 , 81; in enacted curriculum 82-86; epistemic and content-related manner 81; first-order 86; integrative approach 77,80 ; internal alignment 79; pedagogy 80; policy-practice/ implementation gap 80; second-order 86-87; third-order 87; transnational curriculum standards 81

curriculum content $6-7,39,85,105$, 110,125 ; analytical reflections 132 ; curriculum tasks 130, 130; students' perspectives 131

curriculum events 67, 106, 117-118; in classroom 105, 127; students as co-authors 9, 61-63, 115; videotaped 7

curriculum theory $5,9,30,39,63,73$, 144, 150-151; analysis on classroom discourses 6-8; and equity 40, 41, 42-43

democracy 19, 22, 25-26, 105-106, 138, 147, 150; neoliberal reform 2; populism 2-4; values and norms 1 ; voluntary and involuntary isolation 2 , 4 ; in Western countries 14 democratic stance in education $2-5,8$ Deng, Z. 7, 110-111, 143 Dewey, J. 5, 18-22, 26, 91-93, 146 
Didaktik 24, 60, 73, 145; criticalconstructive model 64-66; tradition of General see General Didaktik

Doyle, W. 7, 105-106, 127

Durkheim, Emile 17, 26

Durkheim's sociology of knowledge $17-19,26$

Education 2030: OECD framework of 14-16; policy of see The Policy of Education 2030; student agency 15 educational leadership 90-102

Emirbayer, M. 93-94, 101-102

enacted curriculum $10,77,79,80$, $82-87,150$

epistemic conformity 77

equity in education 9,141 ; ability 31; capability approach 33-36, 35, 144; competence 31 ; concepts of equality and equity 30 ; in educational policy 42-43; educational research on equity 31 ; equivalence $31-32$; evaluation of $38-42,41$; principle of parity of participation 36-37, 38; problematisation of 32-33

Ethical Review Board 8

European Union (EU) 3, 30, 76, 90

feedback 9, 46; teacher's role in see teacher's feedback

Frank, J. 9, 11

Fraser, N. 6, 9, 36-38, 40, 42, 144, 146

The Future of Education and Skills 203015

Garrison, J. 19

General Didaktik: and Bildung orientation 64-66; and pedagogy 62-63

global education policies 77

Globally Structured Agenda for Education 78

Hansen, D. T. 6, 49, 53, 146

Hawkins, D. 57n7

intended curriculum 77-78, 82, 84, 86

Jackson, P. W. 47, 61

James, William 151

Joas, H. 92

Keddie, A. 37

Klafki, W. 9, 23, 64-65

Klette, K. 7 knowledge: concept of 5-7; and democracy norms 1 ; educational 124; hierarchy of 114-116; individual and society 5; meanings of 143-144; powerful 17, 19, 90, 102, 106, 121, 125, 137; powerful knowledge to meaningful $11,150-153,152$; process of recontextualising 6 ; question of 2 ; segregation 82 ; as social realism 16; students' conceptions of 116-120; value of 10 knowledge-based curriculum 19, 145, 151 knowledge concept 25-27; experiential 111 ; idea of Bildung 22-25; practical 111; of social realism 16-19; theoretical/disciplinary 110; of transactional realism 19-22

Ladson-Billings, G. 152

Larch Tree School 67; class 108, 108, 111,113 ; principal's agency 95,96 , 98-99, 101-102; student role in classroom $68-70$

Latour, B. 151

learning environments, students' role in 67; Larch Tree classroom 68-70; Oak Tree classroom 70-73

Levitsky, S. 1

Lingard, B. 37

locally enacted curriculum 76-78, 85, 149

Løvlie, L. 23

Luke, A. 7, 39, 110-111

Martin Luther King, Jr. 53

'matters of concern,' 150-153, 152

Mead 91-92

Mische, A. 93-94, 101-102

Møller, J. 103

Morrison, Toni 52

Muller, J. 106

neoliberalism 2-3

New Public Management (NPM) 2-3

Nussbaum, M. C. 6, 9, 33, 40, 42, 144

Oak Tree School 67; analysis of classroom discourse 129-130; case study 128, 129; principal's agency $95,95,96-100$; student role in classroom 70-73

Ødegaard, M. 7

Organisation for Economic Co-operation and Development (OECD) 8, 30, 76, 90, 142; framework of Education 2030 14-16 


\section{Index}

pedagogical segregation, students' perspectives 123, 137; in classroom see classroom pedagogies; knowledge 124-125; Oak Schoolcontextualisation 128-130

pedagogy: and General Didaktik 64-66; perspective of teaching 63 ; students' co-authorship 63

Pendlebury, S. 49

performance-based curriculum 38

Pine Tree School principal 95, 96-98, 101-102

policy alignment $76,79-80$

The Policy of Education 2030: perspective of Bildung 18-19; social realism 18-19; transactional realism 21-22

populism 2-4

Potter, N. N. 57n9

pragmatism 5, 10, 26, 91-92

principal agency: data analysis 95 , 95; iterational element of agency 94, 95-96; practical-evaluative experiences 94, 97-99; projective element of agency 94, 99-101; as temporally constructed engagement 93; transactional realism 92-93

Programme for International Student Assessment (PISA) 14, 31, 38, 90, 101,149

Roberts, D. A. 13

Rodgers, C. 57n7

Schmidt, C. 11

Sen, A. 6, 9, 33-34, 40, 42, 144

social liberalism 2-3

social realism 8, 16-19, 26-27, 106, 143-144, 152

standards-based curriculum 9, 142; and principal agency 95-101

Standish, P. 23

Steiner-Khamsi, G. 78

Stengel, B. $57 \mathrm{nl}$

Sundberg, D. 10-11, 61

Svein, L. 7

Swedish curriculum $31,77,101$, 107,148
2011 Swedish Curriculum for Compulsory Schooling 107

The Swedish Education Act 125

Swedish educational policy 31-32

Swedish National Agency for Education (NAE) 8, 32, 85, 123

Swedish Research Council 8, $1 \ln 1$

Swedish standards-based curriculum reform of $201177,82,105$

teacher's feedback 55-57; deeper learning $54-55$; in life of classrooms 47-49; truthfulness and teacher development 49-54

teaching repertoires: dominant 108 , 110-111, 113, 114, 120-121; Larch Tree and Birch Tree classes 111-114, 113; lesson elements and 108,109

Tovani, C. $57 \mathrm{n} 8$

transactional realism 5, 8, 10, 26-27, 143, 151, 152; knowledge concept of 19-22; principal agency 92-93; theory of pragmatism 91-92

transnational standards in curriculummaking: high-stakes testing 78 ; standards-based curricula 77; testbased norms 78

Trends in International Mathematics and Science Study (TIMSS) 90, 101

Trump, Donald 49

Unterhalter, E. 32, 34-35, 35

Vogt, B. 11

voluntary isolationism 2,4

Wahlström, N. 7-9, 11, 61, 91-92, 127

Walker, M. 34

Weir, K. 39

Williams, B. 9, 46, 49-50

Woods, A. 39

Young, M. 16-17, 26, 106

Young, M. F. D. 16, 18-19, 125, 137

Zachariassen, J.-R. H. 7

Ziblatt, D. 1 